\section{PRODUCTION OF HIGH INTENSITY ELECTRON BUNCHES FOR THE SLAC LINEAR COLLIDER*}

\section{Mary Beth Jamea}

Stanford Linear Accelerator Center

Stanford University

Stanford, California 94305

\section{Auguat 1087}

Prepared for the Department of Enercy under contract number DE-AC03-76SF00515

Printed in the United Stale of Amcrica. Available from the National Techni cal Information Service, U.S. Depurtment of Commerce, 5285 Port Rayal Road, Springteld, Virginis 22161. Price: Printed Copy A09, Microfiche A01.

Ph.D. Dimereration

\section{ABSTRACT}

PRODUCTION OF HIGH INTENSITY ELECTRON BUNCHES FOR THE SLAC IINEAR COLLIDER

\section{Mary Belh Jamce \\ Department of Applied Physics Stanford University \\ Stanford Linear Accelerator Center}

This thesis describes the design and performance of a high intennity electron injector for the SLAC Linear Collider.

Motivation for the collider and the apecificalions for the injector are discunat. The opecifications include:

- Two electron bunches, 59 ne apart,

- For each bunch, $5 \times 10^{10}$ electsons captured in one acceler ator RF cycle,

- Bunch length and shape which reeult in a $\pm 1 \%$ energy opectrum at a beam enerey of $1.2 \mathrm{GeV}$,

- Invariant tranoverse emittance in botb $z$ - and $y$-planes no greater than $3 \times 10^{-1}$ radian meters.

An analytic theory of the bunching and espture of electrons by RF field is discussed in the limit of low opues charce and omall wimal. The design and performance of SLAC's main injector are described to illustrate a successful application of this theory. The bunching and capture of electrons by RF fields are then discunsed in the limit of high space charge and large slgnal, and a description of the design of the collid ...juctor follows.

In the litnit of high space charge forces and large RF aignals, the beam dynamica are considerably more complex and numerical simulatione are required to predict particle moti- $n$. A computer code which modela the longitudinal dy. namics of electrons in the presence of apace charge and RF Belds is deseribed.

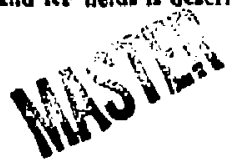

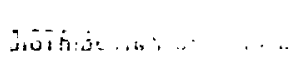


The results of the simulationa, the resulting collider injector design and the various components which make up the collider injector are deacriber. These include the gun, subhasmonic bunchers, traveling-wave buncher and velocily-or. light accelerator section. Finally, the performance of the injector is described including the beam intersity, bunch length, transverse emiltance and energy spectrum.

While the final operating conditions differ somewh from the design, the performance of the collider injector in in good agreement with the numerical imulations and meets all of the collider apecilieatlons.

\section{Aeknowledgement}

All necomplishmento belong to many people; this effort is no exception. I thank Roger Miller for taking on an apprentice. I thank Jirr Clendenin for being a good physicist and helping much more than he known. I thank floger Miller, Jim Clendenin, Joe Sodja and Jack Truher for butlding CID and teaching me most everything. I thank Ron Koontz, Larry Feathers, Jim Hodgers, Fred llooker, George Leger and Boni Cordova for their support and friendehip. I thank the people of MCC for help and comradery, especially in the wee hours. I thank the people of Accelerator Phymich and the Teat Lab for their aupport, pallence, and boundleas faith that this project would, indeed, come to an end some day.

I thank Gregory Loew for drakging me, kicklng and ncreaming, toward a oubatentially more lucid deacription of this work. I thank Bette-Jane Ferandin for crealing a beatiful manusesipt from the harfied acratches of a frazzled graduate atudent, and for her patience and poize under fire. I thank Barbara Woo for much patient help with the computer graphica. I thank the people of Technical Jlustrations for seworkins mont of the figures three times.

I thenk Alaln Schwartemen for many a late night work aeagion. I thank Rich Iverson for supporting me In all of the above endeavorn and believing when I couldn't that this whole thing was a good Idea. I thank Pat Burchat for being oo graceful bbout liniahing frat.

I thank Murshall, Melisan, Linda, Deano, Roger, Lee, Howie, Mary S, Carina, Harry, Frank, Pat, Barb and Theo, Ric, Amy, Tony, Jefr, Jeanne, Mrth, Peter, Jane B., Alaln, Sue, Francen, Dave, the Ted Mac Amateur Hour, Michele, Eric, Mary Lu, Jane W., Paul, and Rick for making this tank take much longer then it ahould have. To paraphrase Mark Twain, "Life is what heppens while you'ro procrastinating, and a good life it is!"

Finally, God bless Mom, Dad, David, Tom, Peter, Ann and Catherine. Lucky me. 
This work was supported by the U.S. Department of Energy under contract number DE-AC03-76SF00515.
TABLE OF CONTENTS

Page

ABSTRACT $\ldots \ldots \ldots \ldots \ldots \ldots \ldots$

ACKNOWLEDGEMENTS

TABLE OF CONTENTS

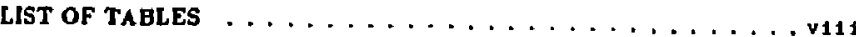

LIST OF FIGURES

1. INTRODUCTION

2. DESIGN OF CID, THE COLLIDER INJECTOR

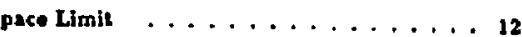

2.1.1 Low Space Charge Beam Dymamice . . . . . . . . . . 12

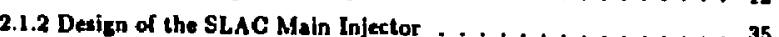

2.2 Collider Injector Delizn . . . . . . . . . . . . . . . 41 2.2.1 Lontitudinal Dynamics in the Low Current,

Large Signal Lirait . . . . . . . . . . . . . . 45 2.2.2 "Gedanten" Hith-Current Injector Desien . . . . . . 72 2.2.3 Original Collider Injector Design . . . . . . . . . . . . 9

This report was prepared as an account of wotk sponsored by an agency of tbe United States Government. Neither the United States Government nor any agency thereof, not any of theis employees, makes any warranty, express or implied, or issymes any legal habaritus, product, of bility for the accuracy, completeness, or usefulness of any information, apparatus, produch of process disciosed, of represents that its use would nol infringe pis by trade rame, trademafk,

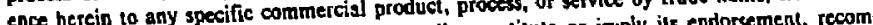
ence herein to an ofherwise dos not necessarily constitute or iniply its endorsemen, recommanuiacturer, or ofherwse dhe United States Government or any agency thereof. The views mendation, of favoring by the Unis ste not necessurily state or reflect those of the and opinions of authors expressed herein do not

\section{.}


2.4 Radiul Dynamics $\ldots \ldots \ldots \ldots$

2.4.1 Radial Emittance Growth . . . . . . . . . . 108

2.4 .2 Radial Focusing $\ldots \ldots \ldots \ldots \ldots \ldots \ldots$

3. PERFORMANCE OF CID $\ldots \ldots \ldots \ldots \ldots \ldots \ldots \ldots \ldots \ldots$

3.1 Hardware Deseription of the CID Injector . . . . . . . . . 123

3.1.1 Electron Gun .................... 123

3.1.2 Subharmonic Bunchert . . . . . . . . . . . . 128

3.1.3 The Traveling-Wave Buncher $\ldots \ldots \ldots \ldots$

3.1.4 Accelerntor Section . . . . . . . . . . . 135

3.2 Comparison of a Typical Performance to Calculated

3.2 Performance of CID . . . . . . . . . . . . . 136

3.3 Transverse Emittance Measurement . . . . . . . . . . 150

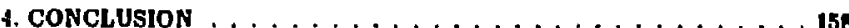

APPENDIX A STREAK CAMERA OPTICS AND RESOLUTION . . 160

REFERENCES

\section{HIST OF TABLES}

Page

1.1. Comparison of achieved luminosity at PEP to design

luminosity at SLC. . . . . . . . . . . . . . 4

1.2. Demping ring acceptance. ............. 8

2.1. Main injector preliminary design upecifications. . . . . . . 39

2.2. Parsmeter optimization and explanations. . . . . . . . . 17

2.3. Buncher admittance as a funetion of phase velocity. . . . . 55

2.4. Injector opecificalions in the low current, large signal limit. . 70

2.5 A high curtent, large tignal injector design. . . . . . . 85

3.1. Peak current and FWIMM versu, bias voltage on the CID gun. 128

3.2. Time-of-flight as a function of SHB phase. . . . . . . 133

3.3. Buncher parameters. . . . . . . . . . . . . 134

3.4. Accelerator parameters. . . . . . . . . . . 135

3.5. Bunch length and current at five locations in the CID

injector for a typical operating configuration. . . . . . . 141

A-1. Streak camera resolution. . . . . . . . . . . . . 169 


\section{LIST OF FIGURES} and linear colliders. . . . . . . . . . . . . . . 2 Schematic diagram of the SLAC Linear Collider. . . . . . 6 Schematic of eap-end-drift prebuncher . . . . . . . . . 14 Gap and drift prebuncher phase apace (from Dôme ${ }^{*}$ ). . . . . 16 Conatent $\boldsymbol{f}$ curves in phase apace for a gap and drilt prebuncher with $\beta_{a}=.5, \alpha=.02$ (from Dome"). . . . . . . .

2.4. Constant phase velocity buncher phase apace for $\beta_{w}<1$ (from Dóme $\left.{ }^{\circ}\right) . \ldots \ldots \ldots \ldots \ldots \ldots \ldots$ 2)

2.3. Bunching in a traveling-wavestructure. .......... 23

2.6. Constant phase velocity capture region phase apace $\left(\beta_{w}=1\right), \ldots \ldots \ldots \ldots \ldots \ldots \ldots \ldots$

2.7. Particle energy a a function of RF phese. . . . . . . . 26

2.8. Capture region admittance. .............. 27

2.9. Field atrength in capture region necessary for optimum bunching of electrons with initial energy $\beta_{0}$ into $a$ bunch with $\Delta E / E=0.01$

2.10. (a) A contunt $\xi$ curve of Fig. 2.3 (the gep-and-drift buncher) uperimposed on the phase epoce orbits of the $\beta_{\omega}=1 \mathrm{cap}$ ture region. (b) A conatant 6 curve of Fig. 2.5 (the $p_{\omega}<1$ traveling-wave buncher) superimposed on the phase space orbits of the $\beta_{w}=1$ capture region. . . . . . . . . .

2.11. Beam eanittance at the end of the prebuncher mapped into the beam emittance at the entrance to the capture region is accomplished by $a$ quarter-wave tranaformation in $a \theta_{w}<1$ traveling-wave structure. ..............

2.12. The SLAC low-current, long-pulse injector. . . . . . . .

2.13. Simulation of particle orbits through thr $\beta_{w}=.75$ travelingwave buncher in SLAC's low-current injector. . . . . . . .

2.14. Simulation of particle orbite through the $\beta_{w}=1$ capture region in SLAC's low-current injector. . . . . . . . . .
2.15. Experimental charge distribution in main injector (from Miller') $\ldots \ldots \ldots \ldots \ldots \ldots$

2.16. Combined buncher rezion and capture region phase space. .

2.17. Capture region momentum acceptance as a function of normalized field atrength. . . . . . . . . . . .

2.18. Capture region admittance as a function of normalized field

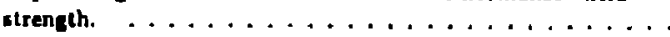

2.19. Buncher admittance as a funetion of buncher phase velocity. Buncher admittance continued, (c) and (d). . . . . . . . Buncher admittance continued, (e) and (I). . . . . . . . .

2.20. (a) Charge density versua time for \& Gaunien-chaped gun pulse. (b) Charge density vereus time alter ainusoidal gepand-drift prebuncher with drtit length $y_{j}-$ to. . . . . . .

2.23. Normalized velocity as a function of time needed to achieve perfect bunching of a Gauating gun pulse with $=0$ of $0.5 \mathrm{na}$.

2.22. Normalized enerey us \& function of time needed to achieve perfect bunchint of a one nanoutcond o gun pulse. . . . . .

2.23. $q$ vesaus $t$ curve of Fig. 2.22 superimposed on sine wave. . .

2.24. Kinetic energy versus time needed to achieve perfect bunching compared to energy veraut time achieved by $20 \mathrm{th}$ oubhermonic sine wave. . . . . . . . . . . . . .

2.25. Beam emittance at the entrance to and exit of the $\beta_{\omega \nu}=.75$

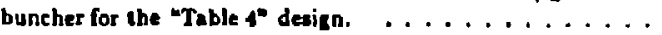

2.26. Schematic diagram of model used to calculate longitudinal beam dynamics in the presence of upnce charge forces. . . . .

2.27. 1 versus $z$ for every third of the 31 inner disks of charge traversing the gap-and-drift prebuncher apecified in Table 2.4.

2.28. - versus \& for every third of the 31 outer annuli of charge traversing the cap-and-drift prebuncher apecified in Table 2.4 .

2.29. Longitudinal emittance at the end of the cap-and-drift prebuncher specified in Table 2.4 ar the current increases from 0 to 12 smps. . . . . . . . . . . . . . . .

2.30. Bunch tength at the end of the gap-and-drift prebuncher ipecified in Table 2.4 as the current increases from 0 to

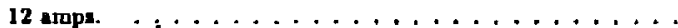


2.31. versus $z$ for every third of the 31 inner disks of charge traversing the injector apecified in Table 2.5. . . . . . .

2.32. veraus 2 for every third of the 31 outer disk of charge - traversing the injector specified in Table 2.5. . . . .

2.33. Longitudinal emittance at five locations in the injector opecified in Table 2.5. . . . . . . . . . . . . .

2.34. Bunch length at five locations in the injector apeciffed in Table 2.5. , . . . . . . . . . . . . . .

2.35. Benm emittance al the entrance to and exit from the 5-band buncher superimposed on the buncher low-current phese upece orbits, $p_{w}=1.134, \alpha_{z}=.50 . \ldots \ldots \ldots \ldots$

2.36. Beam eriitlance at entrance to copture regton and $31.5 \mathrm{~cm}$ downstream superimposed on the capture repion lowcurrent phase epace orbits, $p_{w}=1.28, \alpha_{2}=2.16 \ldots \ldots$

2.37. Langitudinal emittance of the end of a three-meter accelerator

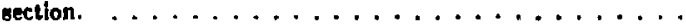

2.38. Energy spectrum at the end of a three-meler wecelerator section. . . . . . . . . . . . . . .

2.39. Bunch length at the end of three-meter accelerator rection. . .

2.40. vereus $\$$ for every third of the 31 Inner dibke of charge traversing the original CID injector detien. ..........

2.41. veraus $*$ for every third of the 31 outer annull of charge traversing the original CID injector deaign. . . . . . . . .

2.42. Longitudinal emillance at hre locations alone the original ClD design. . . . . . . . . . . . .... g

2.43. Bunch length at five locations along the original CID design. . . . . . . . . . . . . . .

2.11. Beam emillance at the entrance to and exit from the S-band bunchet ouperimposed on the low-current buneher phase space

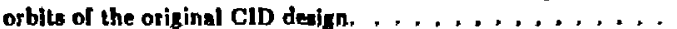

2.45. Beam emiturnce at the entrance of the capture region and $30 \mathrm{~cm}$ downstrenm superimposed on the capture region lowcurrent phase space orbits of the original CiD deaign. . . . .

2.46. Fieldy as a "trapezoid" of eharge passes a given point \&. ....
2.17. (a) Lines of force on electrom in amooth condurting eylinder excited in the TM mode. (b) Forces on electron due to $E_{n}, E_{R}$, and $B_{0} . \ldots \ldots \ldots \ldots \ldots$

2.18. Particles with same $f_{\infty}$ with different $\Delta p$, at end of capture region. . .................. 111

2,49, Magnetic flux through the beam boundary. . . . . . . 118

2.50. Longitudinal magnelle held profle in the CID subharmonic buncher, s-bnnd buncher, and capture region. . . . . . . 121

3.1. Schemalic of collider injector in tprins 1984.

3.2. (a) Cut-away view of the CID thermionic gun assembly. . . . . 125

(b) Computer simulated benm opties for the CID thermionic gun. . ................. 126

3.3. Sketch of apace charge limited Gausaion gun pulse which produces $\& 6$ A, 2 nsee FWhiv pulne at a biss of $150 \mathrm{~V}$. .

3.4. Crose section of a quarter-wave length coaxinl subharmonic buncher envity showing electric field lines. . . . . . . . . .

3.5. Beam current versus time a measured by a gap monitor located Just downstream of CID's three-meter accelerator rection. . . . . . . . . . . . . . . .

3.6. Versus $a$ for every thitd of the 31 inner disks of charge traveralng the injector a apecifited in Table $3.5 . \ldots . . . .$.

3.7. versus $\&$ for every third of the 31 outer annuli of eharge traversing the injector a specified in Table 3.5. . . . . . . .

3.8. Longitudinal emittence al five locations in the injector en apecilied in Table $3.5 ., \ldots \ldots \ldots \ldots \ldots$

3.9. Bunch length at five locstions in the injector as specified in Table 3.5. . . . . . . . . . . . . .

3.10. Beam emiltence at the entrance to and exit tram the S-band buncher ouperimposed on the low-current buncher phase space orblts for the paramelers apecified in Table 3.5. . . . . . . .

3.11. Beam emiltunce ot the entrance to the copture region and $30 \mathrm{~cm}$ downstream uuperimposed on the capture region low. current phase space orbits for the parameters specified in Table $3.5 . \ldots \ldots \ldots \ldots \ldots$ 
3.12. (a) The calculated bunch shape at the end of CID for the paramaters given in Table 3.5 . (b) The streak camera signal from \& $\delta$-function pulse given the resolution limitation deacribed in Appendix A. (c) The calculated bunch shape convolved with the estimated resolution ersor. . . . . . . .

3.13. The calculated and measured bunch thape at the end of CID for the operatine conditions outlined in Table 3.5. . . . . . .

3.14. (a) Measured bunch shape at the end of CID. (b) The calculated bunch spectrum a a function of position at the entrance to the damping rins. . . . . . . . . .

3.15. The calculated spectrum st the entrance to the dampins rins for the measured bunch of $3.14(a) \ldots \ldots \ldots$

3.16. (a) The arbitrarily aligned ellipse 1 represents the horizontal beam emitence at the uptream edge of the lens. The "firt lens" is used to rotate the ellipse to the supine position.

(b) The supine ellipse 2 la theered by the "uecond lens" to achieve the smalleat apot at the reticon array. (c) Ellipat 3 is theered by drifting to athieve smalleat apot, ellipse 4. . . . .

3.17. Ray optica of (a) point A of Kic. 3.16, (b) point D of 3.18. .

3.18. Ellipae 2 of Fig. 3.16(b) tis sheered by strong focuring to produce ellipat 5 . The beam drifts to produce ellipse 6

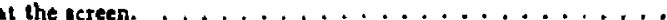

3.19. Chnacteristic plot of beam spol size at a function 'of inverse fotal tength. . . . . . . . . . . . . . . . 156

3.20. Transverce emittance as a function of current for the CID beam. . . . . . . . . . . . . . . 157

A.1. Optical system used to mensure the CID bunch length. . . . 161

A.2. Direction of Cherenkov wave front. . . . . . . . . . 162

A.3. Image broudening due to finite width of quartz radiator. . . . 161

A.4. Image brondening due to finite width of camera alit. . . . . . 166

A.5. (a) Optlas from source to second image; (b) Optice from second to third image; (c) Image broadening due to shift of final image to $\Delta x \mathrm{~cm}$ in front of alit. . . . . . . . . . . .
CHAPTER 1. INTRODUCTION

This thesis deacribes the design and performance of a high current, twobunch electron injector. The injector is part of SLAC's new accelerstor facility, the SLAC Linear Collider (SLC), in which $50 \mathrm{GeV}$ electrons will be incident on $50 \mathrm{GeV}$ positrons. The resulting $100 \mathrm{GeV}$ in the center of mass will enable particle physiciats to explore the epectroscopy of the $2^{\circ}$ particle, as well un to investigate other physice.

Treditionally, colliding beam atorege tinge have been the mainstay of $e^{+} e^{-}$ phycics. Particles toored in storuge ringe lowe energy to oynchsotron radiation at - rate proportional to the fourth power of enerzy,

$$
\frac{\text { eneroy lost to synehraron radiation }}{\text { turn }} \propto \frac{\gamma^{4}}{R}
$$

where $\gamma$ is the normalized enargy of the partiele and $\boldsymbol{R}$ is the mean magnetic radius of the storage rins. To minimize the combined coste of capital and operatins expenses, one normally chooses $R \propto \gamma^{2}$. Thus the RF power needed to replace energy lost to aynchrotron radiation is proportional to $\gamma^{2}$. In linear colliders, losses due to synchrotron radiation are negligible. Both capital and operating (i.e., RF power) casts increase linearly with increasing enargy. Figure 1.1 is a sketch of cost versus energy fos atorage ringe and linear colliders. At aome beam energy (though the exact energy is a matter of debate) linear collidero become more cost effective than storage rings.

The luminasity of colliding beam facilities can be expressed as

$$
L=\frac{\int N^{-} N^{+}}{4 \times \sigma_{z} \sigma_{y}}=\frac{\int N^{-} N^{+}}{4 \pi \sqrt{c_{z} \beta_{x}^{+}} \sqrt{c_{y} \beta_{y}^{*}}}
$$




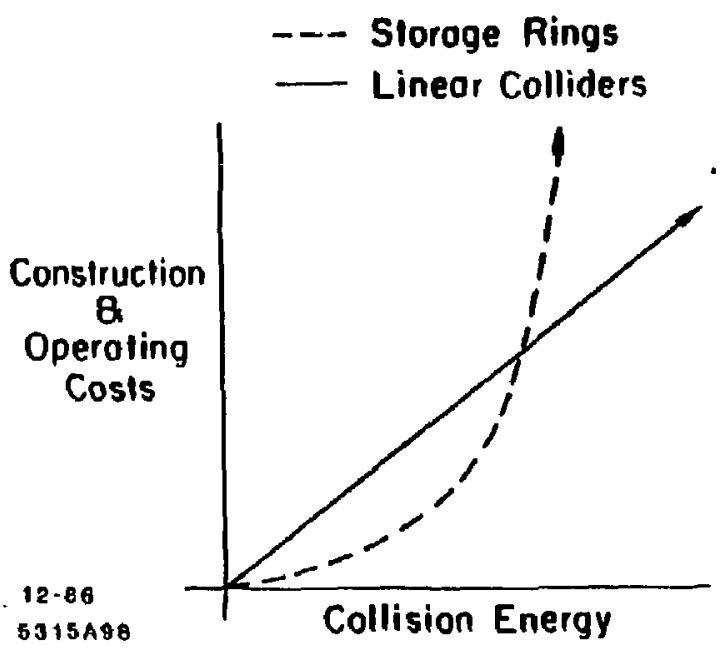

Fig. 1.1. Scaling of cont varave center-of-mese energy for storage rings and linear collldero.

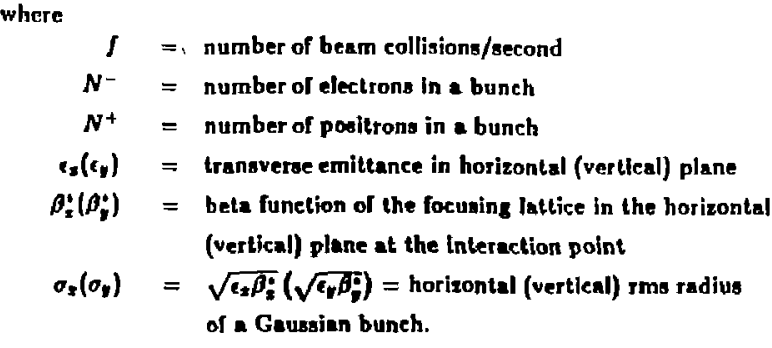

In the left-hand column of Table 1.1 the components contributing to the PEP atorage ring luminosity are listed. In the riglit-hand column the apecifieations for achleving the design luminosity of the SLC are given. Note first that the Irequency of beam collisions at PEP is approximately $1 \times 10^{5}$ per second. In contrast, the frequency of beam collisions in the SLC ia limited by the repetition rate of the linac, which is at most 180 pps. Nole also that the PEP bunches contain $3 \times 10^{11}$ electrons or ponitrone per bunch. These bunches are made by "stacking" pulses from the linac. Ir the SLC, each linac electron bunch colliden once with a position bunch and io loat. The pre-SLC linac could produce and accelerate only $10^{\circ}$ electrons and $10^{\circ}$ positrons per bunch. These two effects combine to produce a loss of luminosity on the order of $2 \times 10^{2}$. As shown in Table 1.1, the lose in luminoslty is recovesed by Incressing $n$, the number of electrons at positrons produced and accelerated in each bunch, by decreasing the tranaverse emittance of the beam in both planes, and by decreasing the value of the $a$ function of the focusing lattice at the interaction point. The center column of Table 1.1 listo the major ayalems necessary to achieve each improvement in luminoaity. 
Table 1.1. Comparion of achieved luminoxity at PEP with derign luminowity at sLC.

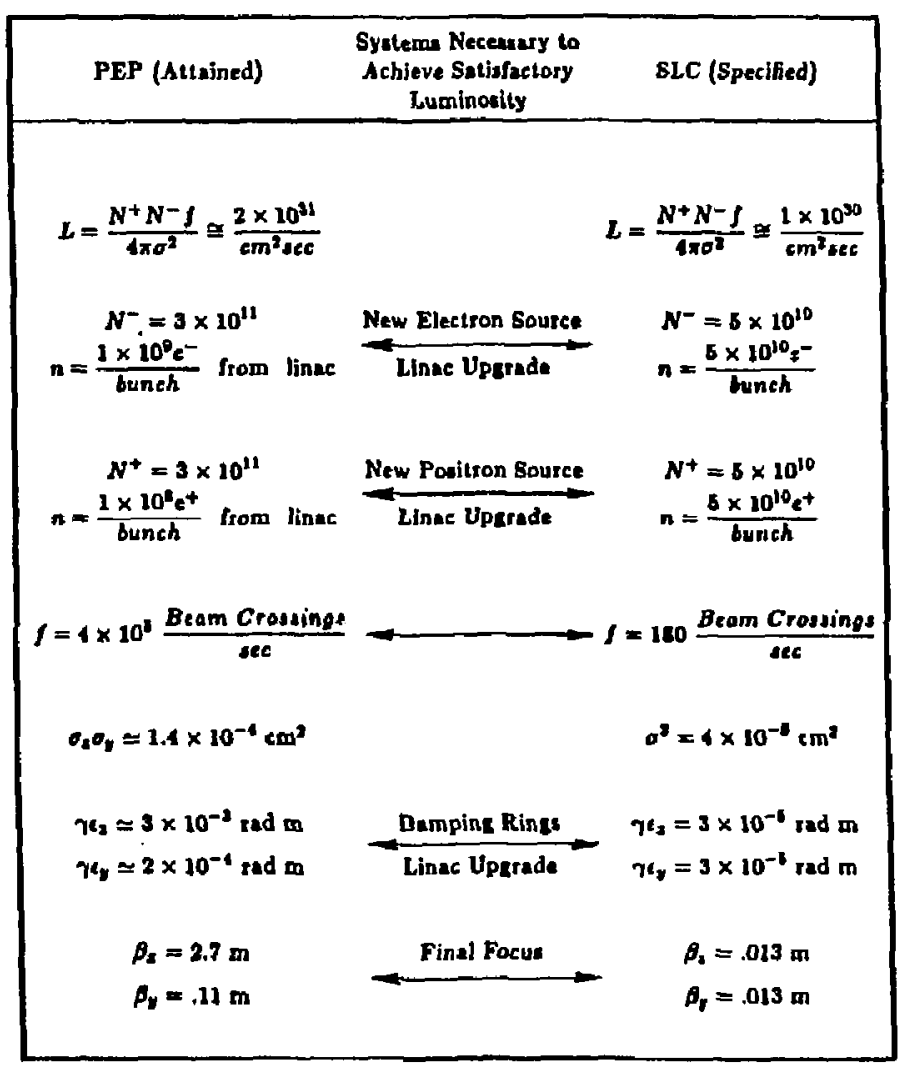

SLAC's linesr collider is shown in echematic form in Fig. 3.2. A detuiled discussion of the deaign apecifications and ayatem descriptions can be found in Refs. 1 and 2. For our purpoten, it is sufficiont to give a brief description of the SLC so that the epecifeations of the electron injector cen be placed in a proper context.

The SLC consists of

- A high current electron injector,

- Two small atorage rings to danp the beame' transverce emiltances,

- A high current pasitron source,

- An extensively uperaded linac,

- The collider arca, and

- The Anal focus.

It is Intructive to deacribe one complote cycle of collider operation.?

1. The electron injector produce two bunches, 50 ne apert.

2. The bunches are accelerated through the firat 100 meters of the accelretor, gaining enerey to $1.21 \mathrm{GeV}$.

3. The bunches enter the north damping ring whero their tranoverae phase epace in reduced by 1 fector of ten in $5.5 \mathrm{~mm}$.

i. The elextron bunches are extracted from the ring, their bunch lengthe compressed, and reinjected into the linse.

5. The two bunches are accelerated through appioximately 1800 meters of linac gaining energy to $33 \mathrm{GeV}$.

6. The eecond electron bunch is diverled by a fast kicker and atrikes the positron target (on the first two cycles of operntion, the firnt $c^{-}$bunch is wasted).

7. Pocitronsol enerey $2-20 \mathrm{MeV}$ are captured and accelerated to $200 \mathrm{MeV}$. 


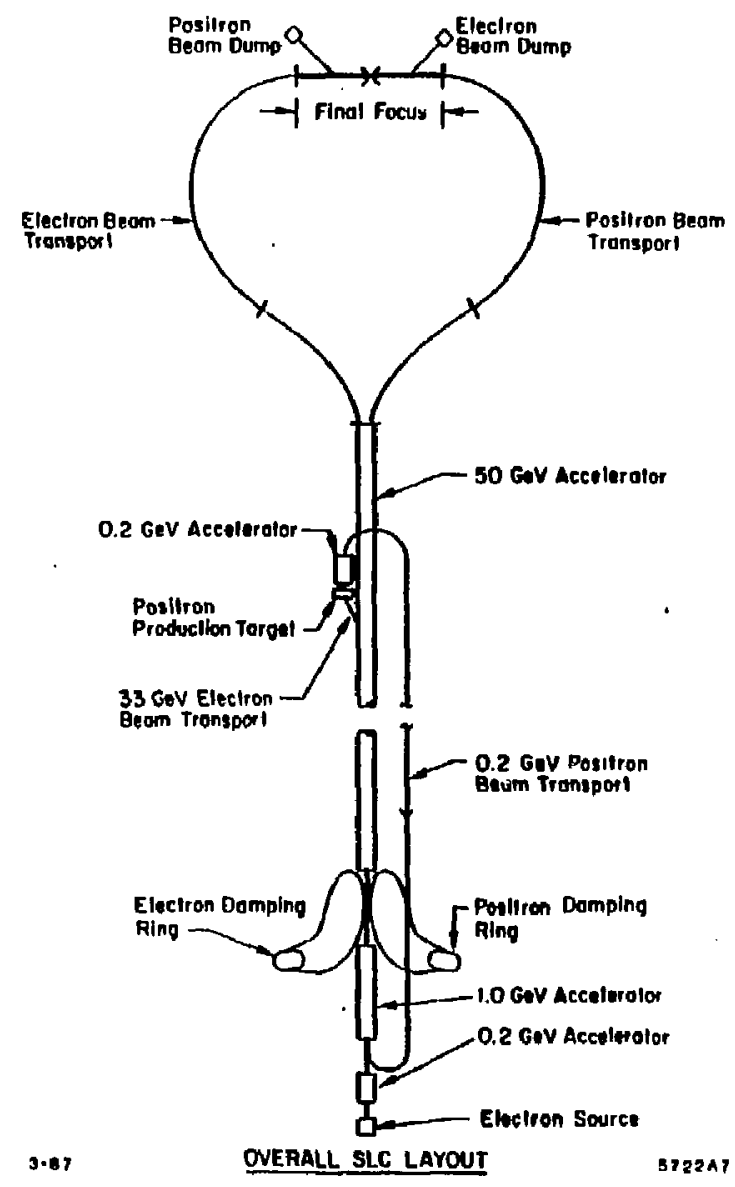

Fig.1.2. Schematic diagram of the SLAC Linear Collider.
8. The positrons are bent through $180^{\circ}$ and transported back to the front of the linac, then bent through another $180^{\circ}$ and injected into the linse.

9. Almost simultaneously the electron injector produces two more bunches of electrons and the three bunches are accelerated to $1.21 \mathrm{GeV}$.

10. The positron bunch enters the south damping ring where its transverse emitlance damps for $11 \mathrm{~ms}$ (two mechine pulses at $180 \mathrm{pps}$ ). Meanwhito the electron buriches enter the north damping ring and are damped for $5.5 \mathrm{~ms}$.

11. After the 5.5 me the two $e^{-}$bunchea are extracted and steps 4 through 10 are repeated. The $e^{t}$ bunch so generated enters the south damping ring in a bucket on the opposite side of the ring from the firat poaitron bunch.

12. The firat $e^{+}$bunch (now fully damped) is extracted from the south damping ring $\$ .5 \mathrm{~ms}$ later. The two $e^{-}$bunches are extracted from the north damping sing and all three bunches are accelerated, the first two bunches to $50 \mathrm{GeV}$.

13. The positron bunch is defiected into the south arc, the first $e^{-*}$ bunch into the north arc and the two collide as the interaction point where interesting ghysice is hopefully produced. The bunches are then discarded. The second $e^{-}$bunch is deflected at the $33 \mathrm{GeV}$ point to produce the next positson bunch.

\section{The cycle is repeated.}

The goal of the collider injector is to prepare highilntensity electron bunch whose aix-dimenulonal emitance at the end of Sector 1 is within the damping ring acceplance. The aix-dimensional damping ring acceplance is summarized in Table 1.2. The invariant transverse beam emittance in both the $x$ and $y$ planes must be no greater then $3 \times 10^{-4}$ radian-meters. The energy aceeptance of the damping ring is $\pm 1 \%$. 
Since the damping rine operates ot the fourth oubharmonic of the linac frequency, it is posaible for the ring to capture two electron bunches accelerated by adjecent RF crests in the linac. However, in the linac the second bunch ctes ot $g$ nifieantly different accelerating fields from the firat. Should this difierence exceed $\pm 1 \%$, the two bunches would not fi within the demping rings energy acceptence.

Table 1.2. Dampins xine acceptance.

\begin{tabular}{|c|}
\hline$t_{2} \leq 3 \times 10^{-1}$ radian meters (invariant) \\
\hline$y \leq 3 \times 10^{-4}$ radian meters (invariant) \\
\hline$E=1.21 \mathrm{GeV}$ \\
\hline$\Delta E / E \leq \pm 1 \%$ \\
\hline Bunch length $\leq 20 \mathrm{~cm}$ \\
\hline
\end{tabular}

To eatimate the entrgy spead between two adjacent bunchen, we write the power per unit length extracted from the linac by the first bunch a

$$
\frac{d U}{d l}=\frac{d q}{d t} E
$$

where

$$
\begin{aligned}
& U=\text { enercy/unit length stored in the linac, } \\
& \boldsymbol{E}=\text { electron charge, and } \\
& E=\text { electric field. }
\end{aligned}
$$

The electric field across a linac cavity as a function of eneray stored per unis length is given by

$$
E^{2}=\omega \frac{r}{Q_{0}} U
$$

where
$\omega=$ frequency of the RF fields, and
$r / Q_{0}=$ shunt impedance of the accelerating atructure.

Combining (1.3) and (1.4) we have

$$
\int \frac{d U}{\sqrt{U}}=\int d g \sqrt{\omega \frac{\pi}{Q_{0}}}
$$

integrating we have

$$
2 \sqrt{V}=\sqrt{\omega \frac{T}{Q_{0}}} Q_{\text {ounts }}
$$

where $Q_{\text {inch }}=$ total charge in the 6rut $e^{-}$bunch. Rearranging and substituting $E=\sqrt{w\left(r / Q_{0}\right) U}$ we eee that the chenge in the field seen by the second bunch due to energy extracted by the firat bunch in

$$
E_{B L}=\frac{1}{2} \omega \frac{r}{Q_{0}} Q_{\text {bunch }}
$$

where we have assumed that the ime between bunches is amall compared to the filling time of the structure, but latse enough that the higher order modes Induced by the firat bunch have lost colerence. This efiect is known an besm landine.

For SLAC'a accelerator atructure, $r / Q_{0}=1.4 \mathrm{kn} / \mathrm{meter}$. For $Q_{\text {munch }}=$ $2.5 \times 10^{10} e^{-}$

$$
E_{B L}=.10 \frac{M e V}{\text { metor }} .
$$

The field gredient necetsary to achiove $1.21 \mathrm{GeV}$ at the demping ring is $E_{A C G}=$ 13.0 MeV/meter. Thus the change in field seen by the second bunch ts

$$
\frac{E_{B L}}{E_{A C C}}=\frac{.16}{13.9}=1.2 \%
$$

Given a $1.2 \%$ energy difference between the two bunches, for both to fall within the damping rine energy accoplanee, each muat have an internal energy apread no ereater than $\pm 0.4 \%$. Ac we shall later ece, $\pm 0.4 \%$ in an unrealistic upper limit on the bunches' internal energy opread. 
Beam loading occurs within a single bunch as well ws between bunches. As discussed in Chapter 2, we can mitigate beam loading in aingle bunch by cap. turing the bunch forward of the RF crent. Using this technique, we can achieve an acceptable energy sprend at the entrance to the damping ring provided we caplure all $5 \times 10^{10}$ electrons into a single RF cycle.

The acceptable longitudinal phane upread of the bunch at the end of the injector is limited not by the phase acceptance of the damping ring but by the fact that the phase spread and thape of the bunch determine the entergy spread at the entrance to the damping rings.

We can now summarize the apecificationa of the collider injector. The spectfications include:

- Two electron bunches, $\sim 50$ ne apart,

- For each bunch, $5 \times 10^{10}$ electrons captured in one accelerator RF cycle,

- Bunch length and.shape which reault in $\$ \pm 1 \%$ energy spectrum at a benm energy of $1.2 \mathrm{GeV}$.

- Invariant transyerse emiltance in both the $x$ and $y$ planes no greatar than $3 \times 10^{-4}$ radian meter.

This thesis is concetned with the problem of the longitudinal eapture of high space charge single bunches.

In Section 2.1, we discuss an analyte theory of bunching and capture of electrons by RF fields in the low apace charge, amall signal limit. We review Miller'b,5 design of SLAC's first injector to Illuatrate a successful application of the theory.

In Section 2.2 we discuss the deaign of the collider Injector, emphasizing that the devign arose from considering the high apace charge, large signal ense as a perturbation of SLAC's successful solution to the low spece charge, small signal bunching problem.
In the collider injector, space charge forces and large RF signals greally complicate the beam dynamica. We must numerically simulate the beam dynamles to have confidence in our design otrategy. In Section 2.3 we discuss a compuler code which models the longitudinal dynamics of electrons in the presence of space charge and RF field. In order to design a simple, one-dimentional model of the longitudinal beam dynamica, we make certain nsumptions about the radial excent of the beam. In Section 2.4 we discuss radial focusing of the beasn to achieve a stable bean radius throughout a given region. In addition we present an approximale calculation which demonstrales that in this design a smalier longitudinal emillance results in transveroe emittance growth.

In Section 3.1 we deacribe the components which make up the collider injecior including the gun, eubhermonic bunchese, traveling-wave buncher and velocityor-light accelerator section. In Section $\mathbf{3 . 2}$ we compare the performance of the injector to its calculated performance. While the final operating conditions differ comewhat from the design, the performance in in good agreement with the numerical aimulation and meets all of the collider opecifications. Finally, in Section 3.3 we discuss radial emillance measurements and compare them to the expected emittance. 


\section{CHAPTER 2.}

\section{DESIGN OF CID, THE COLLIDER INJECTOR}

\subsection{Bunching in the Low Space Charge lmit}

\subsubsection{Low Space Charge Beam Dynamica}

Before diacussing longitudinal bunching in the presence of large apace charge forces, it is inatructive to review the dynamice of bunching in the low space charge limil. In both cases the problem is the same: a continuous stream of low eneray electrons must be bunched into s small fraclion of one RF wavelength. Each bunch must then be captured onto the accelerating RF weve. Our actual problem of longitudinal bunching in the prexence of large spece charge forces is considerably more complex than ita bw apace cherge counterpart, and computet simulations are necestary give us confidence in our detign attategy. Because the Collider injectur Development (CID) desitn arose from considering the high current case a a perturbation of SLAC'e euccesiful rolution to the tow apece charge bunchins problem, a somewhat detailed discussion of buncher derign in the low epece charge limit is appropriate.

For low apace charge beams, derigners often employ tapered loaded waveguider with variable phase velocities and field otrength to accomplish bunching, but tapered waveguides must be "custom cailored" to apecific initial parameters and desired output. Another approach is to design • bunching ayatem where bunching and capture ate tccomplished by a series of constant phase velocity, consunt field strength atructures. This appronch is more robust at the phases and feld atrengths of each component can be varied independently to compeneate for minor design or fabrication errors and to optimize bunching over a range of gun voltages, klyatron powers and waveguide temperatures. SLAC's low current injector designed by Miller", uses three bunching elements, a "gap-enddrift" prebuncher, a traveline-wave buncher with phase velocity less than $c$ and a traveling-wave capture region whose velocity equala c.
With certain simplifyinc assuraptions, we can derive analytic expreasione for the $x$ position and eneray of electrons traversing these three etructures. These expressions lead to longitudinal phese spece plots which give considerable phystcal insight into the bunchins process. The analysis presented here uses Dome's" aproach and notation The same equations are derived and ditcussed in Slater and Chu.

In the "cap-and-dtifl" buncher, a continuous stream of electrone pases through a gap in a resonant structure excited by a sinusoidally time-dependent electric field [see Fis. (2.1)]. For the sake of simplicity we assume that the fieid ecross the cap is conatant in epece and purely ainusoidal in time, f.e., no higher order harmonice contribute to the feld. Then the change in energy of each electron 4 it traverses the gap is given by

$$
\Delta \gamma m_{0} c^{2}=\left(-c E \operatorname{tin} D_{0}\right) \Delta z_{j a p}
$$

or

$$
\Delta y(0)=-a \sin \theta_{0, p p}
$$

where

$$
\begin{aligned}
& m_{0}=\text { electron rest mus } \\
& \text { = electron charge } \\
& \text { e velocily of light } \\
& \tau=\text { total enercy } / m_{0} e^{2}=\text { normalized electron energy } \\
& E=\text { peak electric feld in resonant structure } \\
& \omega_{0}=-w t=\text { where } w \text { is the resanant frequency of the structure } \\
& \text { ( } c=0 \text { at the field null) } \\
& \Delta x_{\text {sap }}=\text { length of cap in resonant structure } \\
& a=c E \lambda / m_{0} c^{2}=\text { normalized electric field } \\
& \text { Eup }=\Delta x_{\text {oug }} / \lambda=\text { normalized length of gap } \\
& \lambda=2 \pi c / \omega=\text { free space wave length of the feld }
\end{aligned}
$$


Electrons which reach the anp when wh $<0$ are decelerated while electrons which arrive at the gap when $w \boldsymbol{t}>\mathbf{0}$ gain energy. As the electrons traverse the drift space following the gap, they bunch around the electrons which crossed the gnp at $=0$. For peak gap voltages small compared to the initial electron energy, the rormalized electron momentum can be approximated as

$$
p(0)=p_{0}\left(1-\frac{p_{0} \alpha}{p_{0}^{l}} \epsilon_{\operatorname{sep}} \sin \theta\right)
$$

whete

$$
\begin{aligned}
p=\sqrt{\gamma^{2}-1}= & \text { normalized momentum } \\
\text { vo. po }= & \text { initial normalized enefgy and momentum } \\
& \text { of the de electrons. }
\end{aligned}
$$

Figure 2.2 in a plot of the longitudinal phase space in the gap-and-drift buncher. The horizontal axis is $=-$ wh where $t$ ia the difference in time between the irrival at a given $\varepsilon$ of the reference particle, which erosses the gap at $\boldsymbol{O}_{0}=0$, and the arrival at the nume $z$ or enother electron which crosses the gap at some ather \% $_{0}$. The vertical exis is 7 , normalized energy of the electron. The vertical lines represent the change in energy, $\Delta \gamma(0)$, ecross the gap; an impulse function is assumed for simplicity. Arter the cap, electron trajectories are represented by the horizontal lines, $a s$ is independent of in the drift space. As the electrons irnverse the drift gonace, ochungea as

$$
\varphi(z)=\omega_{0}+\frac{2 \pi \varepsilon}{\lambda}\left(\frac{1}{\rho_{0}}-\frac{1}{\beta}\right)
$$

In differential form we have

$$
\frac{\Delta 1}{\Delta z}=\frac{2 \pi}{\lambda}\left(\frac{1}{\beta_{0}}-\frac{1}{\beta}\right)
$$

or

$$
\frac{\Delta \theta}{\Delta \xi}=2 \pi\left(\frac{1}{\beta_{0}}-\frac{1}{\beta}\right)
$$




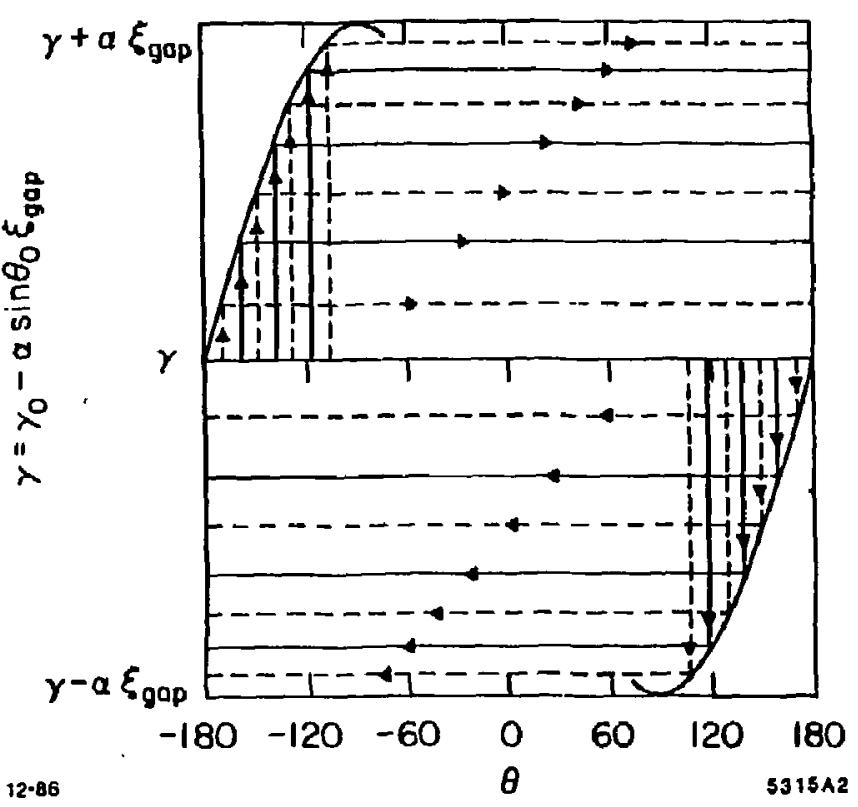

Fiz. 2.2. Gap-and-drif prebuncher phase space (Irom Döme $)$. where

$$
\begin{aligned}
\epsilon & =s / \lambda=\text { normalized distance beyond the gap } \\
\beta=v / c & =\text { normalized electron velocity } \\
\beta_{0} & =\text { initial normallzed velocity of the de electrons. }
\end{aligned}
$$

For each particle traversing the gup-and-drift buncher, we can integrate Eq. 2.3 to find $\boldsymbol{A} 4$ a function of $\xi$ along the drift apace. In Fig. 2.3, we illustrate the bunchine properties of the esp-and-drift prebuncher uning an initially uniform stream of electrons with $\beta=.5$. The curve labeled $\xi=0$ showe the phase and energy of the particles immediately following the gap with peak voltage a $f_{n,}=.02$. Particles traversing the gap at $D_{0}=-90^{\circ}$ have the highest energy, while particles traversing the gap at $+\$ 0^{\circ}$ have the loweat. After drifting one free space wavelength, the positiona of the particles in phase apace are given by the curve habeled $f=1.0$. We ate that the particles which traversed the gap at $b_{0}=-90^{\circ}$ now have $O=-45^{\circ}$. After drifting 1.8 fret-apace wavelengths, the particlea with $\theta_{0}=-\infty 0^{\circ}$ have overtaken the particle which traversed the gap at $P_{Q}=0$. At $\xi=1.0$, electross initizlly occupying $\sim 240^{\circ}$ of phase are bunched into $\sim 70^{\circ}$ of phase.

Now let un consides the bunchine propertiea of a traveling-wave structure. Again, asoume for aimplicity that the accelesating wave is a sinusoidal traveling wave with phase velocity $\boldsymbol{\theta}_{\mathrm{w}}$ and that higher apace harmonica present can be neglected. At \& given 2 dong the waveguide, electrons gain energy per unit length given by

$$
\frac{d m_{0} c^{2}}{d x}=-c E \sin \theta
$$

or

$$
\frac{d y}{d \xi}=-a \sin \theta
$$

where 


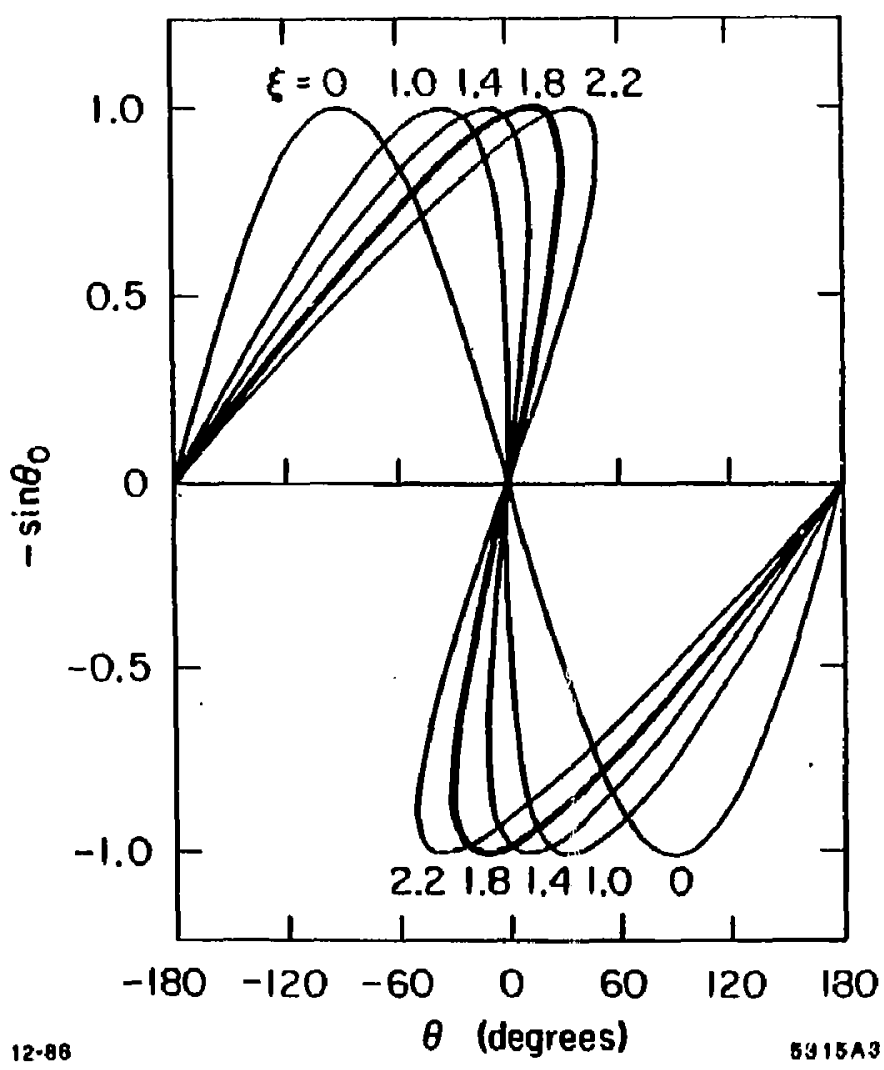

Fig. 2.3. Constant $\xi$ curves in phese opece for a gap-and-drift prebuncher with $\beta_{0}=0.5, \alpha \xi_{a p}=.02$. The $\xi=0$ curve represents the pheses and energies of the particles immediately downatream of the RF voltate gap. The $\xi=1.8$ curve represents the phases of the mame particles 1,8 wavelengths downstream. Considerable bunching has occurred. $\theta=-\omega t$.

$l=$ dilference in time between the arrival of the traveling wave phase null at a given $z$ and the arrival of the electron at the anme $z$, and

$\xi \quad=2 / \lambda=$ normalized dintance along the axis of the buncher.

The variation in phase pet thit length of the electrons ls given by

$$
\frac{d U}{d z}=\frac{2 \pi}{\lambda}\left(\frac{1}{\rho_{\omega}}-\frac{1}{\rho}\right) \text { or } \frac{d U}{d \varepsilon}=2 \pi\left(\frac{1}{\beta_{-}}-\frac{1}{\beta}\right)
$$

Equations (2.4) and (2.5) can be combined to yield

$$
2 \pi\left(\frac{1}{\hat{\theta}_{-}}-\frac{\gamma}{\sqrt{\gamma^{2}-1}}\right) d \gamma=-\operatorname{asin} \theta d \theta \text {. }
$$

For the present discussion we have asaumed that the phase velocity $\rho_{-}$and the field atrength $\alpha$ are constant in the traveling-wave structure. For $\beta_{v}$ and $a$ corstant we can integrate Eq. (2.6) to yiefd

$$
\frac{7}{B_{0}}-\left(\gamma^{2}-1\right)^{1 / 2}=\frac{a}{2 \pi} \cos \theta+H
$$

where $\boldsymbol{H}$ is a constant of integration. Sirce we are interested in longitudinal phase space plots, it is useful to rewrite Eq. (2.7) in terms of the normalized momentum $p=\sqrt{\gamma^{i}-1}=\beta \gamma$. Equation (2.7) yields

$$
\frac{\left(p^{2}+1\right)^{1 / 2}}{\beta_{0}}-p=\frac{a}{2 \pi} \cos \theta+H \text {. }
$$

To solve for the constent in Eq. (2.8) let us define a wew function

$$
y=\frac{\left(p^{2}+1\right)^{1 / 2}}{\bar{\beta}_{0}}-p=\frac{\alpha}{2 \pi} \cos \theta+H
$$

Let us also define $\theta_{m}$ as the value of when $y$ is at its minimum. The value of $p$ corresponding to the minlmum value of $y$ is given by 


$$
\frac{d y}{d p}=\frac{p}{\beta_{\omega} \sqrt{p^{2}+1}}-1=0 .
$$

Substituting $P=\mathcal{\gamma} \beta$ wo have

$$
\frac{\gamma \beta}{\beta_{w \gamma}}-1=0 \text { or } \beta=\beta_{w} .
$$

Thus the minimum value of $y$ occurs when $P=\gamma_{w} \beta_{w}$ where $\gamma_{w}$ is the energy of an electron synchronous with the traveling-wave

$$
y_{m i n}=\frac{1}{7 w \beta_{\infty}}=\frac{\alpha}{2 \pi} \cos \theta_{m}+H
$$

Subtracting Eq. (2.9) from (2.6) and writine $\gamma_{w} \beta_{w}=p_{w}$ we have

$$
\frac{\left(p^{2}+1\right)^{1 / 2}}{\beta_{m}}-p-\frac{1}{p_{\omega}}=\frac{x}{2 \pi}\left(\cos \theta-\cos \theta_{m}\right) .
$$

Equation (2.10) is plotted in Fis. 2.4 for $\beta_{\omega}<1$. The plot show the trajectories of alectrons in longitudinal phuse space. As the couine in an even function, all orbits are aymmetric about the line $\$=0$. Curves labeled y represent unbound orbits (1.e., electrons not captured by the wave) while curvea labeled 1 represent bound orbits. The bound electsons follow closed puths about the point $1=0, p=p_{w}$, l.e., in real space the bound electrons oscillate about the traveling. wave field null. Electrons going slower thin the wave (lower sight quadrant) lose energy (and velocity) until they fall behind the phase null $(\theta=0)$. They then begin to gain energy (lower left quadranti) until they are synchronous with the wave $\left(p=p_{w},=-d_{m}\right)$. They continue to gain energy and velocity (upper left quadrant) until they puss the phase null $(0=0)$. They then lose enercy (upper right quadrant) until they are alower than the aynchronoun velocity, and the cycle begins apain. For each bound orbit, $t_{r}$ is the meximum phase excursion and occurs when $p=p_{w}$.

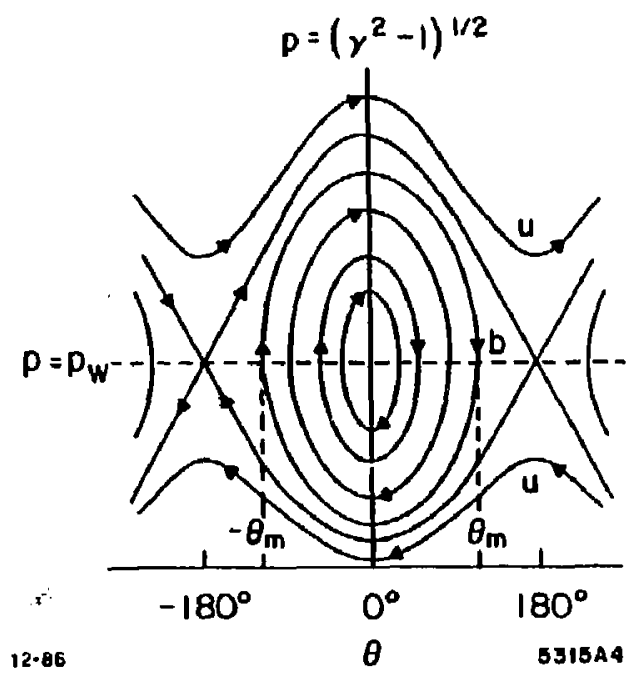

Fif. 2.4. Constant phase velocity buncher phase space for $\beta_{\omega}<1$ (from Dórne'). 
While Fig. 2.4 nicely illustrates the orbits of bound electrons in phase space, it gives us no insight into the rate at which various electrons execute their or bits. Dôme ${ }^{6}$ has shown that for $\alpha \ll \pi \beta_{\omega} / 2 \gamma_{\omega}$ one can derive an analytic expreasion for 1 as a function of $\epsilon$. The actual derivation io laborious but the results are informative. The deshed lines of Fig. 2.5 are the bound orbits of Fis. 2.4. Electrons lesving the gun ean be repremented a monoenergetlc beam evenly distributed along the $z$-axis. If the inilial electron energy to $\gamma=\gamma_{w}$ at the entrance to the buncher $(\xi=0)$, the electrons will be continuously distributed along the $p=p_{\text {w }}$ axis of Fig. 2.5. As the electrons travene the waveguide, they sweep out the constent $₹$ curves (solid lines) of Fis. 2.5. The density of electrons as a function of phase is not constant as the pointe at $-180^{\circ}, 0^{\circ}$, and $+180^{\circ}$ are fixed. Figure 2.5 nicely illustrates the bunching propertiea of $a \theta_{0}<1$ traveling-wave buncher in the IImit of low apace charge and amall velocity modulation $\left(\alpha / 2 \pi<\beta_{-} / \gamma_{\infty}\right)$.

Now let us consider the motion of electrona in the presence of a travelingwave with $\beta_{\omega}=1$. Equation (2.10) is atill valld, but the bound orbits in phase opace are no longer closed curves. At electrons gain enercy, they asymptotically approach the velocity of the wave and aymptotieally approach $\boldsymbol{t}_{m}$. Since infinite momentum would be needed to achleve $\rho=\theta_{w}$, whkh corresponds to $\theta=\theta_{m}$ it is customary to write $\theta_{m}=\theta_{\infty}$ and Eq. (2.10) becomes

$$
\left(p^{2}+1\right)^{1 / 2}-p=\frac{\alpha}{2 \pi}\left(\cos \theta-\cos \theta_{\infty}\right)
$$

or

$$
\sqrt{\frac{1-\theta}{1+\phi}}=\frac{a}{2 \pi}\left(\cos \theta-\cos \theta_{\infty}\right) .
$$

Equation (2.11) is plotted in Fig. 2.6. Again curves labeled u represent unbound orbits while curves labeled $b$ are bound orbits. Av in the $\rho_{0}<1$ case, the curves are oymmetric about $\boldsymbol{A}=0$. Unlike the $\rho_{\omega}<1$ case, the electrons do not oncillate about the wave null, oince it is not possible for electrons to reach

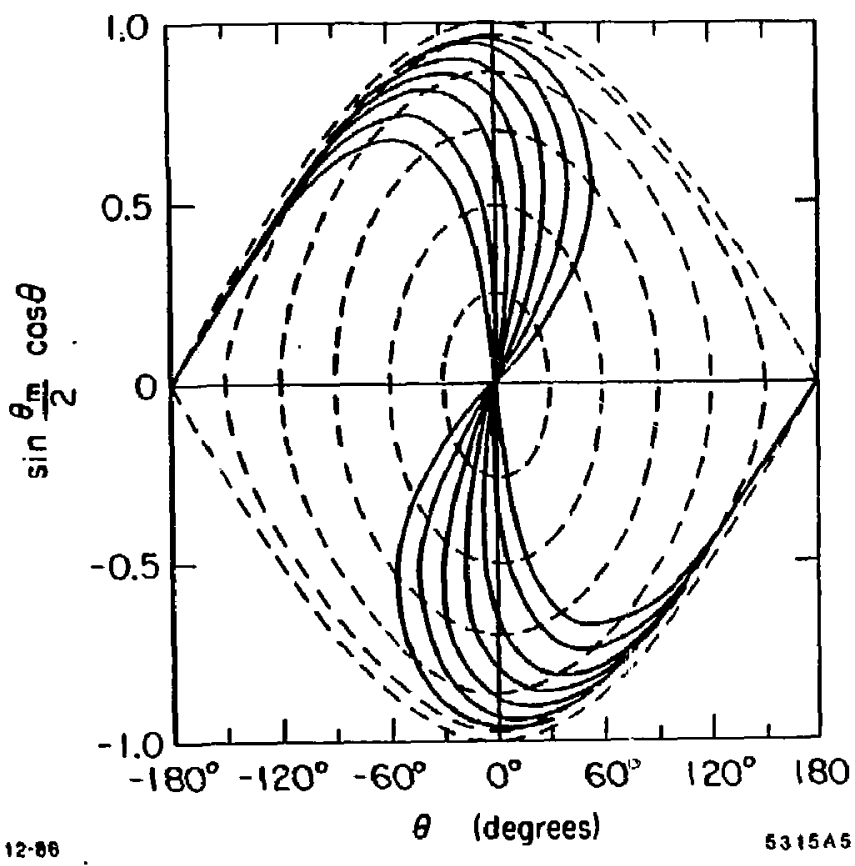

Fig. 2.5. Bunching in a traveling-wave structure. The dashed curves are the phese apace orbits of the individual particles. The olid horizontal line represents a continuous monounergetic beam at the entrance to the buncher with $\beta_{0}=\rho_{w}$. The solid curves show the phase apace occupied by the beam at seven locations on the $z$ axis. 


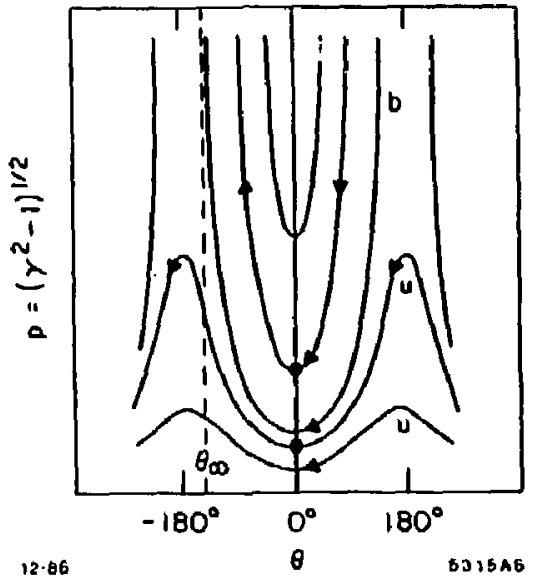

Fig. 2.6. Constant phese velocity capture rezion phewe epace $\left(\beta_{w}=1\right)$. Particles initially shead of the phase null are decelerated, eventually falling behind the null where they are accelerated. Since $\beta_{w}=1$, they can never achieve a velocity greater than the wave. or exceed the speed of the wave. Intead, electron in each orbit epproach the synchronaus velocity $\beta=1$ at foo for that orbit. The electrons are suid to be "captured" by the RF wave.

For $\eta>10, \beta$ does not change aignificantly as $\gamma$ increases, and bunching by velocity modulation due $w$ the RF wave is no longer feasible. Thus the position of an electron in phase space as it entera the velocity-of-light atrueture determines its final phase, and therefore, its energy.

In the low space charge limit, the electron energy at the end of the accelerator is nearly proportional to sin 100 ." Ficure 2.7 augrests that the best apectrum in obtained if the aymptotic phases of the electrons, $\nu_{\infty}$, fall within a narrow range around ${\omega_{\infty}}=-90^{\circ}$. To see this quantitatively, note that for electrons with the same initial momentum and entrance anglex clustered near $\mathcal{M}_{0}$, Eq. (2.11) yie]ds

$$
-\sin \omega_{\infty} d H_{\infty}=-\sin \omega_{0} d \theta_{0}
$$

$$
\Delta \omega_{0}=\frac{\sin \nu_{0} \Delta \omega_{0}}{\sin \theta_{\infty}}
$$

Thus the narrowest soread in finl shase will oceur for electrons whose entrence angles are very near sero and whe - erymptotic angles are near $-00^{\circ}$. For the entrance andle $\ell_{0}=0$ Eq. (2.11a) yiath

$$
\cos \theta_{\infty}^{\circ}=1-\frac{2 \pi}{\alpha} \sqrt{\frac{1-\beta}{1+\beta}}
$$

Where $\theta_{\infty}^{0}$ is the asymptotic phase of particle with $\theta_{0}=0$.

Figure 2.8 in a aketch of the phase apace orbits for particles which will be captured at the extreme phases of the final bunch. Particles on the upper curve,

- This asum met, of course, ebat later accelerator sectiont we in pbese with the capture region 


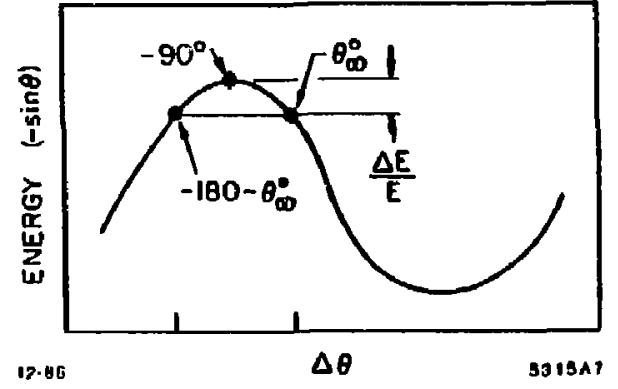

Fig. 2.7. Partiele eneray as a function of aymptotic phase.

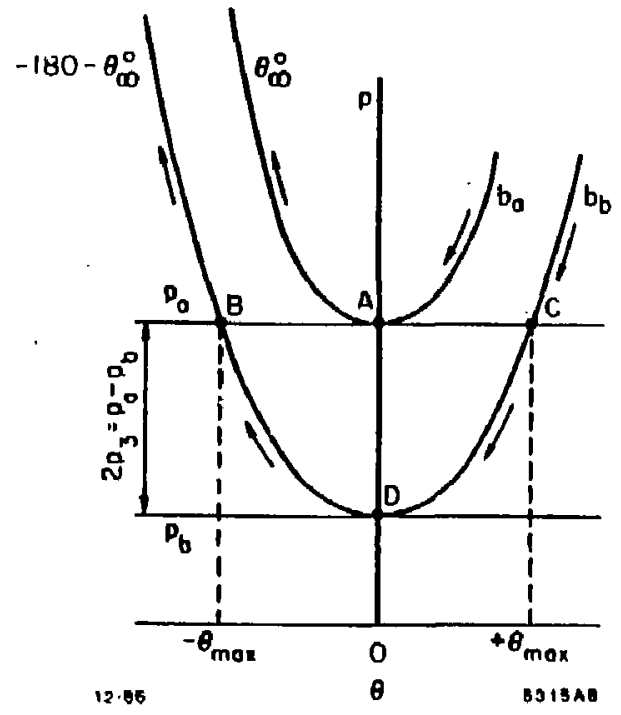

Fis. 2.8. Capture region admittance. Initial phese space which will be captured into energy opread $\triangle E / E$. $\pm \theta_{\text {mas }}$ are the extreme phases of entering particles which will be captured into $\Delta E / E$ energy spread (For $p \leq p_{\mathbf{A}}$ ). 
which include the point $A\left(0_{0}=0, p=p_{k}\right)$ have asymptotic phase $\theta_{\infty}^{\circ}$. Particlet an the lower curve, which includes points $B\left(\omega_{0}=-\theta_{\text {masi }} p=p_{0}\right)$ and $C\left(U_{0}=\right.$ $0_{\text {max }} p=p_{0}$ ) have asymptotic phase $-180^{\circ}-0_{\infty}^{\circ}$. Note that all electrons with the initial momentum $p=p_{\text {a }}$ will have aymptotic pheses behind $f_{\infty}^{0}$. To cepture the most particles within an allowed energy epread, $\Delta E / E, f_{\infty}^{0}$ ahould be forward of the RF crest (-90') (see Fig. 2.7) and sotivfy the equation

$$
1-\left(-\sin \theta_{\infty}^{0}\right)=\frac{\Delta E}{E}
$$

Assuming the desired $\Delta E / E<1$ (it will usually be .01 or less), Eq. (2.14) yields

$$
\cos \theta_{\infty}^{0} \simeq \sqrt{2 \frac{\Delta E}{E}}
$$

Subrtituting into Eq. (2.13) we have

$$
\sqrt{2 \frac{\Delta E}{E}}=1-\frac{2 \pi}{a} \sqrt{\frac{1-\beta}{1+\beta}} .
$$

Erom Eq. 2.13 we see that for $\&$ given initial $\beta, \phi_{\infty}^{0}$ is delermined colely by the value of $\alpha$. Thus, to capture the most electrons within the sllowed energy spread, $\Delta E / E$, we must choose a such that

$$
a=\frac{2 \pi}{1-\sqrt{2 Q q}} \sqrt{\frac{1-\beta}{1+\beta}} .
$$

Figure 2.9 is a plot of the optimum values of a versus bitial normalized electron velocity for $\Delta E / E=.01$. We see that for low initial values of $\beta$, bigh fieldz are reeded in the capture segion to obtain adequate bunching and spectrum.

From Fig. 2.8 we see that all electrons whose final phases are between $\theta_{\infty}^{0}$ and $-\pi-0_{\infty}^{0}$ will have the desired fanal energies. The extreme initial phase extents,

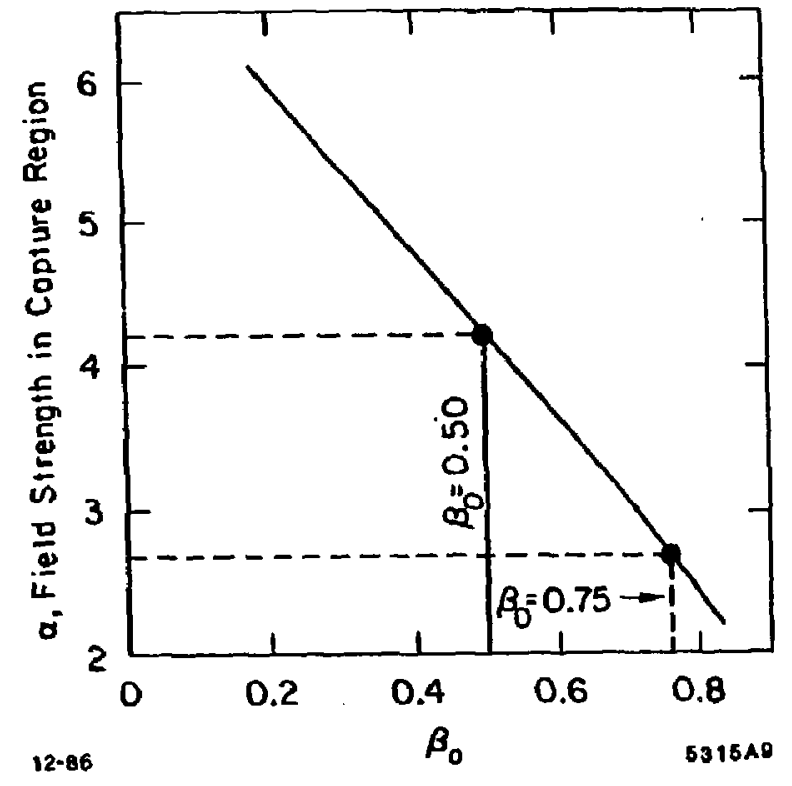

Fis. 2.9. Field strength in capture reginn necessary for optimum bunching of electrons with initial energy $\beta_{0}$ into bunch with $\Delta E / E=0.01$ (fram Dosme"). 
$\pm \theta_{\text {max }}$ have final phase $t_{\infty}=-\pi-\infty_{\infty}^{0}$. Uaing Eqs. (2.11a), (2.13) and (2.15), we find

$$
\begin{aligned}
\theta_{\text {max }} & =\cos ^{-1}\left(1-2 \cos \infty_{\infty}^{0}\right) \\
& =\cos ^{-1}\left(1-2 \sqrt{\frac{2 \Delta E}{E}}\right) .
\end{aligned}
$$

An the tolerance on final energy apread tightens, the acteplabie phase extent of incoming electrons grows smalfer.

The preceding discussion [Equ. (2.12) through (2.18)] wos limited to electrons with the same incident enersy, namely those electrone with $p=p_{0}$, in Fig. 2.8. In general, electrons entering a valoelty-or-light etructure will already have undergone some velocity modulation in a gap-and-drift or $\rho_{\infty}<1$ traveling-wave buncher. From the anme figure we see that all partlele whose orblts lie between b. and $b_{0}$ hare aymptotic phuses between $\omega_{\infty}^{0}$ and $-\pi-\omega_{\infty}^{b}$, and thus fall within the acceptable final epectrum. In particules, II we euperimpone the conalent

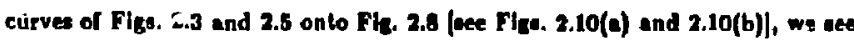
that it is ametimes possible to match the longltudinal emiltance of the $\rho_{w}<1$ structure directiy to the admittance of the $\rho_{0}=1$ capture region. The bet matching (i.e., the most current within the alfowed eneray apread) between the buncher emittance and the capture region admittance occurs when the fold-over points $A$ and $B$ of the $Z$ curves lie close to the $b$ curve.

D6me ${ }^{6}$ has calculated that proper matching of $\phi_{0}=.8$ electrons from either a drift-and-gap or $\approx \beta_{-}<1$ traveling-wave buncher to the $\beta_{a}=1$ capture region resulte in the capture of greater than $70 \%$ of the initially continuous stream of electrona into a spectrum of $1 \%$

If the desired final phase extent (and reaulting eneray spread) b quilte mall, $\Delta E / E<0.01$, problems arise in matching the emittance of either buncher dis cussed above directly to the admittance of the cupture region. From Eq. (2.18) and Fig. 2.8 we see that as the required final energy spread narrowg, the admil.
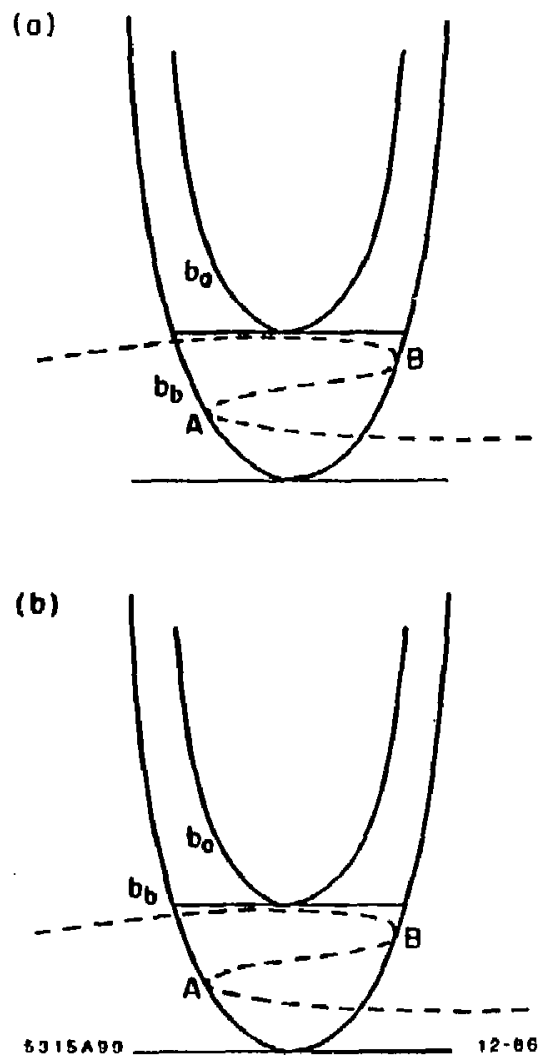

Fig. 2.10. (o) $A$ constant $E$ curve of Fig. 2.3 (the gap-and-drift buncher) vuperimposed on the phese apace orbits of the $\beta_{w}=1$ capture reglon. (b) $A$ constanl $\varepsilon$ curve of Fig. 2.5 (the $\beta_{-}<1$ traveling-wave buncher) superimposed on the.phase space orbits of the $\beta_{2}=1$ capture tegion. 
tance of the capture region grows smaller in both phase and momentum extent; at Uns decreases, $p_{a}-p_{b}$ also decteasen.

It is clear from Figs. 2.3 and 2.5 that bunching of a de beam due to a tinusaidal field is inherently nonlinear. It is not possible to make the resulting bunch arbitrarlly ahort white retuining significant current. A the acceptable final phese extent of the beam shrinks, less and less current from the buncher fits into the capture region admittance.

In order to have a narrow spectrum without unduly low currents, we can capture more electrons into the final phuse extent if we use en intermediate bunching element to match the emittance of the prebuncher to the admittance of the capture rezion. Lichtenbera? sugcested the use of impedstice matching concepts for matching beam emittances to machine admitlances in longitudinal phase space. He defined the "impedence" a the ratio of the momentum extent of the bunch to its phase extent in longitudinal phuse sace. This concept led Miller' to the idea of matchine the emittance of the prebuncher to the admittance of the accelerator with $\approx \beta_{\mathrm{w}}<1$ traveling-wave buncher uned $\&$ \& quarter-wave trannformer. Figure. 2.11 illuatrates the principle of the quarter-wave transformer. In ceneral, the prebuncher emittance has a relatively larce phase extent and amall momentum extent. The capture region admittance has umaller phase extent and larer momentum extent. We choose the phase velocity $\beta_{w}$ of the buncher such that $\beta_{0}<\beta_{\omega}<1$. Electrons from the prebuncher with mean momentum po are injected at the phase null. After a quarter of a cycle in phese apace, the buncher has transformed the injtially large phus extent (umall momentum extent) into a smaller phase extent (and larger momentum extent). The electrone have also gained enercy.

To find the optimum characteristics of the quarter-wave transformer, it in useful to citcumscribe the final prebuncher emittance with the ellipie at the bottom of Fis. 2.11. The ellipse has principal axes $\theta_{1}=(c-d) / 2$ and $p_{1}=$ $(a-b) / 2$ and area $\pi \theta_{j} p_{1}$. Given that the initial phase extent $b_{1}$ lo uppreclably

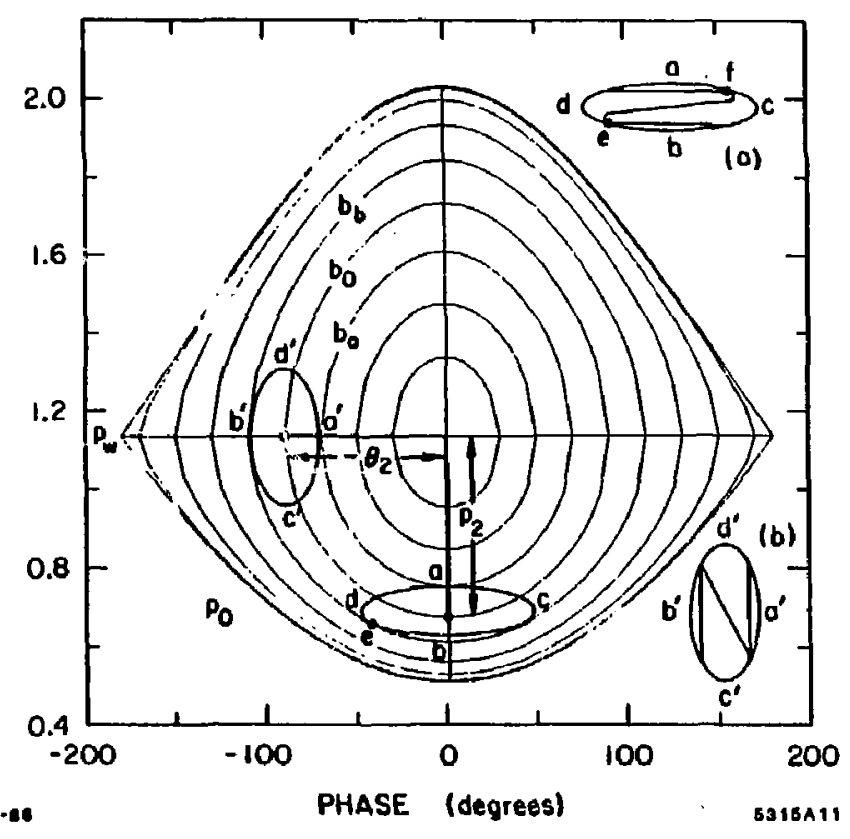

Fic. 2.11. Beam emittance at the end of the prebuncher mapped into the beam emittance at the entrance to the catpure recion is accomplished by a quarterwave tranaformation in a $\beta_{w}<1$ traveling-wavestructure. (a) Beam emittance at the entrance to the buncher circumacribed by ellipse $a, c, b, d$. (b) Beam emilunce at the end of the buncher circumacribed by ellipse $a^{\prime}, c^{\prime}, b^{\prime}, d^{*}$. 
umaller than $180^{\circ}$ and that $p_{i}<p_{w}-p_{0}$, we can assume that the mapping of the prebuncher er 'ttance ellipse from one region of phase apace to another docs not distort the ellipse appreciably. As the ellipare moves through one-quarter of a cycle in the buncher, phase space points $a, b, c$, and $d$ are mapped to points $a^{\prime}, b^{\prime}, c^{\prime}, d^{\prime}$. All points within the prebuncher ellipwe (Fig. 2.11a) are mapped into the capture reglon ellipse (2.11b), with principal axes $b_{3}=\left(a^{\prime}-U\right) / 2$ and $p_{3}=\left(d^{\prime}-c^{\prime}\right) / 2$. Note from Fig. 2.11 that the beam ellipse rotates ebout the particle initislly at the point $\left(0, p_{0}\right)$ which moven in orbit $b_{0}$ to the point $\left(-C_{1}, p_{m}\right)$ a quarter-cycle later. Assuming phase opace orbits $b_{0}, b_{0}$ and $h$ are almilar curves,

$$
\frac{p_{w}-a}{\left|a^{\prime}\right|}=\frac{p_{w}-b}{|v|}=\frac{p_{w}-p_{0}}{\left|-f_{2}\right|} \text {. }
$$

Defining $p_{1}=p_{-}-p_{0}$ and rearsangins, we have

$$
a-b=\frac{m_{2}}{\left|-b_{2}\right|}\left(\left|b^{\prime}\right|-\left|a^{\prime}\right|\right)
$$

or

$$
m_{1}=\frac{p_{2}}{p_{2}} e_{3}
$$

Similarly, we find

$$
\frac{d-c^{\prime}}{d}=\frac{c-d}{p_{2}}
$$

$$
p_{\mathrm{a}}=\frac{p_{2}}{d_{2}} \boldsymbol{p}_{1}
$$

From Eqt. (2.19) and (2.20) the conditions for mapping the prebuncher emittance to the capluse region admittance are

$$
p_{3} \beta_{3}=p_{1} \theta_{1}
$$

and

$$
\frac{p_{2}}{\theta_{2}}=\sqrt{\frac{p_{1}}{p_{1}} \frac{p_{9}}{p_{3}}}
$$

From Eg. (2.21) we see that the areas of the prebuncher and capture region ellipses must be equal. Any decreese in the phase extent of the beam results in momentum spread growth by the same factor. From Eq. (2.22) we see that the buncher orbit ellipticity $p_{2} / \theta_{2}$ must be the geometric mean of $p_{1} / \theta_{1}$ and $p_{3} / \theta_{3}$ to match the prebuncher emittance to the capture region admittance, as would be expected by the analogy with tranamiation line mutching.

\subsubsection{Design of the SLAC Main Injector}

To Illuatrale the previous discussion let un examine the design of SLAC's low cursent injector ${ }^{4,5}$ (see Fig. 2.12). A continuous stream of electrons from the gun are bunched in a sup-und-drift prebuncher. The beam from the prebuneher is injected into $\triangle \rho_{\infty}=.75$ traveling-wave buncher uted as a quarter-wave transformer. Electrons then enter a itandard SLAC accelerator section, the $3 \mathrm{rat} 30 \mathrm{~cm}$ of which acts as the capture reglon.

The SLAC Injector was devigned with an electron gun voltage of $80 \mathrm{kV}$. At this voltage the gun could be housed in a reasonably umall space without oil or high dielectric atrength gur needed at an insulator, allowing easy access for troubleahooting and repair. As is evident from Fig. 2.9, the capture of electrons with mean enercy of $80 \mathrm{kV}$ (and mean velocity $\beta_{0}=.5$ ) requirea electric fielda in the capture region of $210 \mathrm{kV} / \mathrm{em}$. Supplying wuch flelds to a SLAC three-meter accelerator section would requlre more power than an early SLAC klystron could produce. Therelore, the buncher was deaigned with $\beta_{0}<\beta_{v}<1$ to accelerate the beam while matehing the phese apace ellipse from preburcher to capture region. Early SLAC klyatrone could comfortably produce flelds of $130 \mathrm{kV} / \mathrm{cm}$ in a SLAC aecelerator section which corresponds to $\alpha=2.7$ in the capture region. From Fig. 2.0 we aee that the beat capture will occur if electrons en ter the capture segion with tmean velocity $\beta=.75$. The traveling-wave bunches was consequently designed with this phase velocity. 


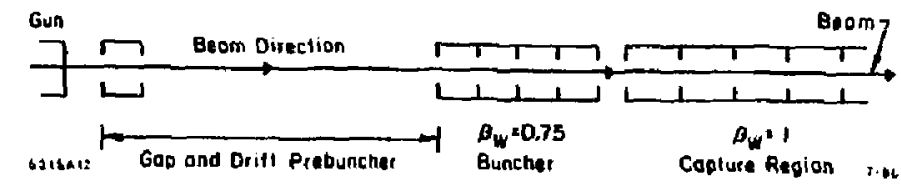

Fig. 2.12. The SL,AC low-current, long-pulse injector.
The field strength in the buncher was chosen to malch the prebuncher anittance to th- capture region odmillnse. The capture region admillance was determined by the desired final phuse (which determines tanal upectrum). For a desired final bunch lenth of 4 " which would yield better than $0.1 \%$ energy spread in the absence of eun vollage or klyatron phese jitter), Eq. (2.18) yields

$$
U_{\max }=C_{3}=\cos ^{-1}\left(1-2 \cos 68^{\circ}\right)=21.5^{\circ}
$$

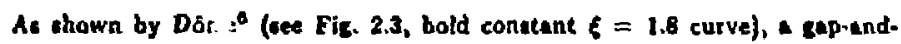
drift prebunchet cen bunch epproximately $70 \%$ of $n$ de beam into $75^{\circ}$. Thus the buncher munt compreas the phute exlent by a factor of 1.7 . The admiltance of the capture tegion fo lluatrated in Fig. 2.8. All particles which lie in orbits between $b_{\text {. }}$ and $b_{b}$ will lie withln the allowed energy cpectrum at the end of the accelerator section. An a practical matter, the mast vestul region of this admittance is the cup-ahaped refion bounded by the line $p=p_{4}$ on top and the curve $b_{b}$ on the bottom. We cen cileulate the maximum momentum accoptence of this rion.

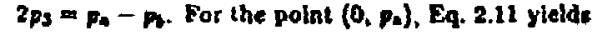

$$
y_{c}=\left(P_{c}^{2}+1\right)^{1 / 2}-P_{b}=\frac{\alpha}{2 \pi}\left(1-\cos \theta_{\infty}^{0}\right)
$$

where we have relintroduced the function $y=\left(p_{0}^{2}+1\right)^{1 / 2}-p_{0}$ from Eq. 2.8. Solving for pa we have

$$
p_{a}=\frac{1-w_{0}^{2}}{2 w_{0}}
$$

For the point $(0,1)$, Eq. 2.11 yield,

$$
y_{l}=\left(p_{b}^{2}+1\right)^{1 / 2}-p_{b}=\frac{a}{2 \pi}\left[1-\cos \left(-\theta_{\infty}^{0}\right)\right] .
$$

Again, solving for fo yields

$$
p_{b}=\frac{1-y_{1}^{2}}{2 y_{b}}
$$


For $\varphi_{\infty}^{0}=-88^{\circ}$ and $a=2.7$

$$
2 p_{3}=p_{\bullet}-p_{s}=0.10
$$

From Eq. (2.21) we know that a.factor of 1.7 comprension of phuse extent will resule in a factor of 1.7 increase in momentum extent. Thus the prebuncher momentum extent $2 p_{1}$ ahould be no more than 0.06 . This requires a prebuncher sap voltage of no more than $7.8 \mathrm{kV}$. To achieve $\mathrm{7} 75^{\circ}$ bunch, the drift space Collowing the gap at $8 \mathrm{kV}$ should be $30 \mathrm{~cm}$.

At this point, only $\alpha$ in the buncher in undetermined. From Eq. (2.10), we can find the final phases of the particles which enter the buncher at a and $e$ of Fic. 2.11, as these particlea move to the buncher emitince phase extrema, $\boldsymbol{t}_{m}$ and $t_{m}-2 O_{3}$. Specifically, Eq. $(2.10)$ steldo for the particle Initially at a with momentum p.

$$
\frac{2 \pi y_{1}}{a}=\frac{2 \pi}{a}\left(\frac{\sqrt{p_{a}^{3}+1}}{\hat{\beta}_{a}}-p_{4}-\frac{1}{p_{\infty}}\right)=1-\cos \left(\theta_{m}-2 \theta_{3}\right)
$$

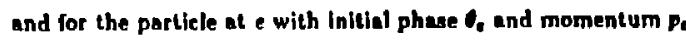

$$
\frac{2 \pi y_{e}}{\alpha}=\frac{2 \pi}{a}\left(\frac{\sqrt{p_{g}^{2}+1}}{\beta_{\omega}}-p_{e}-\frac{1}{p_{m}}\right)=\cos \theta_{e}-\cos \theta_{m} .
$$

Solving for a we find

$$
y_{1}\left(\cos \theta_{e}-\cos \theta_{m}\right)-y_{1}\left[1-\cos \left(\theta_{m}-2 \theta_{3}\right)\right]=0
$$

Equation (2.28) can be solved numerically. For $\ell_{1}=37.5^{\circ}, l_{3}=21.5^{\circ} p_{a}=.61$ and $p_{r}=.55$ we find $\pm \theta_{m}= \pm 148.7$. Subotituling into (2.27) we find $a=.33$ which cortesponds to a field strength of $16 \mathrm{kV} / \mathrm{cm}$.

The final parameters for a low current injector are oummarized in Table 2.1.
Table 2.1. Main injector preliminary design specifications.

\begin{tabular}{|c|c|c|c|c|c|c|}
\hline Element & $k V / \mathrm{cm}$ & Length $(\mathrm{cm})$ & $\theta_{w}$ & $\Delta \theta$ & $\Delta p$ & $\Delta E / E$ \\
\hline Gun & - & - & 0.5 & $270^{\circ}$ & 0 & \\
\hline Gap-and-drilt prebuncher & 8 & $36^{*}$ & - & $75^{\circ}$ & .06 & \\
\hline Quarter-wave transformer buncher & 16 & 10.5 & .75 & $43^{\circ}$ & .10 & \\
\hline Capture region & 130 & 21.0 & 1.0 & $4^{\circ}$ & - & \\
\hline End of accelerator section & - & - & - & - & - & $0.1 \%$ \\
\hline
\end{tabular}

"Including drift.

The upectications derived here depend on the assumptions of emall energy modulationa and undiatorted mapping in the buncher region. Since we have calculated a bunch of $75^{\circ}$ entering the buncher and $13^{\circ}$ leaving it, we expect some distortion in the mapping es electrons in outer orbits "lag behind" those in inner orbils.

The final design values for the field strengths, drift length and phase shifes brtween elements were delermined by computer modeling of the injector outlined in Table 2.1. Equations (2.4) and (2.5) were numerically integrated to delermine electron orbits in the bunching system. The theoretical performance of the "Table 2.1" injector to summerized in the phase apace plots of Fig. 2.13 and 2.14 . The numerical resulto are in excellent agreement with the analytic results.

Figure 2.13(a) showb the beam emiltance al the end of the prebuncher drift spece. The energy eprend introduced by the prebuncher is $20 \%$ of the initial energy of the besm and thus the bunching is slightly asymmetric about the center particle (t.e., the particle which passed through the gap at the phase nill). The deceleraled electrons are further behind the center than the accelerated particles are ahead. From Fig. 2.11 we see that, if anything, we should enter the buncher slightly forward of the phase null, as the electron density is higheat at points $e$ and $f_{1}$ and we wish these electrons to fall between orbits $b_{*}$ and $b_{b}$. Henee the 


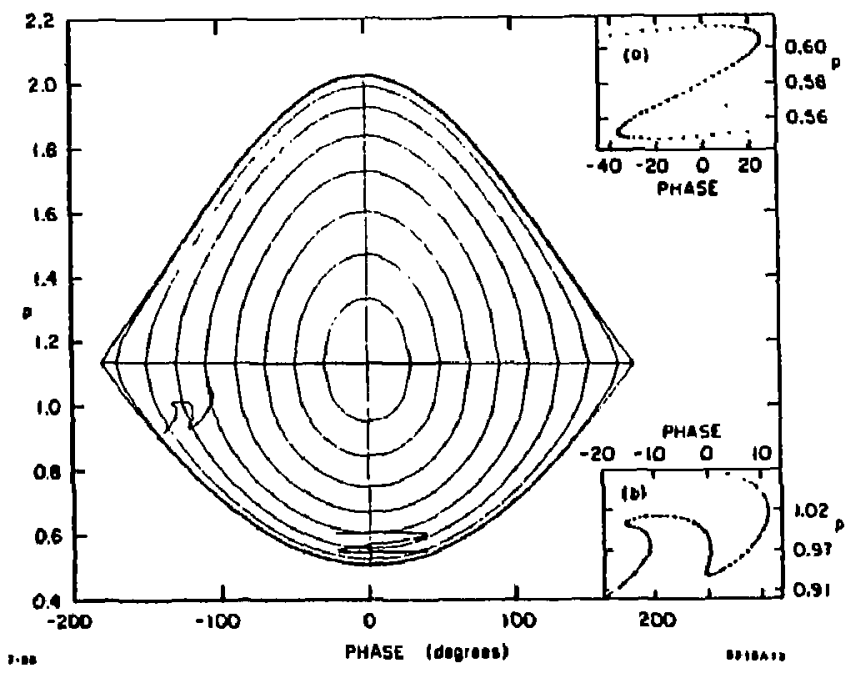

Fig. 2.13. Simulation of particle orbits through the $\beta_{w}=.75$ traveling-wave buncher in SLAC's low-current injector. theoretical performance is improved by introducing a phose shift of $15^{\circ}$ between the prebuncher and buncher (eee Fiz. 2.13).

Figure 2.13(b) ts a plot of the beam ernittence at the output of the buncher. The mapping from prebuncher output ta capture segion in put is reasonably undistorted. The ares in also conserved, as $\Delta p \Delta t=.43$ for both ellipses. Note that the beam enters the buncher w three atraight-line segrnents in a region of curved orbits and emerges as three curved aegments in a region of atraight orbita.

The beam anters the capture region with $28^{\circ}$ of phase extent and a momen. tum extent of .156. The numerical sesults predict that the injector described in Tuble 2.1 will auccessfully capture $67 \%$ of the de electrons from the gun into $4^{\circ}$ of RF phase (Fit. 2.11).

SLAC'a main injector has specifications very similar to those in Table 2.1, although the devign calln for slightly higher prebuncher and buncher valtages. Figure 2.15 shown two longitudinal beam profile mensurements at the end of the Injector three-metes-lons accelerator eection. In curve $A, 70 \%$ of the gun current is ceptured into $4^{\circ}$ of S-bund phese. Experience with the SLAC injector has shown that the discrete, constant-phase velocity element bunching technique described here indeed sobust. Good bunching has been achieved with gun voltuges ranging from 50 to $00 \mathrm{kV}$ by propes optimizing of other parameters." 


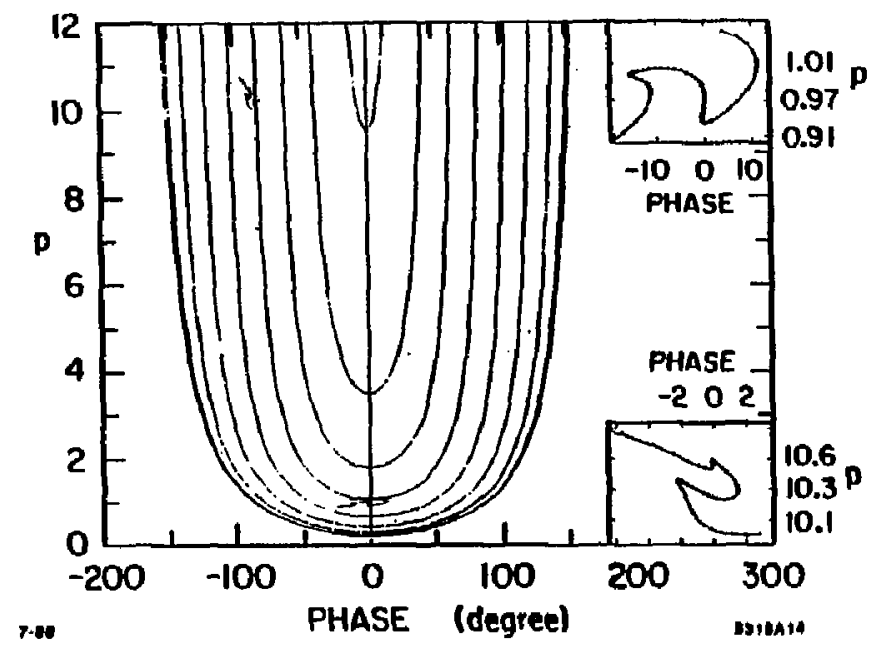

Fic. 2.14. Simulation of particte orbils through the $f_{m}=1$ capture region in SLAC's fow-current injector.

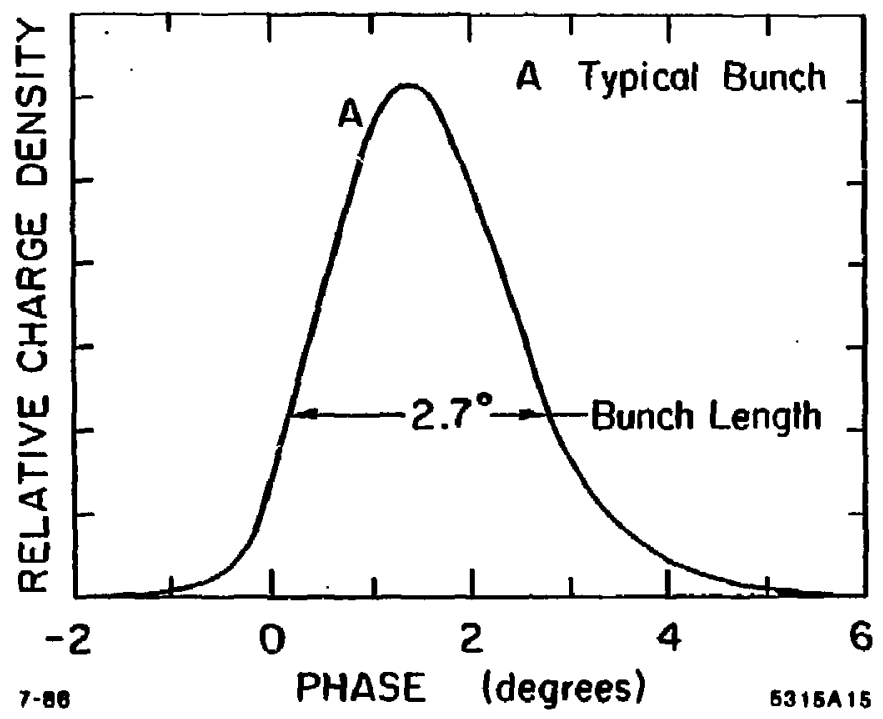

Fis. 2.18. Experimental charce diat ribution in maln injector (from Miller ${ }^{6}$ ). 
2.2 COLLIDER INJECTOR DESIGM

As discussed in the introductory chapter, the collider injector must capture 5 to $7.5 \times 10^{10}$ electront on a single RF crest. Averaged over one cycle of RF, this is an accelerated current of 23 to 34 emps, considerably higher than any $S$ band linear accelerator had operated before, and two orders of magnitude highes than the cursent shown in Fiz. 2.15. In addition, the $1.21 \mathrm{GeV}$ bunch entering the damping rine must have an energy spread no greater than $\pm 1 \%$. As we will discuss in srealer detail in Section 3.2, this can be eccomplished if the final bunch length is of the order of $20^{\circ}$ FWHM at S-band.

Bunching and capturing $5 \times 10^{10}$ electrons in $20^{\circ}$ of S-band phae presents two seriout complications to the design strategy used in SLAC'a main injector. Firat, SLAC's main injector was designed to bunch and capture a large fraction of the de gun current onto a serier of adjacent RF crests, forming pulses a short as three bunches or as long $5 \times 10^{3}$ bunches. For rewons we shall explain below, our goal is now different: rather then formins small bunches at $360^{\circ}$ intervals and capturing them onto edjacent RF crest, we must now bunch and capture electrons spread over approximately $3500^{\circ}$ of S-band onto one RF creat. The second complication to the previous design strategy is that at weh high charge densities, space charge forces are no longer negligible.

These compliations compromise a number of assumptions that were vaild in the low current, multi-bunch pulse case, in particular

- Due to the large phase extent of the initial electront, we ahall aee that the beam occupies a large aree of phase apuce in the buncher and we cannot expect mappings from one region to another to be distortion free.

- Due to spacu charge, particles no longer follow the phase apace orbits described in Section 2.1; oniy the center of muss of the bunch follows these orbits.

Although some very useful assumptions of the last section have les! validity here, we begin by considering the design of the CID injector as a perturbation on the desizn of the main injector. The mme design atrateay lo employed and outlined below:

1. Use * Eap-and-drift prebuncher to accomplish initial bunching.

2. Use $a \beta_{w}<1$ buncher as a quanter-weve transformer to match the prebuncher emittance to the capture region admittance.

3. Use a $\beta_{w}=1$, high a accelerator acction to eccomplisin final bunching and capture.

The CID injector was initially designed and constructed in a period of 18 months. The analyais presented here is the product of our original design atratesy combined with idess accumulated from working with the actual injector. This section is divided into three parts. In Section 2.2 .1 we discuss longitudinal betm dyramics in the low current, large sienal limit. This analyain was completed after CID wa constructed, and incorporates ideas developed from operational experience. In Seetion 2.2 .2 we present a Gedanken injector denign which incorporates the analysis of Section 2.2.1. This dexign is more compreheneive (and more euccessful, in theory) then our ectual CID design. For completeness, in Section 2.2.3 we present our original CID design.

It is inatruetive to describe the high current design as a two-step process. First, in Section 2.2.1 we examine the problem of bunching and cupturing a beam with an initially large phase extent in the absence of opace charge. Next, in Section 2.2.2 we "turn on" the space charge forces and adjust our design to accommodate them.

\subsubsection{Loneitudinal Dynamics in the Low Current, Large Signal Limit}

As stated earlier, the CID injector must bunch and capture electrons with an initial phase extent of $\sim 3500^{\circ}$ of S-bend. This is due to the fact that our state-of-the-art pulser electronics for thermionic cathodes could produce no more 
than 12 amps of peak current. At this current one would need a gun pulse of 1 no $\mathrm{FWHM}$ (or $\sim 1000^{\circ}$ at S-band) to produce $7.5 \times 10^{10}$ electrone. In practice we have found that the gun cannol produce such short pulses at 12 amps, but can yield a Gaussinn pulse of 6-8 amps, 2 no FWHM. To capture electrons out to $\pm 2 \sigma$ (or $95 \%$ of the charge in the gun pulae) we must capture electrons whose initial phase extent to $\sim 3500^{\circ}$ or 10 cyclea at S-band.

The gap-and-drift buncher must compress this rery long bunch by a factor of ten Juat to get ell the electrona into one 8 -band cycle. As we bunch it with a gapand-drift prebuncher, space churge forces eventusily oppose bunching, leading to large phase extent at the entrance of the buncher. Therefore we begin our design by optimizing the phase acceptance of the combined buncher/capture region acceptance.

There are five paramelers over which we have control to accomplish this optimization, specifically, the phase at which the bunch enters the buncher, the phase velocity of the buncher, $\beta_{w}$, the field atrength in the buncher, $\alpha_{2}$, the phese at which the bunch enters the capture reglon; and the fietd strength in the capture region, ay.

In the following pages, we calculate the required values of these parameters necessary to map a given emittance al the entrance to the buncher into $16^{\circ}$ of phase at the end of the capture region. A bunch of $16^{\circ}$ of phase extent eaptured in the RF crest yields an eneray opread of $1 \%$. The logical fow of determining optimum values for the five control parameter bomewhat abscured by the specific calculation. We therefore lint all relevant parametesa in Table 2.2 with a ahort explanation of their source. The quantitative detalls follow in Table 2.3 .

Examination of Table 2.2 ahowg that given $\Delta E / E$, po and the condition for optimum bunching in the buncher and captura refions (Eq. 2.12), sll other parameters are fixed or determined by our cholte of $\beta_{0}$. Therefore, $\rho_{0}$ is the firnt column of Table $\mathbf{2 . 3}$ and we shall discusa the buncher acceptuncen generated by variout choices of $\beta_{b}$.
Table 2.2. Functional Dependence of Injector Parameters.

\begin{tabular}{|c|c|}
\hline Parameler & How Determined \\
\hline$\Delta E / E$, Energy spread & Given \\
\hline $\begin{array}{l}\text { Do. Mean momentum of electrons } \\
\text { entering buncier }\end{array}$ & Given \\
\hline $2 \theta_{3}$, Phase acceptance of capture region & $\begin{array}{l}\text { Function of } \Delta E / E \\
\text { (Eq. 2.30b) }\end{array}$ \\
\hline $\begin{array}{l}\text { Optimum phase of bunch at entrance } \\
\text { to the bunchet }=0^{\circ}\end{array}$ & $\begin{array}{l}\text { Condition for optimum } \\
\text { bunehing (Eq. 2.12) }\end{array}$ \\
\hline $\begin{array}{l}\text { 12, Optimum phase of bunch it } \\
\text { exit of the buncher }=-90^{\circ}\end{array}$ & $\begin{array}{c}\text { Condition for optimum } \\
\text { bunching (Eq. 2.12) }\end{array}$ \\
\hline$p_{2}=p_{0}-p_{0}$ & Funetion of $p_{0}$ and $\theta_{w}$ \\
\hline a. Field strength in the buncher & $\begin{array}{l}\text { Function of } p_{0} \text { and } \beta_{w} \\
\text { (Eq. 2.29) }\end{array}$ \\
\hline $\begin{array}{l}\text { Optimump phase of bunch at entrance } \\
\text { to eaplure region }=0^{\circ}\end{array}$ & $\begin{array}{c}\text { Condition for optimum } \\
\text { bunching (Eq. 2.12) }\end{array}$ \\
\hline $\begin{array}{l}\text { Optimum phase of bunch at entrance } \\
\text { to capture region }=-90^{\circ}\end{array}$ & $\begin{array}{l}\text { Condition for optimum } \\
\text { bunching (Eq. 2.12) }\end{array}$ \\
\hline$\alpha_{3}$ Field atrength in capture region & Function of $\rho_{-}$(Eq. 2.30a) \\
\hline $\begin{array}{l}\text { 2ps. Momentum acceptance of caplure } \\
\text { region }\end{array}$ & $\begin{array}{c}\text { Function of } \Delta E / E \text { and } \alpha_{3} \\
\text { (Equ. 2.34= or b) }\end{array}$ \\
\hline $2 p_{1}$, Momenlum acceptance of buneher & $\begin{array}{l}\text { Function of } \mathrm{O}_{3} \mathrm{pg} / \mathrm{O}_{2} \\
\text { (Eq. 2.19) }\end{array}$ \\
\hline 20, Phase acceptance of buncher & $\begin{array}{l}\text { Function of } p_{3} \theta_{2} / p_{2} \\
\text { (Eq. 2.20) }\end{array}$ \\
\hline
\end{tabular}

We begin our quantitative discussion of the conclusions in the Table 2.2 by considering the combined buncher/capture region phase space shown in Fig. 2.16. The emittance of the beam as it leaves the gap-and-drift prebuncher is circumactibed by the ellipse $a, c, b$, and $d$. Having traversed a quarter of a cycle in 


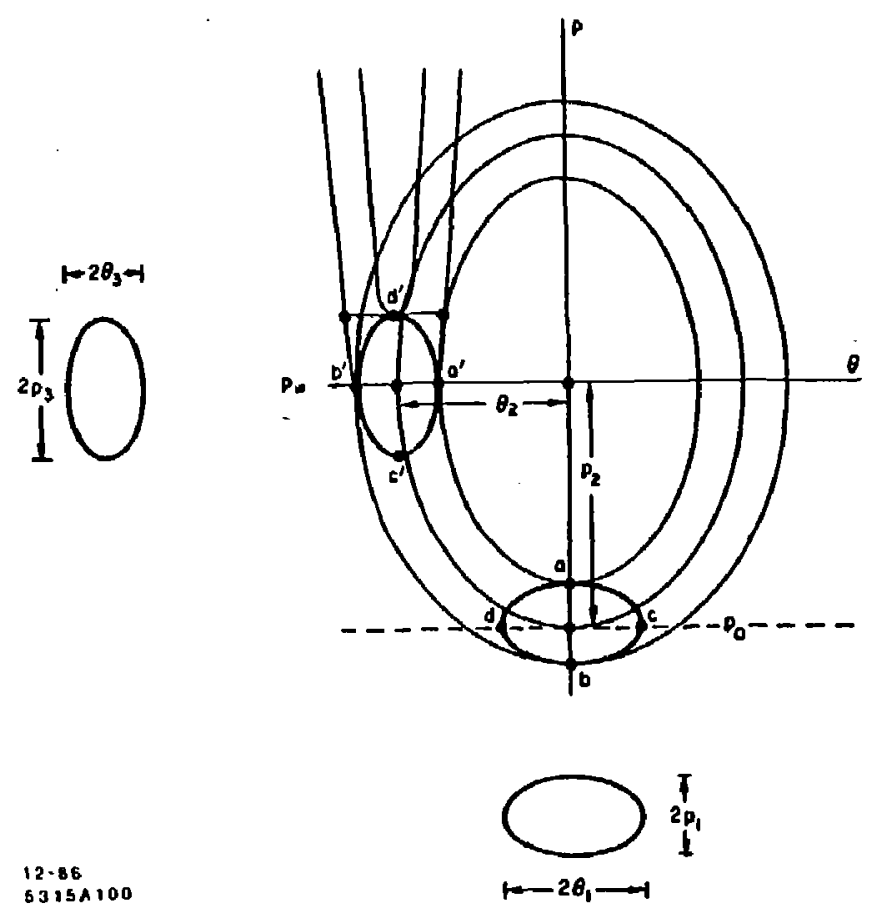

Fig. 2.16. Combined buncher region and capture region phere space. the buncher phase apace, the beam anithence is circumacrlbed by the new ellipre $a^{\prime}, c^{\prime}, b^{\prime}, d^{\prime}$. This ellipse must be contuined within the capture region acceptance which yields a $1 \%$ energy spectrum at the end of the accelerator mection.

The phase spread of the bunch at the output of the buncher is approximately $\bullet_{m}\left(a^{\prime}\right)-\bullet_{m}\left(b^{\prime}\right)=\Delta \bullet_{m}$. For electrona with the ame initial momentum, po (i.e., those on line segment c-d), $\mathrm{E}_{q} .(2.12)$ is also valid for $\hat{\beta}_{w}<1$ traveling wave structures, i.e.,

$$
\Delta \theta_{m}=\frac{\sin \Delta \theta}{\sin \theta_{m}}
$$

The apread in phase at the output of the buncher is minimized if the entrance angles are neat $0^{\circ}$ and the exit angles are neus $-\infty 0^{\circ}$. Ansume that the center of the bunch entere the buncher at $0^{\circ}$ of phase and with momentum po. We can quantify this optimization condition by chooting the field etrength and phase velocity of the buncher wo that the electron which enters the buncher at $\left(0, p_{0}\right)$ exits the buncher at $\left(-90^{\circ}, p_{w}\right)$. Equation $(2.10)$ yields

$$
\frac{\left(p_{0}^{d}+1\right)^{1 / 2}}{\beta_{\omega}}-p_{0}-\frac{1}{p_{\omega}}=\frac{\alpha_{1}}{2 \pi}
$$

where

$$
\begin{aligned}
& \text { po = normalized mamentum of the center electron after } \\
& \text { it has eraversed the prebuncher cap } \\
& P_{w}=\rho_{\omega} \gamma_{w} \text {, where } \beta_{v} \text { is the phase velocity of the buncher } \\
& a_{2}=\text { normalized electric field strength in the buncher. }
\end{aligned}
$$

Equation (2.12) also applies to the eapture region; optimum bunching is occomplished when the bunch has initial phesen near $0^{\circ}$ and aymptotic phases near $90^{\circ}$. We can also quentify this condition by requiring that the particle which leaves the buncher with phase equal to $90^{\circ}$ and momentum equal to Pu enters the capture region at $0^{\circ}$ of phase and achieves an asymptotic phase of $-00^{\circ}$. 
Equation (2.11) gives

$$
\left[p_{i}^{2}+1\right]^{1 / *}-p_{m}=\frac{\alpha_{s}}{2 \pi} .
$$

Nole that the feld strength in the capture region depends only on the phase velocity of the buncher.

We can now calculate the phase and momentum. acceptances of the capture region. To find the phase acceptanee, note that points $a^{\prime}$ and $b^{\prime}$ of Fig. 2.16 transform to an asymptotic phue of $-180^{\circ} \ldots$.. $_{\infty}^{\circ}$. From Equ. (2.11) and (2.30a) we heve

$$
\left.O_{1}=\arccos \mid 1-\cos \theta_{\infty}^{\infty}\right) \text {. }
$$

To find the momentum acceptence note that point 2 of Fig. 2.16 transforma to

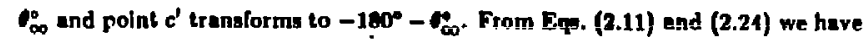

$$
y=\sqrt{p^{2}+i}-p=\frac{\alpha}{2 \pi}\left(\cos \theta_{0}-\cos \theta_{\infty}^{\circ}\right) \text {. }
$$

For point $d$, trensformed to $\varnothing_{m}^{\circ}$

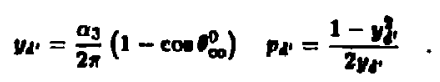

For point e', tranaformed to $-180^{\circ}-\infty$

$$
y_{c^{\prime}}=\frac{\alpha s}{2 \pi}\left(1+\cos \infty_{\infty}^{\infty}\right) \quad P_{c^{\prime}}=\frac{1-y_{c^{\prime}}^{2}}{2 y_{c^{\prime}}} .
$$

The momenturn arceptance of the capture region, $2 p_{3}$, is given by combining Eqs, (2.32u) and (2.32b)

$$
2 m_{3}=p_{d^{\prime}}-p_{c^{\prime}}=\frac{1-y_{d^{\prime}}^{2}}{2 y_{c^{\prime}}}-\frac{1-u_{c^{\prime}}^{2}}{2 y_{c^{\prime}}} .
$$

Alter some algebra we find

$$
2 p_{3}=p_{c^{\prime}}-p_{c^{\prime}}=\frac{1+\left(\alpha_{3} / 2 \pi\right)^{2} \sin ^{2} p_{\infty}^{0}}{\left(\alpha_{3} / 2 \pi\right)\left(\tan \theta_{\infty}^{2} \sin p_{\infty}^{2}\right.}
$$

We can simplify this expression for the case where the center of the bunch is asy mptotically approaching $-90^{\circ}$. Using the approximations

$$
\begin{gathered}
\sin \theta_{\infty}^{0} \approx-1 \\
\cos \theta_{\infty}^{0} \approx \theta_{\infty}^{0}+\frac{\pi}{2} \equiv \Delta \theta_{\infty}
\end{gathered}
$$

we find a simple relationship between the aymptotic bunch length and the momentum acceptance of the capture region:

$$
p_{3}=\left(\frac{2 \pi}{\alpha_{3}}+\frac{\alpha_{3}}{2 \pi}\right) \frac{\Delta l_{\infty}}{2} .
$$

From Eqs. (2.31) (see Fig, 2.17) we find that $p_{3}$ goes to infinity for $\alpha_{3}=0$ and $a=\infty$, and passes through a broad minimum near $\alpha=2 \pi$. To increase $p_{s}$, we should move away from $\alpha=2 \pi$ in either direction. $\alpha=2 \pi$ corresponds to a Held strength of $K=300 \mathrm{kV} / \mathrm{cm}$ or $30 \mathrm{MeV} / \mathrm{m}$. SLAC's $30 \mathrm{MW}$ klyotrone (available at the time CID was buile) can provide a maximum feld atrength of $17 \mathrm{MeV} /$ meter, or $a=3.5$, thus we have the ability to vary $a$ in the range from 0 to 3.5. The acceptance of the capture region phase apace is plotted in Fig. 2.18 for tix different values of $a$ from 2 to 4 . The phase acceptance remains constant (Eq. 2.30b), while the momentum eceptance increases for decreasing a. Of course, a a gete imull, the initial momentum for capture increases (see Fig. 2.9) and the diatance needed to capture increases.

From Eqs. (2.30) and (2.31) we nee that the momentum acceptance of the capture region depends on the phase velocity, $\beta_{*}$, of the buncher region. $A s \beta_{*}$ and $p_{w}$ increase, the momentum acceptance of the capture region increases.

We now examine how the buncher acceptence io affected by choice of phase velocity. To begin, let us assume that the transiormation of the phase apace ellipse of the beam in the buncher is selatively undistorted (we refer to this in Table 2.3 as the "linear approximation"). Consider again Eqs. (2.19) and.(2.20). 


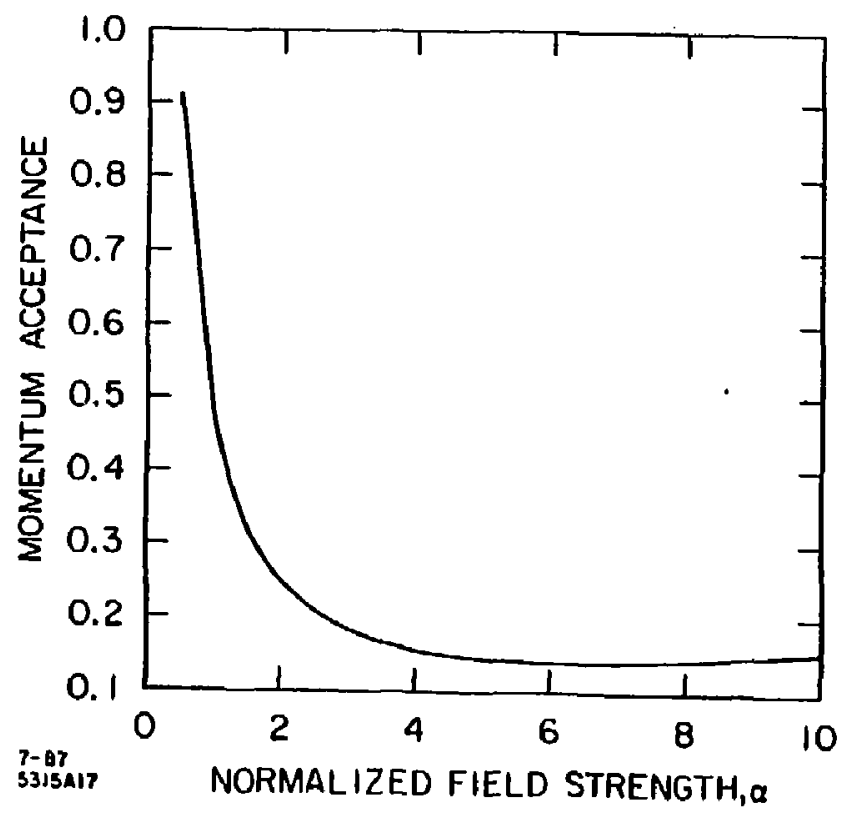

Fic. 2.17. Capture region momentum acceplance as a funetion of normalized field strength.

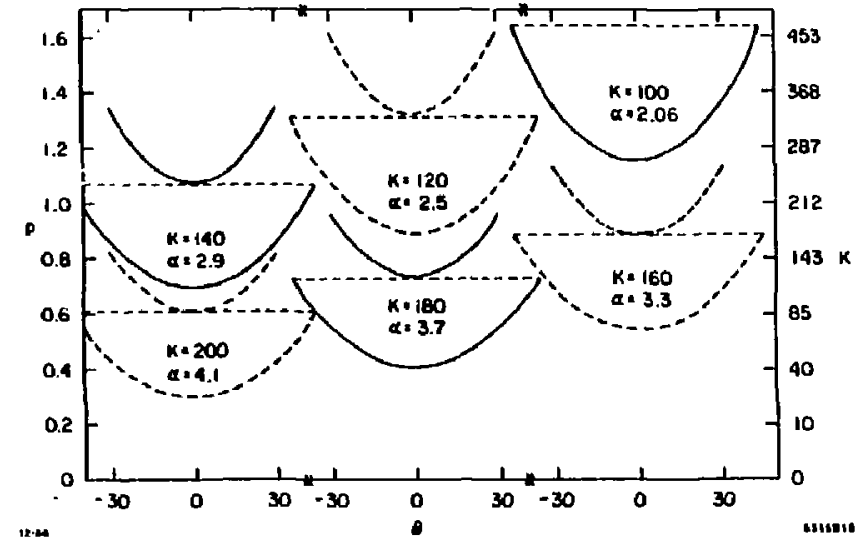

Fig. 2.18. Capture region admittance a a function of normalized seld utrength. $K=$ electric field atrength in $\mathrm{kV} / \mathrm{cm}$. 


$$
p_{1}=\frac{\theta_{3}}{\phi_{2}} p_{2} \quad(2.19) \quad O_{1}=\frac{p_{3}}{p_{2}} p_{2}
$$

In this cass $C_{3}$ is already determined by Eq. (2.30b). As mentioned entlier, maximum phase compression in the buncher is achieved if electrons enter the bunchar near the field nult and move to $-90^{\circ}$ in a quarter of the phase space cycle. Thun ${ }_{2}$ is also deter mined. From Eq. (2.20) we wee that phese acceplance is proportional to the ratio $p_{3} / p_{y}$. Using Eq. $(2,34 b)$ and recalling that $p_{y}=p_{w}-p_{0}$ we have

$$
\frac{p_{3}}{p_{j}}=\left(\frac{2 \pi}{a_{3}}+\frac{a_{3}}{2 \hbar}\right) \frac{\Delta t_{\infty}}{2\left(p_{\infty}-p_{0}\right)}
$$

Differentiating ivith respect to $p_{0}$ we hind

$$
\frac{d\left(p_{j} / p_{2}\right)}{d p_{0}}=-\left(\frac{2 \pi}{a_{3}}+\frac{a_{3}}{2 \pi}\right) \frac{\Delta \nu_{\infty}}{2\left(p_{0}-\omega_{0}\right)^{2}}
$$

Since $\Delta P_{\infty}$, as and $\left(p_{\infty}-p_{0}\right)^{2}$ are all pooltive quantitien,

$$
\frac{d\left(p_{0} / p_{1}\right)}{d p_{0}}=\frac{1}{\theta_{1}} \frac{d d_{1}}{d p_{0}}<0 \text {. }
$$

Thus as the phase velocity $\beta_{-}$of the buncher Inereasen, the phase acceptance decresses, while fby Eq. (2.19)] the momentum acceptance increases.

Using Eqs. (2.19), (2.20), (2.30b), and (2.35) we can calculate the phase and momentum acceptances for a range of phase velocities. The resullo appear in columns 5 and 6 of Tuble 2.3 .

As mentioned earlier, ahould the initial phase apace occupied by the beam be large, we casnot expect mappinge to be undistorted. For an accurate prediction or the efieet of buncher phase velocity on phase and momentum acceptance, we

\begin{tabular}{|c|c|c|c|c|c|c|c|c|c|c|c|}
\hline 1 & 2 & 3 & 4 & 5 & 6 & 7 & $\bullet$ & 9 & 10 & 11 & 12 \\
\hline$A_{0}$ & $p_{w}$ & $a_{3}$ & $a_{2}$ & $\begin{array}{c}\text { tinear } \\
\text { Appr. } \\
2 p_{1} \\
\end{array}$ & $\begin{array}{c}\text { Linear } \\
\text { Appr. } \\
\mathbf{1 0}_{1} \\
\end{array}$ & $\begin{array}{c}p_{1} p_{3} \theta_{3} \\
\left(1 p_{1} \theta_{1}, 1\right)\end{array}$ & $\begin{array}{c}\text { Integrated } \\
\text { Arten } \\
\text { Cop. Rez. }\end{array}$ & $20_{2}$ & $2 p_{1}$ & $\begin{array}{c}\text { Approx. }_{1} \\
\mathbf{A H}_{1 \mathbf{P}_{1}}\end{array}$ & $\begin{array}{c}\text { Integrated } \\
\text { Area } \\
\text { Buncher }\end{array}$ \\
\hline .7071 & 1.0 & 2.60 & .120 & 1777 & 141 & 25.0 & 24.2 & 180 & .13 & 23.1 & 27.3 \\
\hline .75 & 1.134 & 1.37 & .230 & .269 & 100 & 20.8 & 20.5 & 150 & .21 & 31.5 & 29.9 \\
\hline .7802 & 1.2 & 2.26 & .260 & .s14 & 18 & 27.0 & 26.9 & 130 & .25 & 32.3 & 32.5 \\
\hline |0137 & 1.4 & 2.01 & 4860 & .451 & 46 & 31.7 & 31.8 & 120 & .32 & 38.4 & 38.1 \\
\hline 8480 & 1.6 & 1.80 & .639 & .588 & 19 & 33.4 & 31.9 & 100 & $-40 \mid$ & 40.0 & 40.3 \\
\hline .0742 & 1.8 & 1.63 & 800 & .725 & 10 & 36.5 & 35.3 & $\infty 0$ & .48 & $\$ 3.2$ & 11.0 \\
\hline
\end{tabular}
muat numerically integrate Eqs. (2.4) and (2.5) for key phase apace trajectorles.
Table 2.3. Buncher admittance as a function of phase velocity $\rho_{\mathbf{w}}$. $\Delta E / E=.01, p_{0}=.7410, \theta_{3}=30.8^{\circ}$, and $\theta_{2}=-90^{\circ}$

Specifically, we wish to know the phase space occupied by the perimeter of the capture region admittance one-quarter cycle earlier in phase space (i.e., at the entrence to the buncher). This showa un the perimeter of the buncher admittance. As a practical matter, it he eimpler to have particles move forward in time through the computer code which numerically intezrates Eqs. (2.4) and (2.5). This is equivalent to clockwise motion around the phare opace orbits of Fig. 2.4. Because these orbits are aymmetrical about the $=0$ axis, we can use a "mirror image" of the capture region perimeter as input to the computer code. A quarter of a cycle later, this input has been transformed to the usable phase space at the entrance to the buncher.

Buncher admittance as a function of buncher phase velocity is illustrated in Figs. 2.10(a-f). The higher enclosed region of each plot represents the acceptance of the eapture region for electrons with mean momentum Pw (i.e., the mean momentum of the bunch after one quarter cycle in buncher phase apace). Note that for greater clarity the boundiry of the capture region phase space is truncated at $p_{t}$ of Fig. 2.8. The lower region represents the corresponding admittance of the buncher. As predicted in columns 5 and 6 of Table 2.3 , as $p_{\text {s }}$ increases the total admittance of the buncher grows (i.e., $\sigma_{1} p_{1}$ ) but the phase acceptance shrinks. 

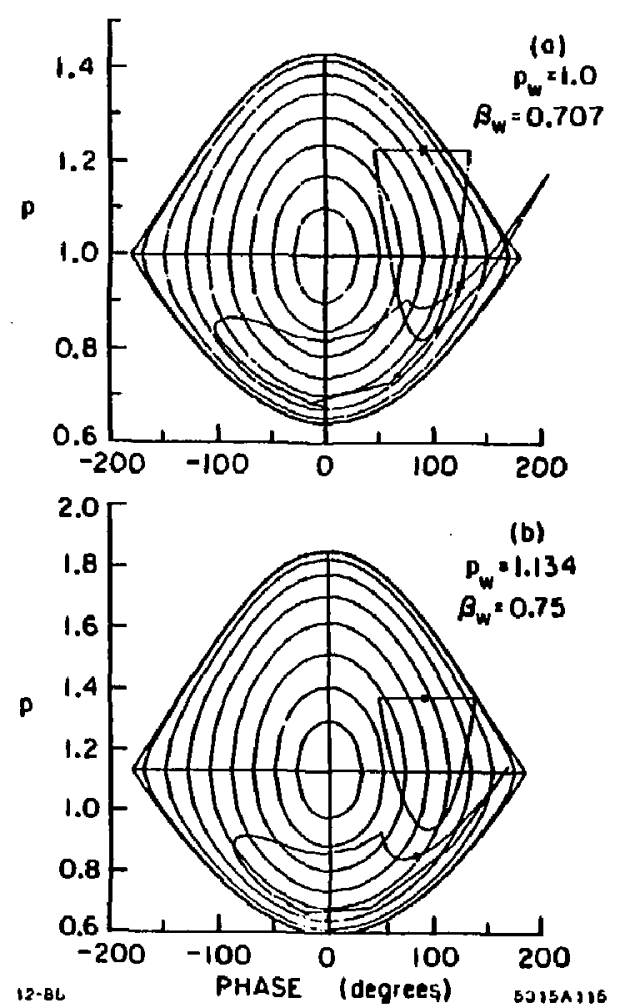

Fiz. 2.19. Buncher admitlance as a function of buncher phase velority. The higher enclosed region of each plot is the acceptance of the capture region for $\Delta E / E=.01$. The lower enclosed region is the corresponding buncher admittance for $p_{0}=.741$, and a) $\left.\left.\left.p_{w}=1.0, b\right) p_{w}=1.134, c\right) p_{w}=1.2, d\right)$ $p_{w}=1.4$, e) $p_{w}=1.6$, and $\left.f\right) p_{w}=1.8$
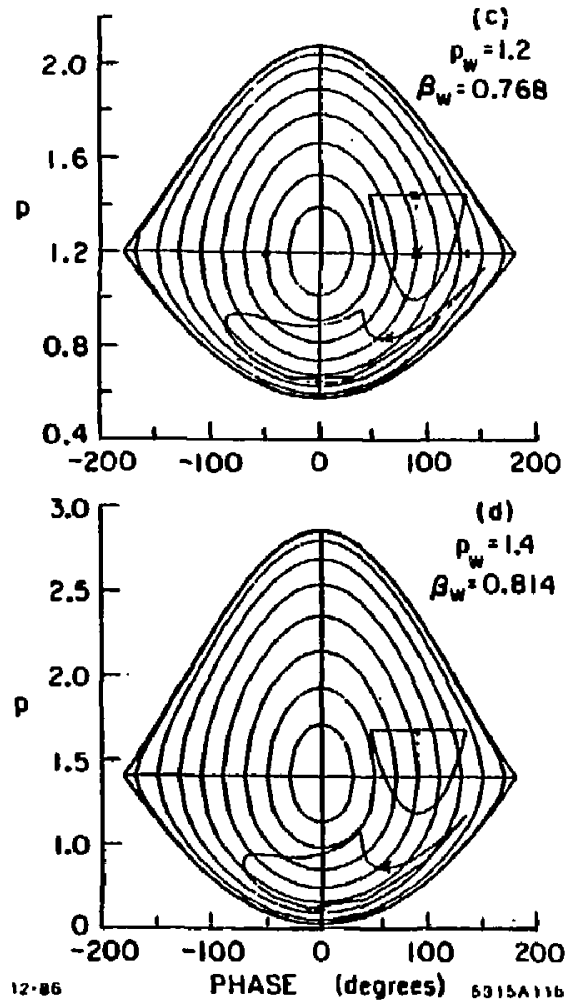

Fig. $2.19(\mathrm{c})$ and (d) 

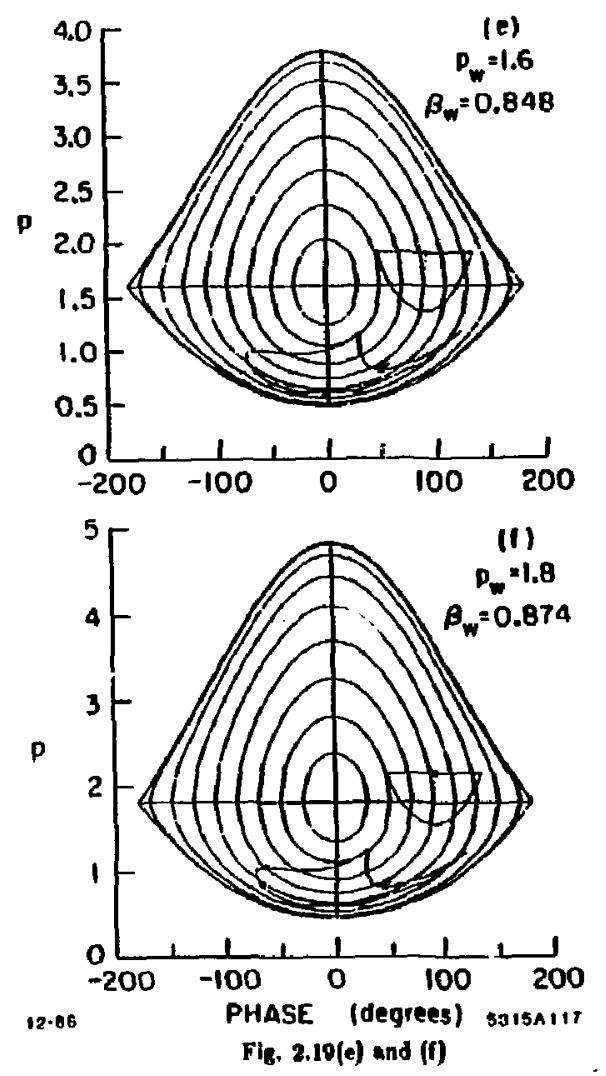

Columns 9 and 10 of Table 2.3 are the approximate buncher phase and momentum acceptances predieted by Fig. 2.19. Note that as the phase space is distorted during its ore-quarter wavelength transformation, the phase acteptances ase larger than predicted by the linear theory and the momentum acceptances are amaller. Columns 8 and 12 are the integrated arean of the capture region admiltance and the buncher admittance of Fig. 19, respectively. Note that the buncher admittunce has a ulightly larger area than the capture region admittnnce for given phase velocity. However, the ahape of the acceplance region may be too dislorted to take adrantage of this increase.

In the CID injector we can anticipate that phase cornpression by a gap-anddrift buncher will be limited by opposine apece charge forces. Thus we should choowe a phese velocity which allows generoun phase acceptance, probably in the sange of $\beta_{-}=.70$ to $\beta_{\infty}=.80$. At the time SLAC'r main injector was built, two extsa buncher/cupture region sectiona were manu(actured. These conaist of $210.5 \mathrm{~cm}$ long $B_{t}=.75$ buncher and a 3 meter velocity-of-light capture region. From Fig. 2.19n-c we wee that this wection fallo within the eppropriate range of p.

Given a buncher admittance Irom the phase upace plots of Fig. 2.19, we must now optimize the parametera of the gap-and-drift buncher to achieve a beam emittance mabched to the buncher admittance. Assume that the gun produces a roughly Guussian pulse with initial velocity $p_{0}$ (see Fig. 2.20). The pulse pasaes through a whort gap at zo; the center of the pulse crosses $2_{0}$ at time $f=0$. The pulae then drifts for a distance $L=z_{j}$ - so; the center partlcle reaches $z$ at time

$$
T=\frac{z_{j}-\varepsilon_{0}}{c \beta_{0}}
$$

where $\beta_{\text {a }}$ is the normalized velocity of the center particle after it has traversed the gap. From Eq. (2.3) we have for each particle 

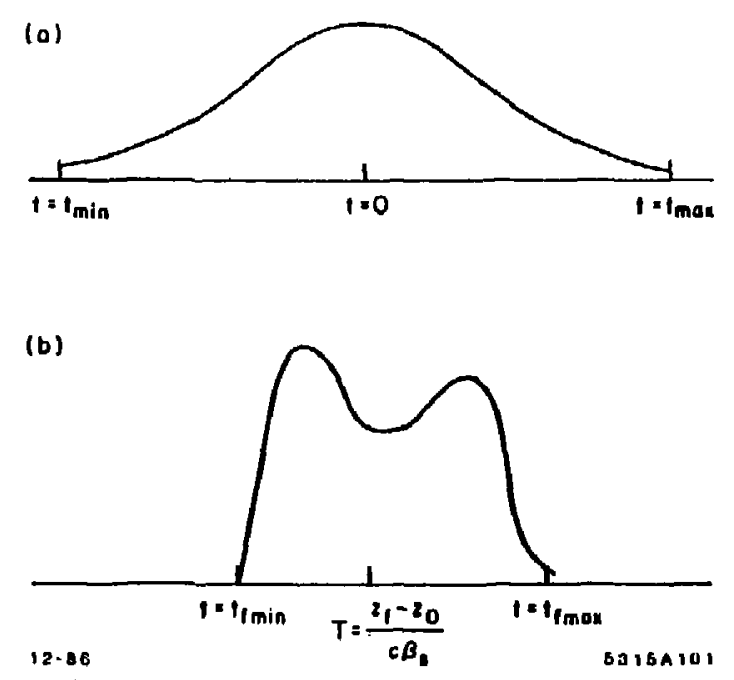

Fis. 2.20. (a) Charge density versus time for a Gaussianshaped gun pulue. (b) Charge density versun time after rinucoidzl sap-end.drift prebuncher with drift length $2 f-x_{0}$.

$$
t_{f}-t=\frac{L}{c}\left(\frac{1}{\beta}-\frac{1}{\beta_{1}}\right)
$$

where

$t=$ time at which the particle crosess $\varepsilon_{0}$

- $y_{f}=$ time at whieh the particle crosses af measured with reapect to $T$.

Perfect bunching is achieved if $t_{I}=0$ for each particle. To achieve perfect bunehing, we whould choose

$$
\theta(t)=\left[\frac{1}{\beta_{0}}-\frac{c t}{L}\right]^{-1}
$$

If we choose $\beta_{w}$ in the buncher, column 10 of Table 2.3 dictates the minimum and maximum acceptable moments, Pmas and $p_{\operatorname{mix}}$, with corresponding velocitie $\beta_{\text {max }}$ and $\beta_{\text {min }}$. For good bunching, the particle which enters the gap at the latest time ( $t_{\text {mas }}$ of Fig. 2.20n) should leave the gap with the greatest velocity $\beta_{\text {mes. }}$. Likewise the firt particle through the gap $\left(t_{\text {min }}=-t_{\text {max }}\right)$ should have final velocity $A_{\text {min. }}$. Subatituting Into Eq. 2.38 we heve

$$
\theta_{\text {max }}=\left[\frac{1}{\rho_{\alpha}}-\frac{c t_{\text {max }}}{L}\right]^{-1} \quad f_{\text {min }}=\left[\frac{1}{\beta_{\alpha}}-\frac{c t_{\text {max }}}{L}\right]^{-1} .
$$

We can now colve for $D_{0}$ and $L$

$$
\begin{aligned}
& \beta_{2}=\frac{2}{1 / \beta_{\min }+1 / \beta_{\max }} \\
& L=\frac{c l_{\text {mal }}}{1 / \beta_{0}-1 / \beta_{\text {max }}} .
\end{aligned}
$$

For $\beta_{\omega}=.75$ in the buncher, $\beta_{\operatorname{mas}}=.656$ and $\beta_{\min }=.551$. Fram Eqs. (2.40) and (2.41), we find $\beta_{a}=.5989$ and $L=174 \mathrm{~cm}$. For $1 \mathrm{na}$ FHM Gaurian 
eun pulse, the \pm 20 point fall $\$ 1 \pm .85 \mathrm{~m}$. The optimum $\beta$ versus $t$ curve firom Eq. 2.38)| for a 1 hs gun pulse is graphed in Fig. 2.21. Note that the desired $\beta(t)$ grows alightly faster than linearly, because $1 / \beta$ varies linearly with $t$. The normalized energy, $n(t)$, required to achieve this $\rho(t)$ io

$$
r_{1}(t)=\left[1-\beta(t)^{2}\right]^{-1 / 2}=\left[1-\left(\frac{1}{\beta_{a}}-\frac{c t}{L}\right)^{-2}\right]^{-1 / 2}
$$

$\gamma_{1}(t)$ is graphed in Fig. 2.22. We see that over ouch a large sange $\gamma_{1}(t)$ is fat from linear. Thus the bet bunching bo not accompliahed simply by choosing a low snough gap frequency oo that the entire gun pule fall on the linear retion of the sine wava. Rather, we whould explolt the eurnature of the sine function by ahliting the phure of the pulce with respect to the null of the sine wave to optimize bunching.

Figure 2.23 suggests that the aine funetion is moal aimilns to the gi $(t)$ function If the center of the pulse in ahifted to the left of the null and the frequency is choaen such that the pulse aubtenda approximately of of phase. $t_{\text {max }}$ then falls in the linear region of the acceletating aine meve and $t_{\text {min }}$ falle junt after the decelerating creat, that is

$$
-45^{\circ}<w t_{1}<-18^{\circ}
$$

$$
0^{\circ}<\omega\left(t_{0}+t_{\text {mex }}\right)<30^{\circ} \text { and }-90^{\circ}<\omega\left(t_{1}+t_{\min }\right)<-60^{\circ}
$$

where

$\omega=$ radial frequency of the accelerating field in the gap

$w l$, = phase shift of the renter particle with respect to the null of the accelerating feld.

The actual energy $\gamma(t)$ of a particle after traveraing the gap is glven ty Eq. (2.1) (note that we now write $\gamma$ as a function of $t$ rather than 0 ):

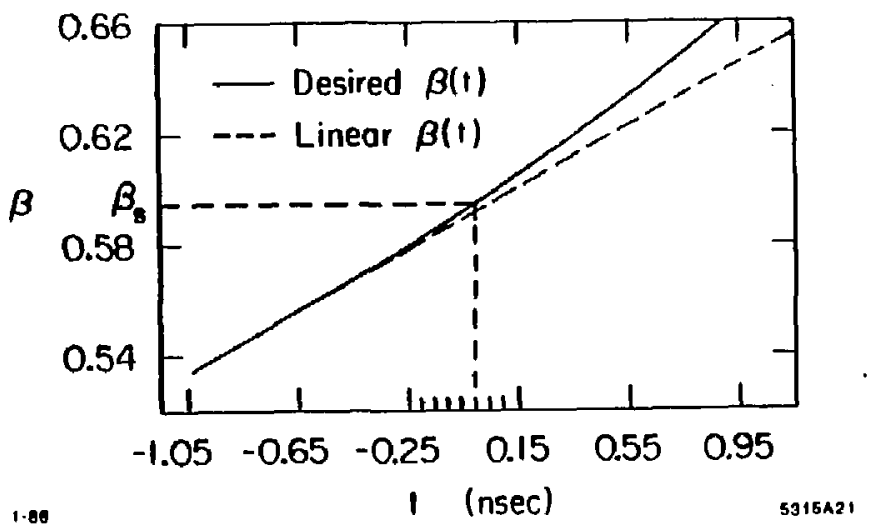

Fis. 2.21. Normalized relocity as a function of time needed to achieve peifect bunching of a Gauscian gun pulae with a $\sigma$ of $0.5 \mathrm{~ns}$. 


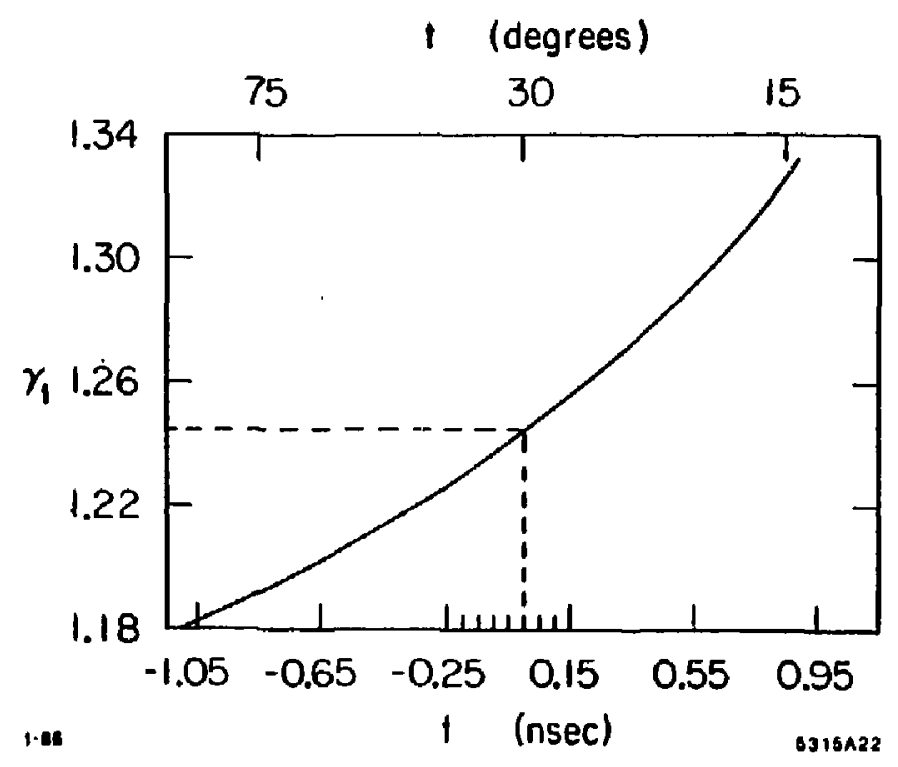

Fig. 2.22. Normalized energy as a function of time needed to achieve perfect bunching of anussien gun pulae with $\triangle \sigma$ of $0.5 \mathrm{~m}$.

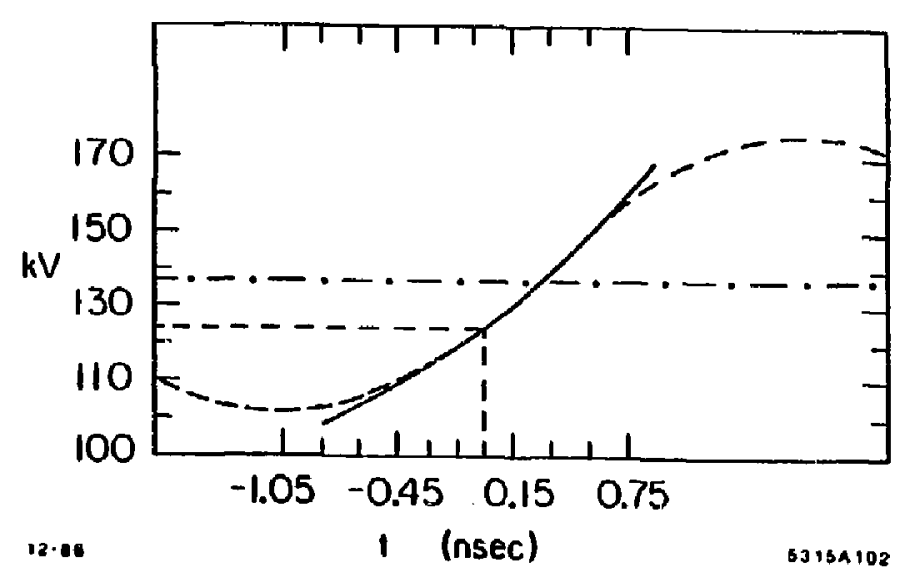

Fig. 2.23. T versus $t$ curve of Fig. 2.22 superimposed on sine wave. 


$$
\begin{aligned}
\gamma_{3}(t) & =\gamma_{0}+\alpha \xi_{10} \sin \omega\left(t_{0}+t\right) \\
& =\gamma_{0}+\varepsilon \sin \omega\left(t_{0}+t\right)
\end{aligned}
$$

where $\mathcal{E}=a \xi_{, y}$, and the slope is

$$
\gamma_{2}^{\prime}(l)=\omega C \cos \omega\left(t_{0}-l\right)
$$

We choose the phase shift $w \mathrm{t}$, by requiring that the ratio of the slopes at the extremes of the pulse be equal for both $\tau$ funclionn; that is, we choose wl, by requiring

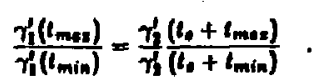

The slope of $\gamma_{2}(t)$ In the linear region $\left(-30^{\circ}<\omega t<30^{\circ}\right)$ in approximately wakgop. The rytio of this alope at $t_{\text {mes }}$ to the slope at $t_{\text {min }}$ is thus

$$
\frac{\gamma_{p}^{f}\left(t_{0}+t_{\text {max }}\right)}{\gamma_{2}^{\prime}\left(t_{0}+t_{\text {min }}\right)}=\frac{\omega \alpha \varepsilon_{\text {gap }}}{\omega \alpha t_{\text {pop }} \cos \omega\left(t_{0}+t_{\text {min }}\right)}=\frac{1}{\cos \omega\left(t_{0}+t_{\text {min }}\right)} .
$$

The slope of $\gamma_{1}(t)$ is given by

$$
\gamma^{\prime}(t)=\frac{c}{L}\left(\frac{1}{\rho_{c}}-\frac{c t}{L}\right)^{-3}\left[1-\left(\frac{1}{\rho_{e}}-\frac{c t}{L}\right)^{-3}\right]^{-3 / 2} .
$$

For a gum pulae of 1 ns FWHM, the ratlo of $\gamma_{1}^{\prime}(t)$ for $t_{\text {mas }}=+2 \sigma=.85 \mathrm{~ns}$ and $t_{\text {min }}=-2 \sigma=.85 \mathrm{~ns}$ is

$$
\frac{\gamma_{1}^{\prime}(.05 \mathrm{ng})}{\gamma_{1}^{\prime}(-.05 \mathrm{ng})}=2.29
$$

Equating Eqs. (2.46) and (2.48), wo have

$$
\omega\left(t_{0}+t_{\min }\right)=-\arccos \frac{1}{2.29}=-64.1^{\circ}
$$

Thus the earliest parl of the pulae ahould reach the gap when the phase is $\approx-65^{\circ}$, which sugses ts a phase shift of $-20^{\circ}$ with respect to its original centered position.

As mentioned earlier, we thould ehoose the frequency of the aine wave such that the gun pulse subtends approximately $80^{\circ}$ of piknse, f.e.,

$$
f=\frac{1}{40}\left(\frac{90}{360}\right)
$$

where $95 \%$ of the pulse charge is contained in \pm 20 . For a 1 no FWHM gun pulse, $4 a=1.7 \mathrm{~ns}$ and Eq. (2.49) yields $f=146.2 \mathrm{MHz}$. The nearest aubharmonic of the accelerator frequency (with a reasonable number of harmonics which are aloo gubharmonics of SLAC'e $2856 \mathrm{MH}$ ) is the $20 \mathrm{~h}$ subharmonic $f=142.8 \mathrm{MHz}$.

We now find $a_{1}$, the strength of the gap accelerating field, such that $\mathrm{rz}_{2}(t)$ is a good fit to $7(t)$. In particular, we wish the fit to be as close as possible in the region between $\pm \sigma$, where the initial charge density is highest. We choose the peak voltage of the electric field $E$ ouch that

$$
\tau(\sigma)-\tau_{1}(-\sigma)=\gamma_{2}(\sigma)-\gamma_{2}(-\sigma)
$$

or

$$
K E_{1}(\sigma)-K E_{1}(-\sigma)=K E_{2}(\sigma)-K E_{2}(-\sigma)
$$

where

$$
\boldsymbol{K} E_{\mathbf{l}}=\text { kinelic energy of a particle required for perfect bunching }
$$

$K E_{2}=$ kinetic enerky of a particle produced by a sine wave.

Thus

$$
E=\frac{K E_{1}(\sigma)-K E_{1}(-\sigma)}{\sin \left(\omega \sigma+\omega t_{0}\right)-\operatorname{\theta in}\left(-\omega \sigma+\omega t_{1}\right)}
$$


for $w t_{0}=-20^{\circ}$ and $a=125 \mathrm{~ns}$

$$
\begin{aligned}
E & =\frac{31.6}{\sin (21.8-20)-\sin (-21.8-20]} \\
& =15.2 \mathrm{kV}
\end{aligned}
$$

Initially, we estimated the phase shift by requiring that the ratio of the alopes at the extremes of the pulse be equal for $\eta 1$ and $\gamma$. Since a zood malch between $7_{1}$. and $\gamma_{2}$ is most important at the center of the pulse, we correct $t_{0}$ and $E$ to sutisfy Egs. (2.10) and (2.60). From Eq. $(2.40)$ we find $\beta_{1}=.5980$ which corresponds to $K E_{1}\left(t_{s}\right)=127.1$. Thus we want

$$
K E_{2}\left(t_{0}\right)=K E_{0}+E \sin t_{0}=150+45.2 \operatorname{tin}\left(\omega t_{0}\right)-127 \mathrm{kV}
$$

where

$$
K E_{0}=\text { initial voltage of the cun pulse } \approx 150 \mathrm{keV} .
$$

Solving for $\omega t_{0}=t_{\text {, }}$

$$
0 .=\arcsin \left[\frac{22.0}{45.2}\right]=30.5^{*} \text {. }
$$

Iterating between Egs. (2.10) and (2.50), we Ind suitable values of $E$ and $t$, to utisly both conditiona.

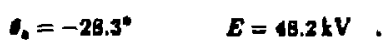

The kinetic energy desired for perfect bunching, $K E_{3}(t)$, and the kinetic energy produced by the electric field $K E_{2}(t)$, are shown in Eis. 2.24. We now have a complete system design which bunches a $1 \mathrm{~ns}$ low current gun pulse for capture into a $1 \%$ energy spectrum in the accelerator. This design is summarized in Table 2.4.

\section{1 (degrees)}

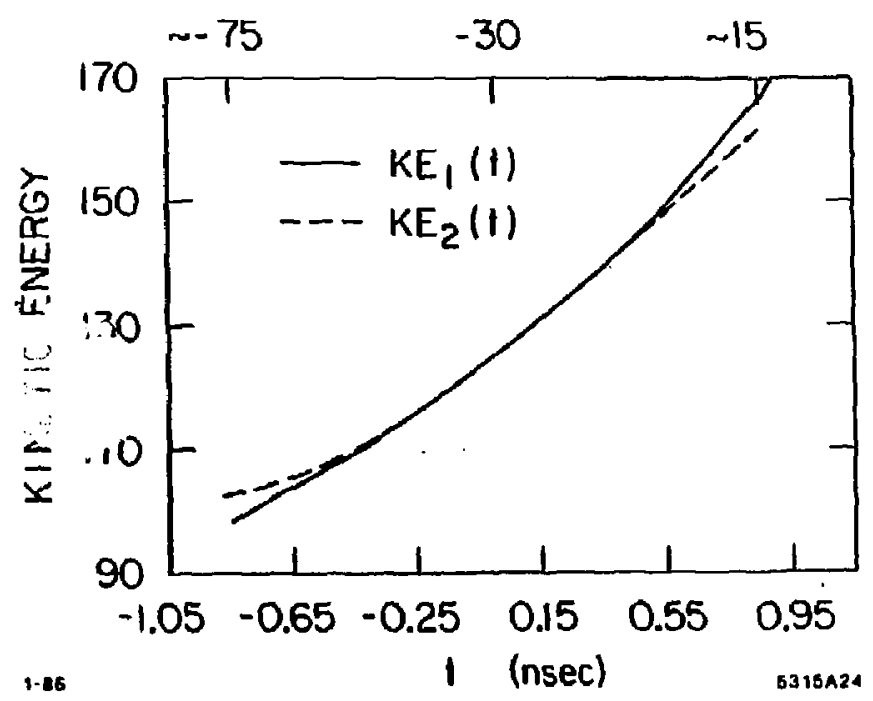

Fis. 2.24. Kinetic enercy, $K E_{1}(l)$, versus time needed to achieve pesfect bunehing compared to erercy, $K E_{2}(t)$, versus time achieved by 20 th subharmonic aine wave. 
Table 2.4. Injector specifications in the low current, large signal

limit. $\Delta d$ and $\Delta p$ are given at end of element.

\begin{tabular}{|c|c|c|c|c|c|c|}
\hline Element & $\mathrm{kV} / \mathrm{cm}$ & Length $(\mathrm{cm})$ & $\beta_{-}$ & $\Delta \varphi( \pm 20)$ & $\Delta p$ & $\Delta E / E$ \\
\hline Gun & - & - & .63 & $1700^{\circ}$ & 0 & \\
\hline $\begin{array}{c}20^{\text {th }} \text { Subhurmonic } \\
\text { prebuncher }\end{array}$ & 13 & $\begin{array}{c}3.8 \mathrm{gap} \\
176 \mathrm{drift}\end{array}$ & - & $45^{\circ}$ & .10 & \\
\hline Buncher & 11 & 10.5 & .75 & $60^{\circ}$ & .10 &. \\
\hline
\end{tabular}

Equations (2.4a) and (2.4b) were numerically integrated to determine the electron phese space orbits in the bunching ayatem. The theoretical performance of the "Trable 2.4" injector is summajized in the phere apace plots of Fig. 2.25.

F/gure $\mathbf{3 . 3 5}$ shows the phase space at the end of the prebuncher drift apace. The original gun pulse, some 1700 8-band degres long, has been compressed Into $\sim 40^{\circ}$ of phese. This bunehing to good enough that, in the absence of apace charge, we could omit the $\beta_{\boldsymbol{\omega}}<1$ travelint-mave atructure and atill capture atmost all of the charge in the gun pula into a $1 \%$ apectrum. After a quarter-wave transformation, we plot the beam emittance at the output of the buncher. The tranoformation in the buncher is reasonably linear a the ahape of the beam In phase apace is well preserved. Note that the phase apread at the oulput of the buncher is larger than the phwe spread at the input, although the oulgoing emiltance is still within the capture region acceptance. The final buncher phase spread is dominated by the large momentum apread at the entrance to the buncher. Clearly we have not optimited the lone nun pulse, low current dewign, but that is not our intent. The "Table 2.4" injector to intended only as a jumping-oll point for the high curtent dedzn.

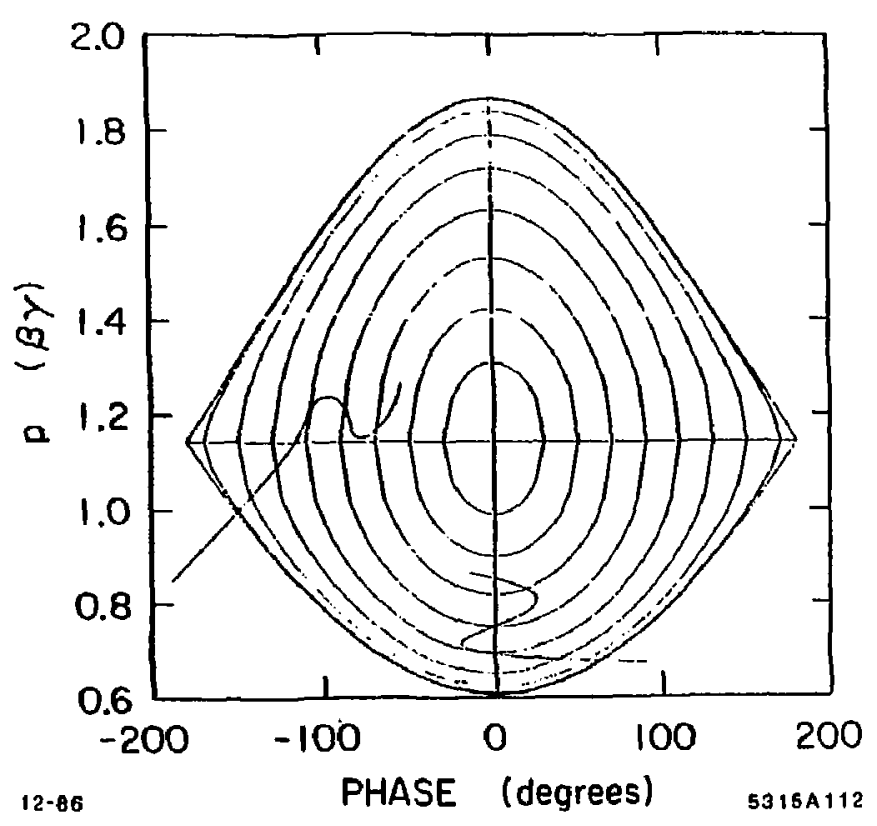

Fig. 2.25. Beam emittance at the entrance to and exit of the $\beta_{0}=.75$ buncher for the "Table 2.4 " design. 


\subsection{2 "Gedanken" High-Current, Large Signal Injector Design}

Baving completed a low-current design, we now consider the effects of apace charge on the bunching process. In the crudest approximation, we can think of epace charge as adding a spring-like quality to the beam pulae. For example let us conaider the eap-and-drift prebuncher. The bunch crosses the gap where the oinusoidal electric field Imparts a momentum kick to the electrons. In the drift space, the electrons begin to converge on the center particle. The space cherge forces grow greates as the bunch compsesses, impeding further bunching. Eventually, the initial momentum kick imparted to the beam at the ap is offet, then overcome by the space charge forces and the beam begins to debunch.

Rather than attempting to develop a timple anulytic model of bunching in the presence of apace charce forcen, we have used a coraputer simulation to understand the longitudinal dynamice. For the sake of contisuity, the details of the computer model ase described in the next aection. At this point, a brief qualitative description of the model will suffice. We model the benm as a finite number of infinitely thin disk and ringe of charge in an infinitely long conductlne cylindet (ue Fig. 2.26). The ansuli are free to move longitudinally, but their radif and cherge densities are fixed throughout a given bunching alement. The space charge forces between annuli are found by oolving for the average atatic force between annuli surrounded by the grounded conducting cylinder. The change in tho energy of each ennulus due to all other ennuli is computed. Equetion (2.1) becomes

$$
\frac{d \gamma}{d \xi}=-\alpha \sin +\text { energy change due to presence of other annuli. }
$$

The ongitudinal dynamics of the electron pulse are calculated by numerical integration of Eqs. (2.55) and (2.5).

The gap-end-drifl prebuncher of the "Table 2.4" injector is modeled uring 31 diaks ('annuli' of inner radius 0 ) of radius $.93 \mathrm{~cm}$ and 31 annuli of inner

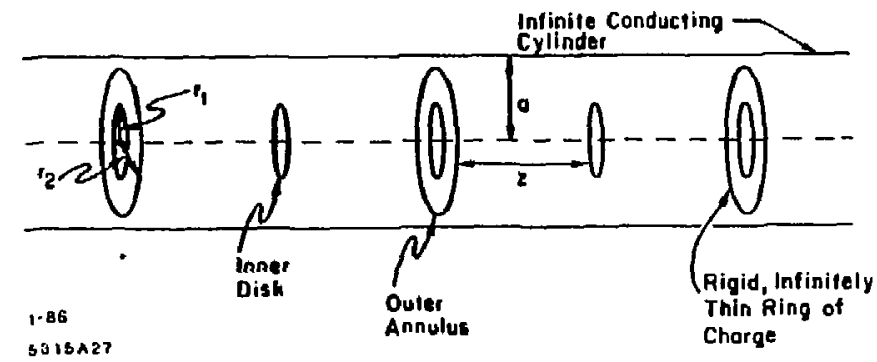

Fig. 2.26. Schematic diagram of model used to calculate langitudinal beam dynamics in the presence of space charce forces. 
radius $.93 \mathrm{~cm}$ and outer radius $1.75 \mathrm{~cm}$. The annuli are initially apaced evenly over the length of the gun pulse; the charge on each annulus is weighted to reflect the Gaussian distribution of the gun pulse. The phese and momentum of each annulus are calculated as functions of the 2 position in the gap-and-drift prebuncher.

Figure $2.27(\mathrm{a})$ is a plot of phase (with respect to the center of the pulae) veraus $x$ position of every third of the 31 inner diske traveling though the gap and drift prebuncher. The gap $k$ at the far left, $a t z=0$ to $z=3.8 \mathrm{~cm}$. The Inittal $1700^{\circ}$ bunch compressee lo approximately $40^{\circ}$ of 3-band phase at the waint it $:=176 \mathrm{~cm}$. Figure $2.27(\mathrm{~b}-\mathrm{g})$ reprewent the seme inillal burch traveraing the anme atructurs in the presence of Inereasins opece charce forces. The plot represent peak gun currents of 3,6,9, and 12 impe, reapectively. (A gun current of 12 amps is required to produce $7.5 \times 10^{10}$ electrons in $11 \mathrm{ne}$ FWHM pulse.) As the gun current increases, the phase apread at the maint increases but the waist is located at the same 2 position.

The correaponding versus $z$ plots for the outer annuli are plotted in Figs. 2.28(a-e). Note that the space charge forces are contiderably weaker for the ouler annuli. The reasons for this are discussed in the next section.

Figures 2.29(-e) are plote of the longitudinal phave epace at the waids ( $z=$ $176 \mathrm{~cm})$ of Flga. $2.27(\mathrm{a}-\mathrm{e})$ and $2.28(\mathrm{a}-\mathrm{e})$. In the abence of apace charge, the diaks move past each other in a smooth manner |i.e., Figo. 2.27-2.29(a)|. In the presence of space charge, the diske are cometimes "acattered" by other disks causing "hernias" in the phase space diagrams. Thts may be an artilact of the model, and we shall address this point again in the next section. Notice that in the presence of apprecisble currenl ( $\geq 3$ amps), the momentum spread of the Inner dinks is quile narrow. $A$ s the current increnses the minimum phase apread increases. For a gun current of 12 ampe, the phase upread bo $\sim 400^{\circ}$ of S-band (see Fig. 2.30e), too large to be captured into the buncher phase acceptnnce.

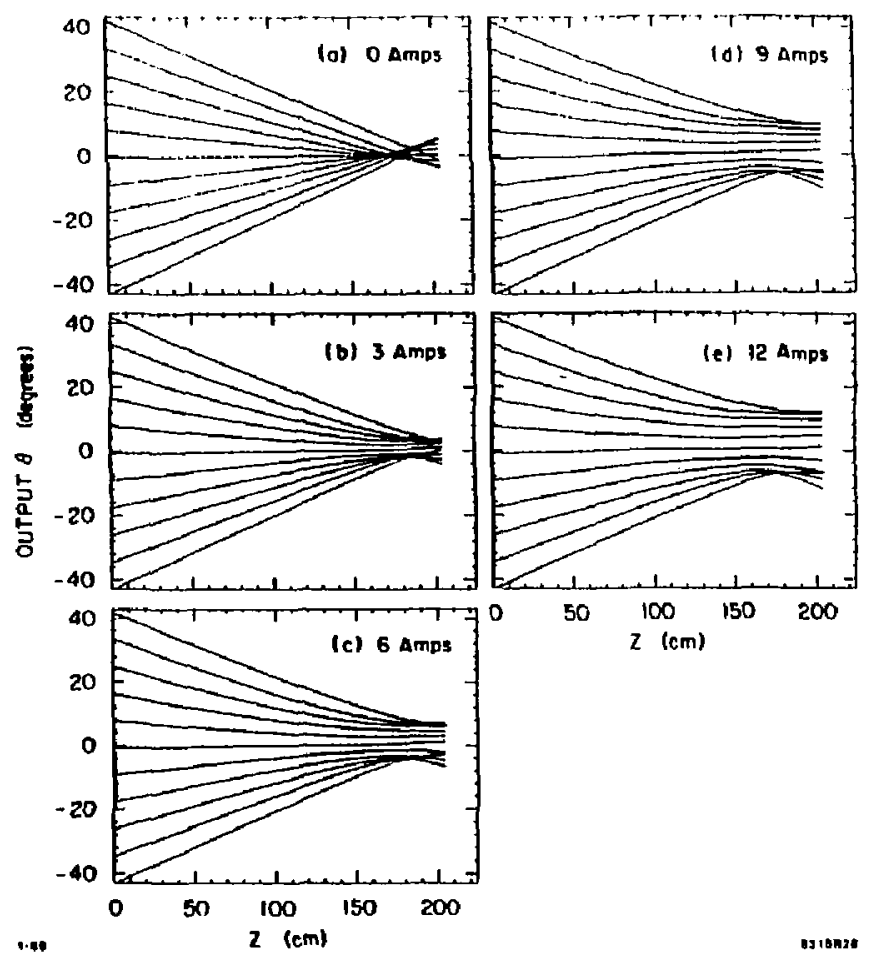

Fig. 2.27. versun $z$ for every third of the 31 inner disks of charge traversing the gap-end-drilt prebuncher speeified in Table 2.4 ss the eurrent increases from 0 to 12 amps. Ia given in degrees at the 20th subharmonic of S-band. 

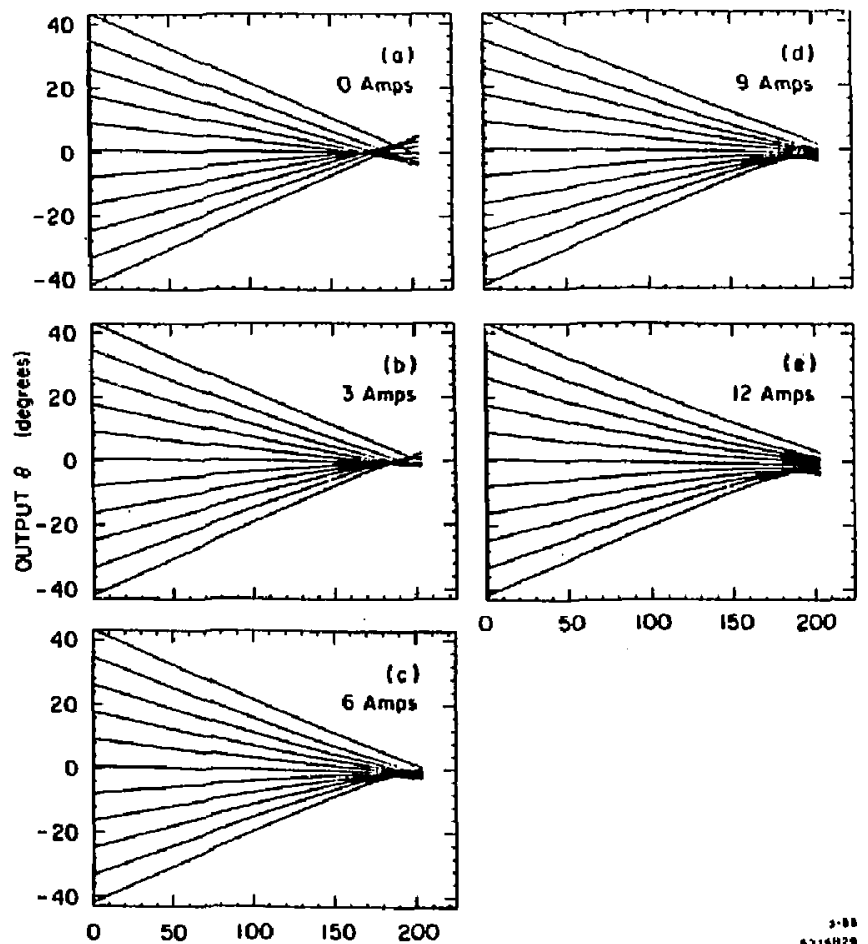

M1362

Fig. 2.28. versus 2 for cvery third of the 31 outer annuli of charge traversing the gap-and-drift prebuncher apecified in $\mathrm{Ta}_{\mathrm{a}}$ ble 2.4 as the current increases from 0 to 12 amps. Is given in degrees at the 20 h oubharmonic of S-band.
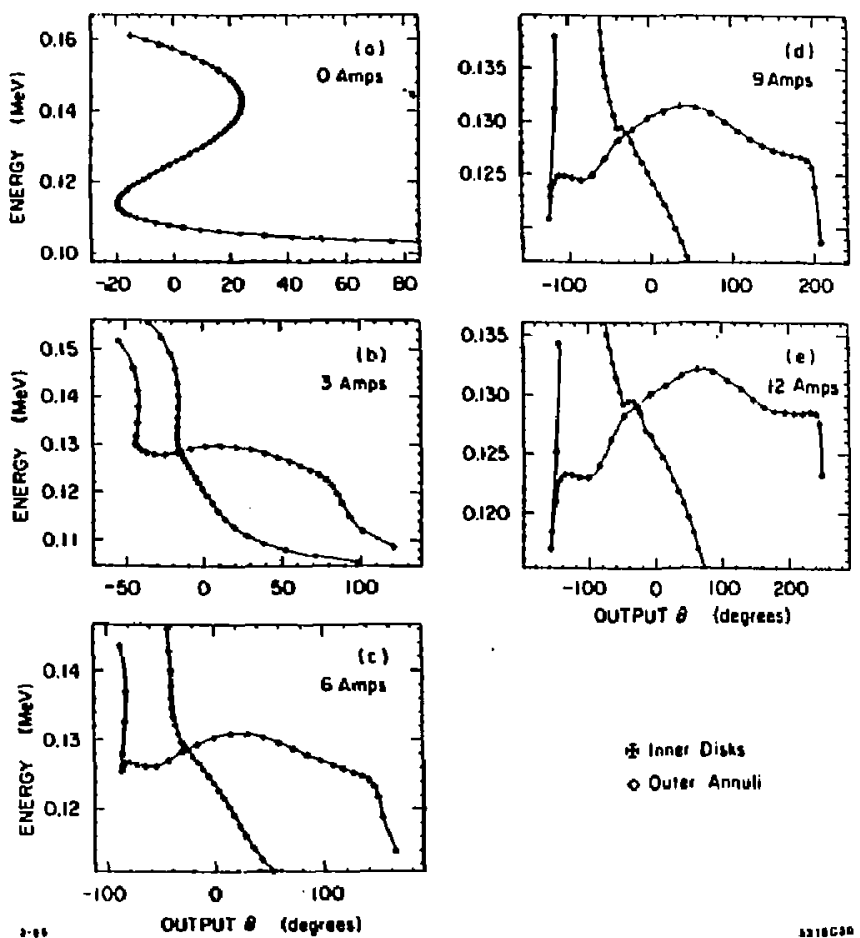

Inner Disks

- Outer Annuli

Fig. 2.29. Longltudinal emittance at the end of the gap-and-drift prebuncher specified in Table 2.4 at the current incresses from 0 to 12 ampu. 1 is given in degrees at S.band. 

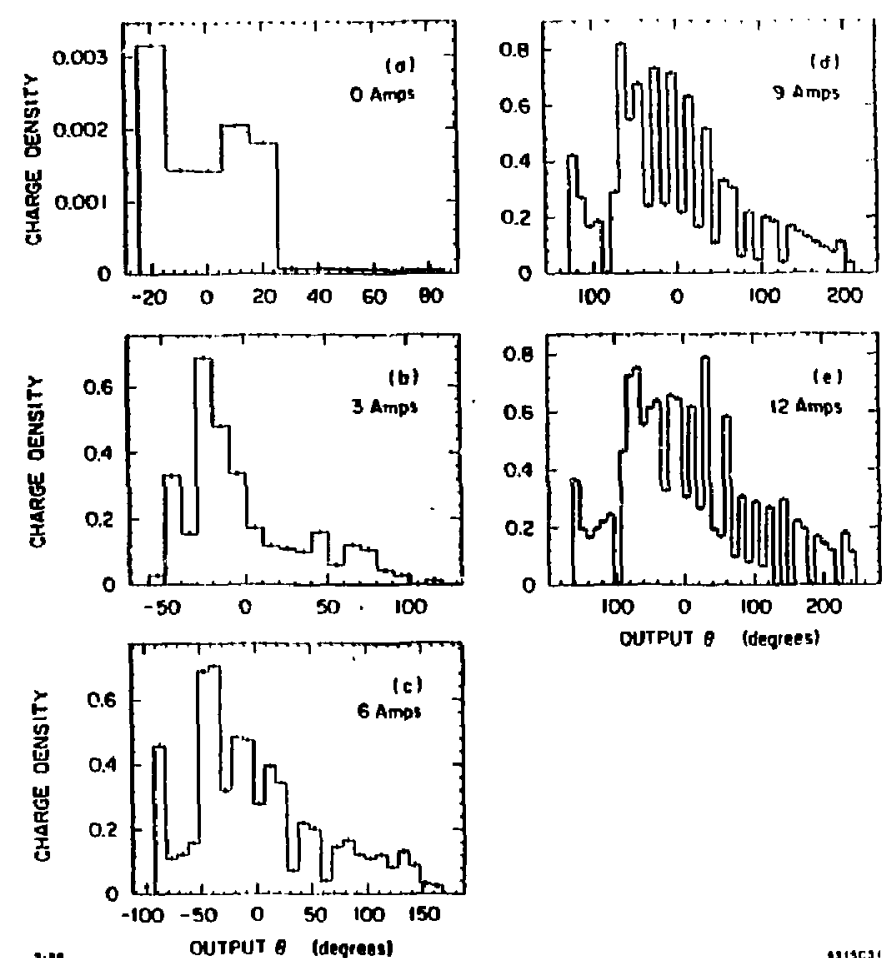

OUTPUT $\theta$ (degrees)

Fig. 2.30. Bunch length at the end of the gap-and-drift pre buncher specified in Table 2,4 a the current increases from 0 to 12 amps. 1 is given In degrees at S-band. Charge density units are relative.

At this point there are several options for desreasing the phase extent of the bunch entering the $\rho_{m}=.75$ buncher. One option is to incresse the strength of the electric field in the prebuncher gap. Three considerations suggest that this may not be the beat approach:

1. In doing this we abandon our matehing of the amplitude and phase of the field in the gap to offect the inherent asymmetry in bunching relativistic electrons with uppreciable field otrengths.

2. Increasing the gap field otrength increased the disparity between the phase apaces of the inner diskn and outer annuli, and this in turn increases the total phese space oceupled by the bunch.

3. We find that as the gap held atrength increases, the "hernias" grow, and this increases the efiective emittance of the bunch.

Another approach is to put a second gap-and-drift prebuncher at the phase walst. Since the outer ennuli are bunehed appreciably better than the inner disks, we ahould concentrate on bunching the disks as we choose the parameters of the second ap-and-drift buncher. Note that, with the exception of the "hernis" at the far lelt, the energy apread of the disiks in Fig. $29(e)$ is reasonably amall and cluatered about the ener $g y$ of the center particle after passing the firat gap. Hence it seems censible to use the ame approach to design the second gap-and-drift prebuncher as we used for the first.

The bunch now opana 400 po, and Eq. (2.49) yields $J=625 \mathrm{MHz}$, which falls between the fourth and Afth oubhermonics of SLAC's s-band frequency. Choosing the highest reasonable frequency has s olight advantage in that less phase ahift lo needed to exploit the asymmetry of the olne wave, and the beam centroid is decelerated less. We choose $714 \mathrm{MHz}_{2}$, the fourth subharmonic of 5 band. Because the bunch is much more affected by opace charge forces in the sccond gap and drift prebuncher, the gap field strength and drift length are found using the computer model. 
In optimizing the gop field itrength, we must strike a compromise between the very difterent dynamice of the inner and outer annuli. Figure 2.31 (c) and 2.32(c) show 11 of the 31 disks (onnuli) traversing a second gap at the fourth pubbermonic and $\mathrm{2} 2 \mathrm{~cm}$ drifi space. The outer annuli see much less apaco charge and are busched more rapidly. Aa the gap field atrength incseanes the disparity between the optimum drift for the diaks and annuli growa. On the other hand, at the sap field decreasex (and the drift incresses) we reach a point whese the inner ansuli are not bunched at all. The solution thown in Fige. 2.31 and 2.32 where $E=64 \mathrm{kV}, L=24 \mathrm{~cm}$ is a compromise between these competing factors.

The langitudinal beam emittance and bunch length at the end of the $21 \mathrm{~cm}$ drilt are shown in Figs. 2.33(c) and 2.34(c), sespectively. From Fis. 2.33(c) it is clear that the phase apaces occupied by the inner diaks and outer annull are quite different, the disks having a larger phase extent but arallet momentum extent. The calculation giving rise to Fig. 2.34(c) predicts thet $00 \%$ or 10 of the charge is contained within $200^{\circ}$ of S-band which can reasonsbly be coplured by the $\beta_{w}=.75$ S-band buncher.

In Fig. 2.35 the emittance of Fig. 2.33(c) is superimposed on the low current buncher phase space orbits. These orbits were calculaled in the absence of apace charge. The electrons in the high cutrent bunch are aubject to apace charee forces and their trajeclorite in phase space will not, in jeneral, follow these orbits. We include them principally as reference trajectories. At onticipated, the bunch bos a buge phase apread and relutively narow momentum spread. The modeling predicts that a buncher field strength of $a_{2}=.56$ (about 2.5 times that calculated for the Table 2.3 buncher) results in the best bunching. The resulting emiltance and bunch length are shown in Figs. 2.33(d) and 2.3s(d) respectively. Mont of the charge is now contained within $50^{\circ}$. Note that the dynamice in the buncher resemble those of the capture region in that the bunch "folds over" sbout the centroid. The "fold aver" increases the bunching of the inner diaks which enter the bunçher with a lerge phese extent. Note also that becuuse of the larget $a_{2}$, the centroid of the bunch exits the buncher with $p=1.26>p_{w}$.
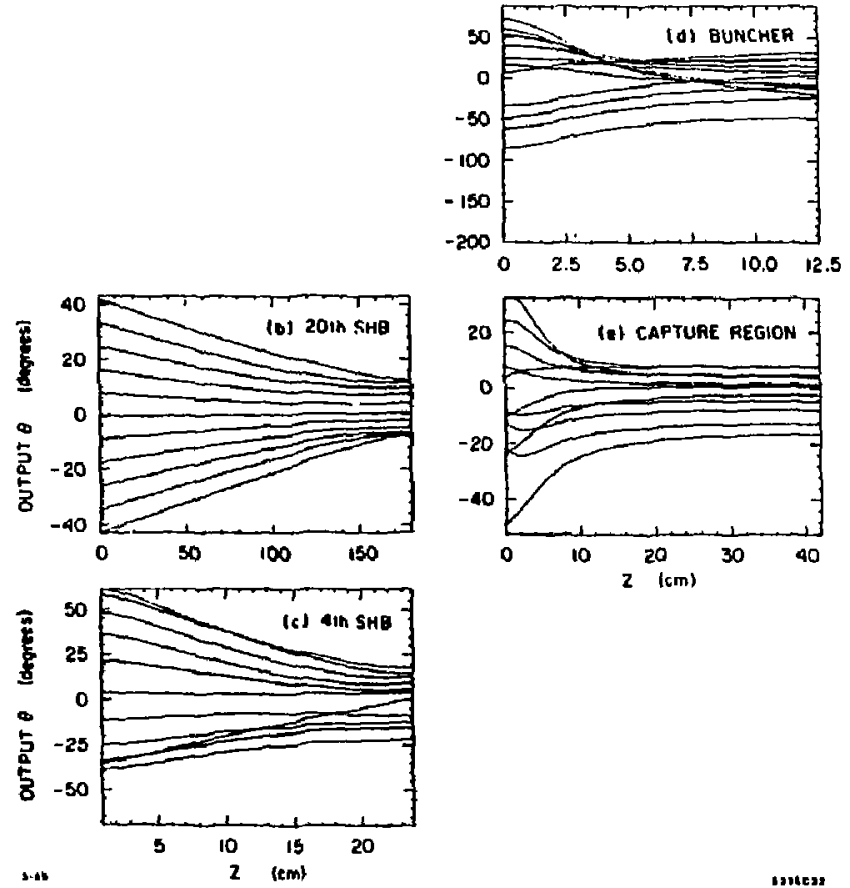

$z \quad \mathbf{c m}$ 

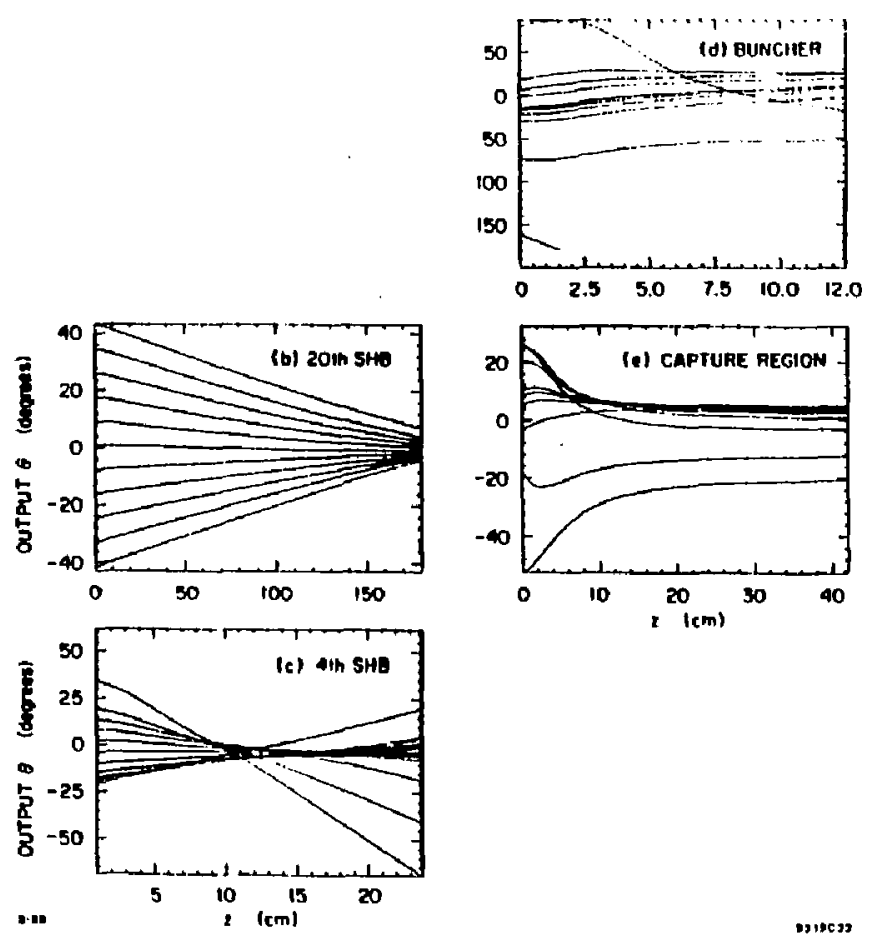

Fis. 2.32. versus $z$ for overy third of the 31 outer annull of charge traversing the injector epecifted in Table 2.4. (b) 20 th uubharmonic gap and $176 \mathrm{~cm}$ drift (0 given in degrees at $20 \mathrm{th}$ uubharmonic). (c) th aubharmonic gap and $20 \mathrm{~cm}$ drilt (0 given In degrees at th aubharmonic). (d) $10.5 \mathrm{~cm} 8$-band buncher and $2 \mathrm{~cm}$ drifl (1 given in deprees at S-band). (0) Firat $40 \mathrm{~cm}$ of velocily-or-light acceleralor nection (1 given in degrees at S-band).
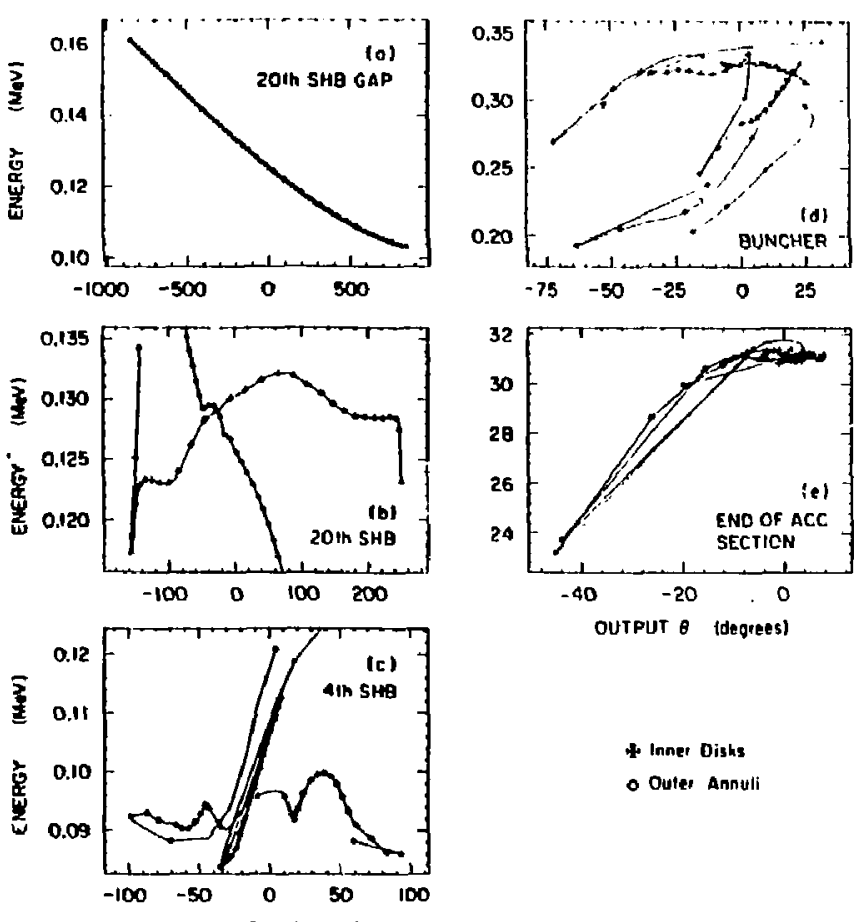

OUTPUT $\theta$ idegrees)

+ Inner Oisks

- Outes Annul

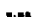

OUTPUT a (deques)

Fig. 2.33. Longitudinal emittence at five locations in the injector specified in Table 2.4. (a) Just downstream of the 20th subharmonic gap. (b) End of $176 \mathrm{~cm}$ drift. (c) End of $20 \mathrm{~cm}$ drift following 4 th subharmonic gap. (d) End of S-band buncher. (e) End of three-meter meter accelerator section. In all figures, $\theta$ is mensured in degrees at S-band. 

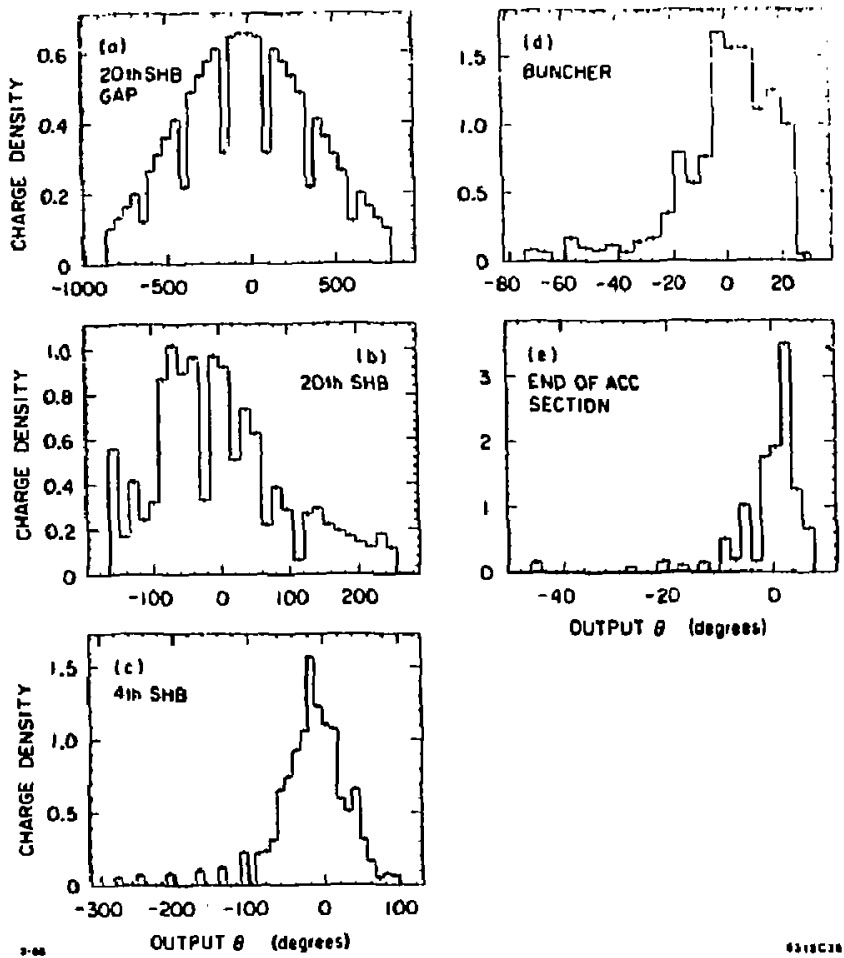

Fiz. 2.34. Bunch length at five locations in the injector specified in Table 2.4. (a) Output of the 20th subharmanic gap. (b) End of $176 \mathrm{~cm}$ drift. (c) End of $20 \mathrm{~cm}$ drift following ath cubharmonic gap. (d) End of S-band buncher. (e) End of three-meter accelerator section. In all figures, $t$ is given in degrees al S-band. Charge density units are relative.
We use Eq. (2.30) to calculate the optimum value of the field atrength in the capture region for $p_{w}=1.28$. We find $\alpha_{3}=2.16$. In Fig. 2.36 the emlitance at the end of the buncher is superimposed onto the low current phase space trajectories of a capture rezion with $\mathrm{ag}_{\mathrm{a}}=\mathbf{2 . 3 6}$. The calculations which give rise to Fig. 2.36 predict that after $42 \mathrm{em}$ most of the charge falls within $10^{\circ}$ near $-90^{\circ}$. From Figs. 2.31(e) and 2.32(e) we see that the bunch length remains constant after the first $20 \mathrm{~cm}$ or so of the capture recion. At the beam energy increases, space charge forces fall off as $1 / \gamma^{2}$. In the absence of other effects, the final emiltance and bunch length at the end of the three-meter accelerstor section sre thown in Fiz. $2.33(\mathrm{e})$ and $2.34(\mathrm{e})$. Approximately $6.8 \times 10^{10}$ electrons are captured into $18^{\circ}$ or $1.2 \%$ spectrum. The parameters of this high eurrent desizn are summarized in Table 2.6 .

Table 2.5. A high current, large signal injector design.

( $\Delta \theta$ calculated at output of each bunching element.)

\begin{tabular}{|c|c|c|c|c|c|c|}
\hline Etment & $\mathrm{dV} / \mathrm{cm}$ & Lenget $(\mathrm{cm})$ & $\beta_{\omega}$ & $\Delta \prime$ & $\Delta p$ & $\Delta E / E$ \\
\hline Gan & - & - & .0 & $1700^{\circ}$ & 0 & \\
\hline 201 h aubharmonic prebunther & $12(x+\mathrm{cm})$ & 178 & - & $400^{\circ}$ & .050 & \\
\hline th irblumonic prebuecher & $10(x+c m)$ & 20 & - & 3200 & .00 & \\
\hline S-Buad buscher & 27 & $10 .(1+2)$ & .78 & $50^{\circ}$ & .25 & \\
\hline Coppure region (no wate) & 105 & 12 & 1.0 & $10^{\circ}$ & & \\
\hline End of ecceleracer enction (no wakt) & 100 & 261 & 1.0 & $10^{\circ}$ & & $1.2 \pi$ \\
\hline Capture retion (with wate) & 100 & 12 & 1.0 & $14^{\circ}$ & & \\
\hline End of acceleterwitor cection (will wile) & 100 & 251 & 1.0 & $14^{\circ}$ & & $2 \%$ \\
\hline
\end{tabular}

As the electrons enter the disk-loaded waveguide (i.e., the buncher and accelerator aections), they excite longitudinal and traneverse fields known wo wake fields. The wake fields generated by electrons at the front of the bunch affect the energy and transyerse position and momentum of trailing elsctron.. The longitudinal wake field zenerated by a point charge moving at the speed of light in a SLAC accelerator structure has been cajeulated by Wilson and Bane. ${ }^{10}$ These 


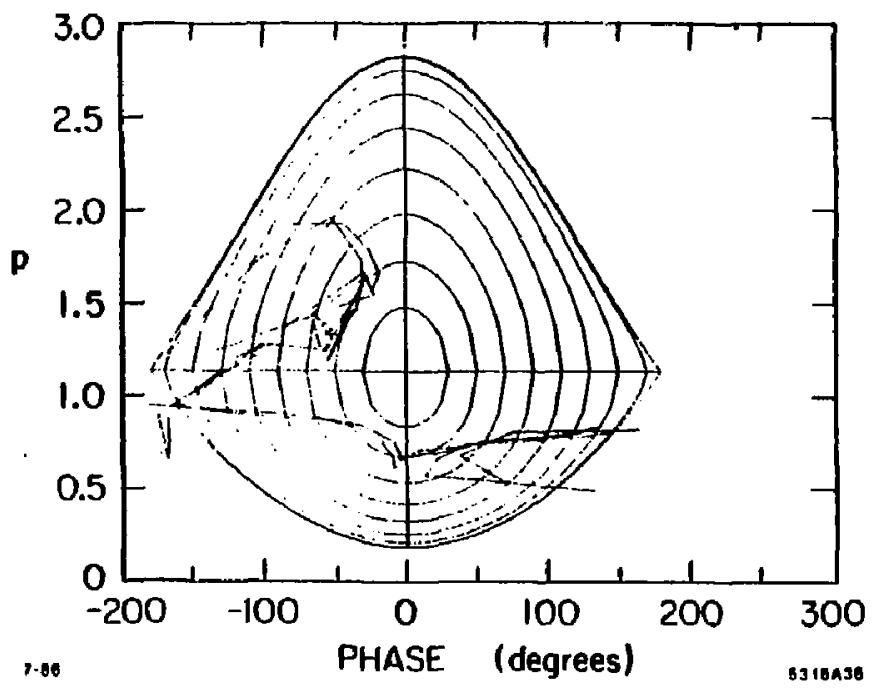

Fig. 2.35. Beam emittance at the entrance to and exit fram the S-band buncher superimposed on the bunches low-current phese opace orbits, $p_{w}=1.131, a_{2}=.56$.

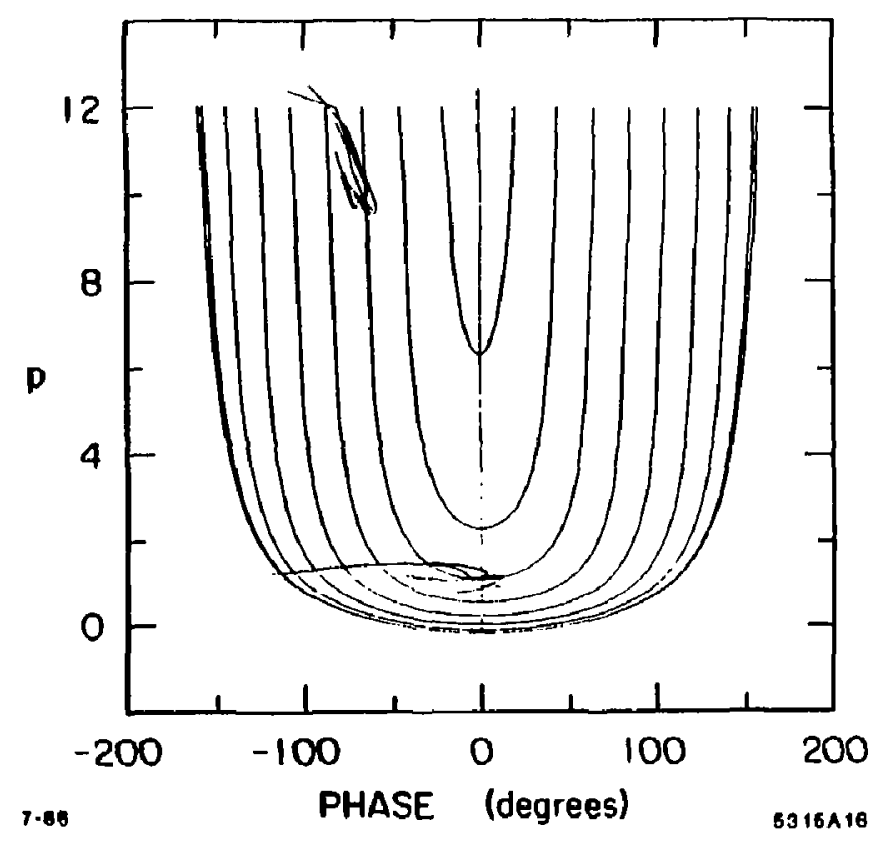

Fig. 2.36. Beam emittance at entrance to capture region and $31.5 \mathrm{~cm}$ downatream superimposed on the capture region low. current phase apace asbite, $p_{\infty}=1.28, o_{s}=2.10$. 
fields have been added to the ring-and-disk model program in the velocity of light section. The wake fields ore calculated ar if all particles were moving at opeed $c$ in the capture region and accelerator. This assumplion probably overeatimates their effect in the capture region, although the total error is amall compated to the averall wate field effect. No attempt hes been made to model wake field effects in the buncher. More poweriul programs such a MASK" are required to attuck this problem accurately.

Assuming that wake felde primarily affect the energy spectsum of the beam rather than its bunch length, we can learn amething from the preaent madel. Figures 2.37-2.39(a) show the final emillance, spectrum and bunch length of the "Table 2.5" injector calculated without longitudinal wake fielda. Fizuret 2.372.39(b) ahow the emittance, spectrum, and bunch length in the presence of wake fieldp. Note that the spectrom has greatly deteriornted while the bunch length is slightly broudened. The deterioration of the apectrum can be offect by capturins the electron bunch forward of the RF rrest, where the alope of the RF is opposite to that of the wake fields. In particular we choose $t_{\infty}$ auch that

$$
\nu_{\infty}=\arccos \frac{\Delta E / \text { radian }}{E_{\text {max }}} \text {. }
$$

To choose $\triangle E / E$, we examined Fig. $2.37(b)$ and found that in the region of higheal charge denuity $\left[1^{*}\right.$ to $3^{*}$ as ween in Fig. $\left.2.30(b)\right]$ the change in energy per degree $\Delta E /$ degree $=3.0 \mathrm{MeV} /$ degree. Converting to radiunı and eubstituting in Eq. 2.56 yields $C_{\infty}=-65^{\circ}$. Thus we wish to capture the bunch $25^{\circ}$ ahead of the RF creat. Equation 2.11 giver

$$
a_{3}(\text { new })=\frac{a_{3}(\text { old })}{1-\cos \theta_{\infty}}=3.7
$$

Figurea 2.37(c), 2.38(c), and 2.39(c), respectively, show the emittance, spectrum and bunth length of the "Table 2.4" injector assuming an secelerator acction field strength of $K=180 \mathrm{kV} / \mathrm{cm}$. Although the beam is captured $25^{\circ}$ shead of
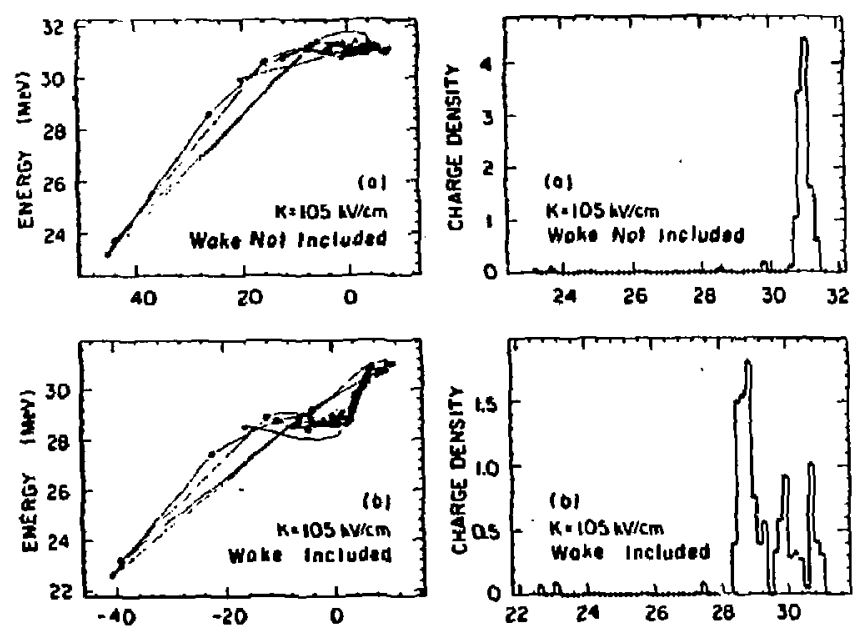

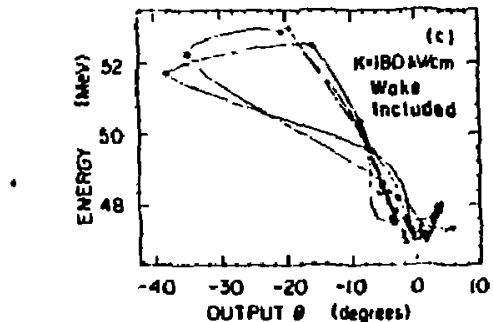

12.16

Fiz. 2.37. Langitudinal emittance at the end of a three-meter accelerator mection with (a) $K=105 \mathrm{kV}$ without whlefields calculated, (b) $K=105 \mathrm{KV}$ with watefields calculated, and (c) $K=180 \mathrm{kV} / \mathrm{cm}$ with wakefields calculated.

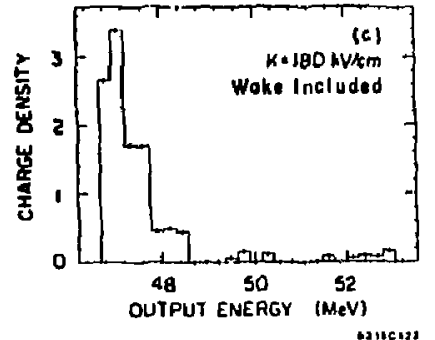

Fis. 2.38. Energy epectrum at the end of a three-meter accelerator section with (a) $K=105 \mathrm{kV}$ without wakefielda calculated, (b) $K=105 \mathrm{kV}$ with wakefields ealculated, ind (c) $K=180 \mathrm{kV} / \mathrm{cm}$ with wakefields calculated. 

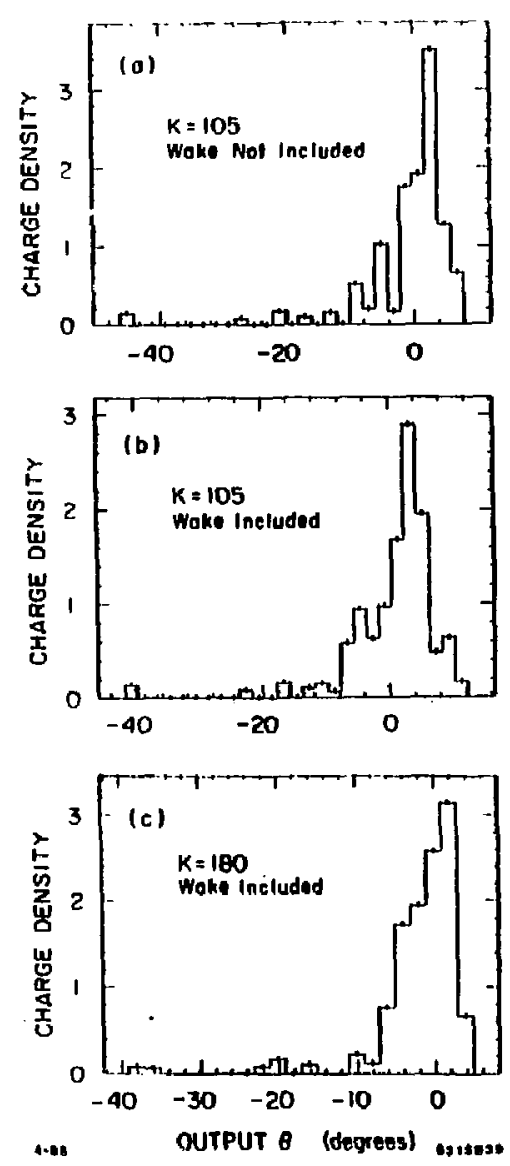

Fis. 230. Bunch lenth the end of three-meter accelerator section with (a) $K=105 \mathrm{kV} / \mathrm{cm}$ without wakefielda calculaled, (b) $K=105 \mathrm{kV} / \mathrm{cm}$ with wakefields calcuinted, and (c) $K=180 \mathrm{kV} / \mathrm{cm}$ with wakefields calculated. the RF crest, the final energy of the beam is $15 \mathrm{MeV}$ greater than in the $\alpha_{3}=\mathbf{2 . 1 6}$ case because of the higher accelerating gradient. The spectrum, while not as good as it would be in the absence of wake fields |Fig. 2.38(a)| is greatly improved over the case in which the bunch is captured on the erest in the presence of wake fields.

The computer pimalation? which include wake field ealculations predirt that approximalely $80 \%$ of the charge in the gun pulse is contuined within a $\pm 1 \%$ epectrum at the end of the three-meler accelerator mection. The bunch is alightly better |Fig. 2.39(c)| than in the case where wake fields are not calculated as $7 \times 10^{10}$ electront are captured into $14^{\circ}$ of S-band phase.

\subsubsection{Original Collider Injector Design}

As atated earlies, the actual CID design was undertaken without the benefit of hindsight, and therefore does not rellect all the insighto discussed in the last two section. The original design also diftere from the eursent running condition of the CID injector. However, for completeness ardi continuity we review the actual CID design here. The original CID dealgn difters from the "Trble $2.5^{\mathrm{n}}$ injeetor in one important respect: in the "Tuble 2.5 " injector design, we atudied and accommodated the effecte due to bunehing with the large signals used in the gap. and-drift prebunchers. In the original CID design, we began with the less valid (but timpler) asoumption that the voltages in the prebunchers would produce relatively omall changes in the tinetic energy of the partieles when, in fact, if is changed by as much as $50 \%$. In the small aignal approximation, velocity varies linearly with energy

$$
\Delta \boldsymbol{\theta} \propto \Delta \boldsymbol{\gamma}
$$

With this assumption, perlect bunching is obtained when the gap voltage varies linearly In time.

In the original CID design," we assumed that the gun produces a $15 \mathrm{amp}$, $1 \mathrm{~ns}$ FWHM Gaussian pulse. The frequency of the subharmonic bunchers is not 
critical as lone as the frequency is low enouth that the gun pulec falls in the linear region of one cycle. Choosing a cavity with the highest frequency which mets this condition has an advaniage in that leas power ba required to achieve a siven field gradient ecross the gap. We chose $178.5 \mathrm{MHz}$, the 16 th nubharmonic of S-band an the frequency of the firat subharmonic buncher sap. The $1.7 \mathrm{~ns}$ ( \pm 20 ) gun pulse aubtenda $110^{\circ}$ of phase, At $178.5 \mathrm{MHz}$ the change in the energy of each particle as it crosses the gap in to reasonably linewr function of phase for time) as thown in Fis. 2.42(c).

When bunching with a linear sicnal, if we try to use a high field gradient and upproprinte drift apace to match the beum from the first gap-and-drift prebuncher directly into the $\beta_{\omega}=.75$ buncher, neveral problems arise:

1. Anymmetries due to selativiatic effects increase,

2. Space charge forces act uymetrically within set of annuli. ("Hernias" develop.)

3. The disparity between the phase speces of the inner and outes annull grows.

All three effecte increace the effective emittance. Thus we chose to use two cap-and-drift prebunchers. In the first subhermonic buncher we chose $\alpha=.39$ and $C=108 \mathrm{~cm}$ which leads to the $600^{\circ}$ bunch shown in Fig. $2.43(b)$. Note [Figa. 2.40(b) and 2.41(b)] that the lower energy particle (poitive phases) wte converging on center faster then the higher enercy (negutive phases) due to the relativintic aymmeiry. A second ubburmonk buncher b needed to mateh tho beam to the buncher acceplance. The frequency of the eecond gap could easily be as bich as the wixlh aubharmonic of S-bend (although the eighth subhermonic should be chosen as it is a harmonic of the 16th), but any frequency below the sixth will sufice.

Compuler modeling ohowe that the field gradients needed in the second gap we not higis wo that a low power-lo-field gradient ratlo io nat an linportant critetion. To minimize time ond costs in designing and machlning the aub-
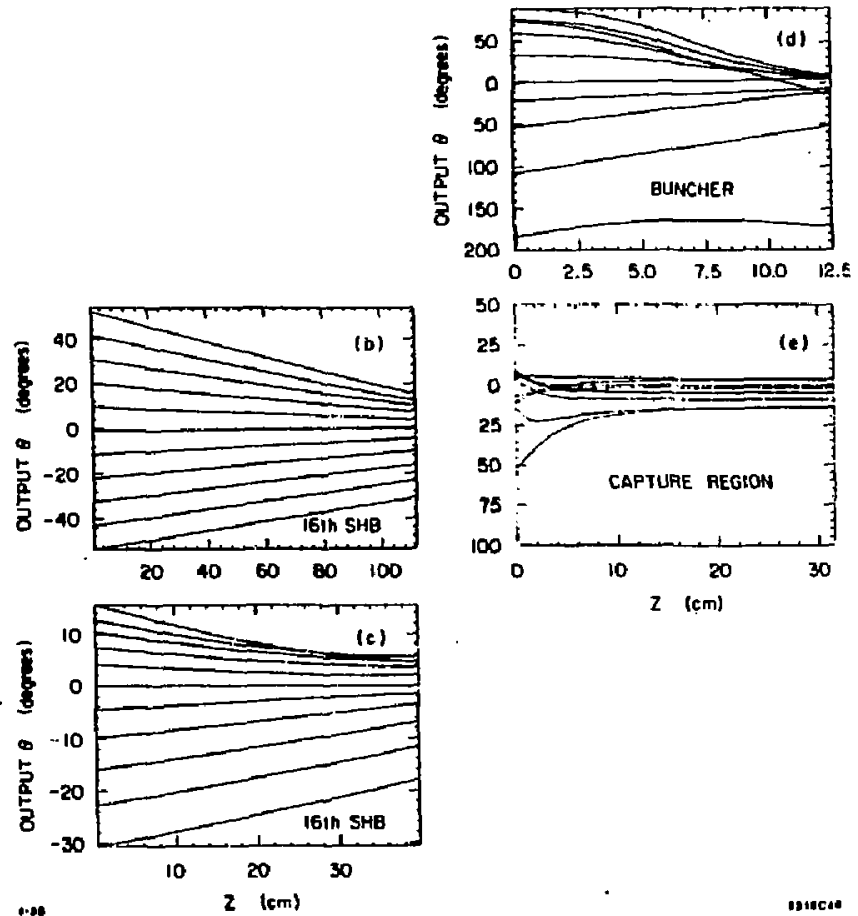

Fig. 2.40. vernus $z$ for every third of the 31 inner disks of charge traverning the original ClD injector design. (b) First 16th subharmonic ap and $108 \mathrm{~cm}$ drift, aiven in degreet the 16th wubharmonic of S-band. (c) Second 16th oubhermonic gap and $36 \mathrm{~cm}$ drifl, given in deyteet at the 16th eubharmonic of S-band. (d) $10.5 \mathrm{~cm} 5$-band buncher and $2 \mathrm{~cm}$ drift, 1 given in degrees at s.band. (e) Firat $30 \mathrm{~cm}$ or velocity-of-light accelerator aection, $t$ given in degrees at S-band. 

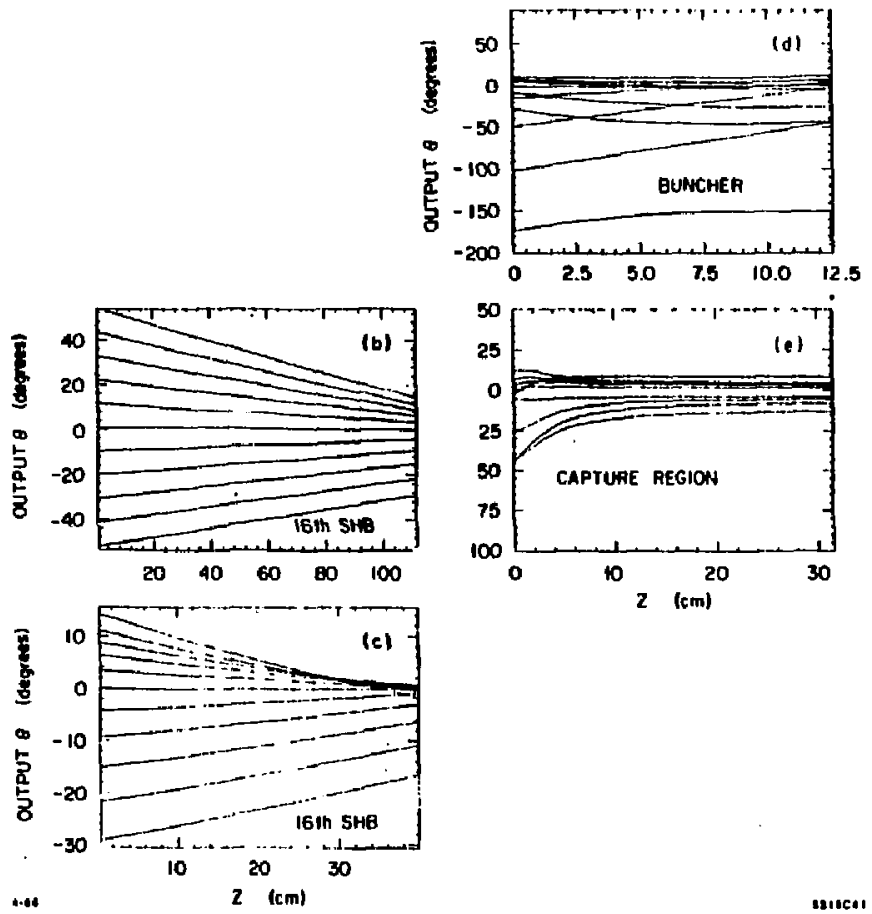

sencal

Fis. 2.41. versus 2 for every third of the 31 outer annuli of charge traveruin: the original CID injector design. (b) Firat 16th subharmonic gap and $105 \mathrm{~cm}$ drift, civen in degrees at the 16th subharmonic of s-band. (c) Second 18 th

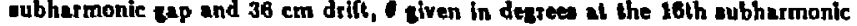
of S-band. (d) $10.5 \mathrm{~cm}$ S-band buncher and $2 \mathrm{~cm}$ drift, given in degrees at S-band. (e) Firat $30 \mathrm{~cm}$ of velocily-of-light aceelerator eection, given in degrees at S-bend.
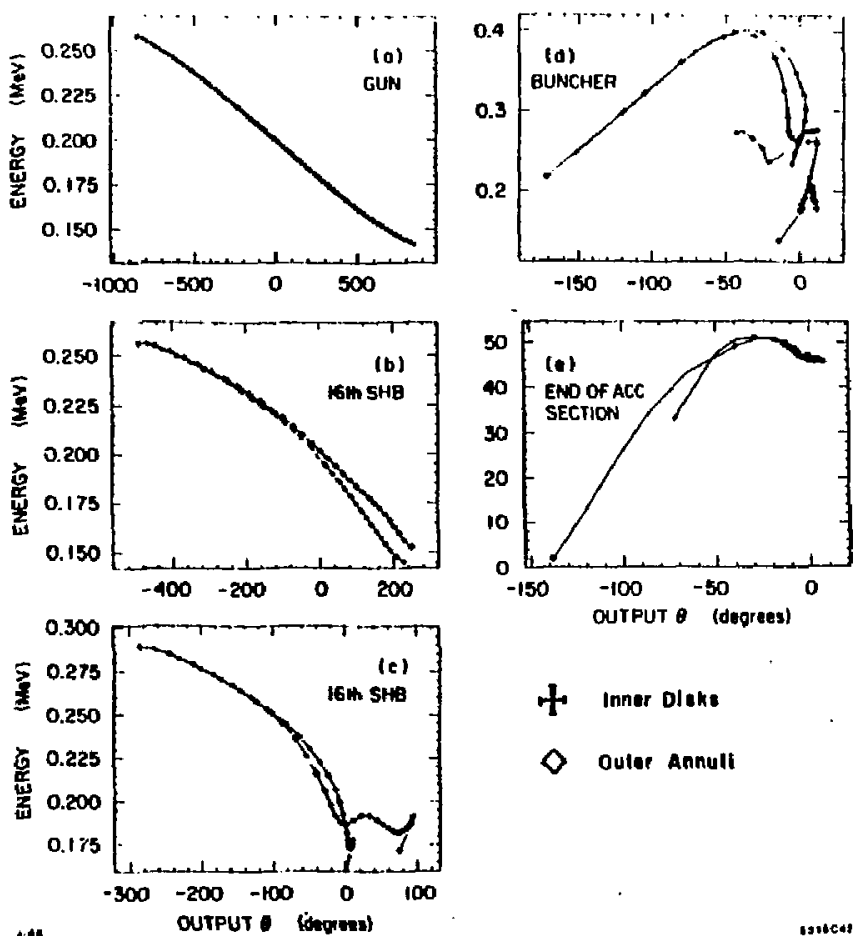

f. Inner Dleks

$\bigcirc$ Oulae Annult

Fig. 2.42. Longitudinal emittance at five locations along the original CID design. (a) Juat downatream of firt 16 th subharmonic gap. (b) End of $108 \mathrm{~cm}$ drift. (c) End of $36 \mathrm{~cm}$ drift following recond $16 \mathrm{th}$ subhemonic gap. (d) End of S-band buncher. (e) End of three-meter accelerntor section. in all figures given in degrees of S-band. 

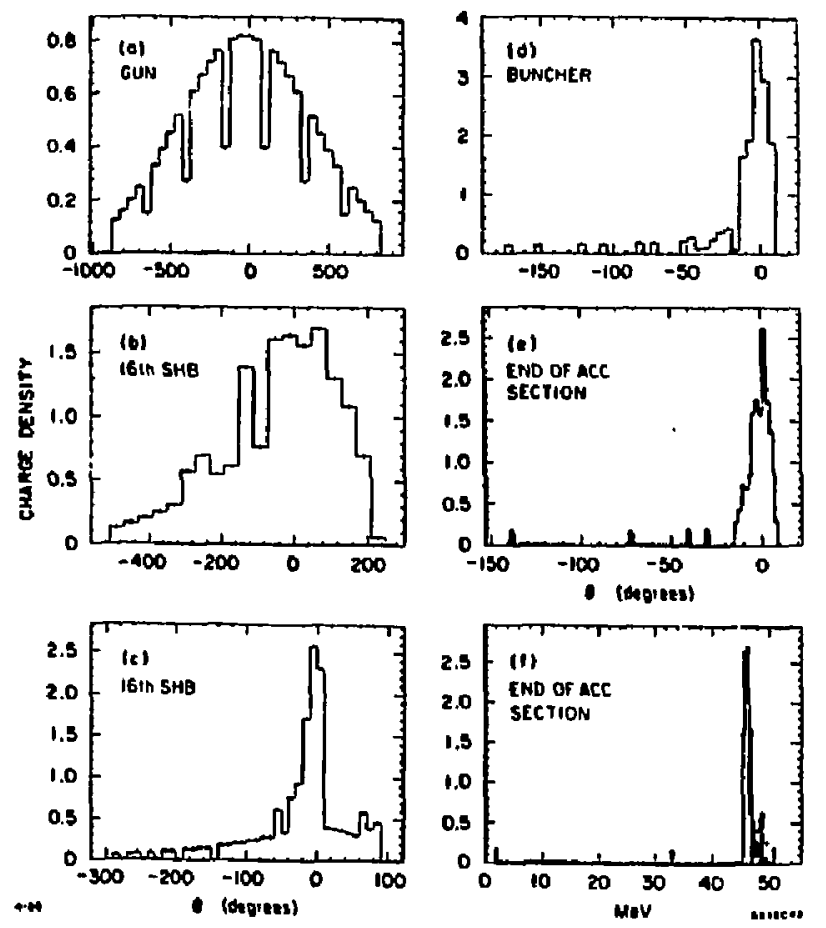

Fig. 2.43. Bunch length at five locations alor, the orizinal CID derign. (a) Just downstream of Erst 16th eubharmonic cav. (b) End of $108 \mathrm{~cm}$ drift. (c) End of $36 \mathrm{~cm}$ drifh following second 16 th subhermonic eap. (d) End of S-bend buneher. (c) End of three-meter accelerator ocction. All charge dentitien are relative. In (a)-(e) are given in degrees at S-band. (f) Spectrum at end of three-meter acceleralor section. harmonic bunchers, we chose to build the two cavities at the sume frequency. In the second ubharmonic buncher we chose $\alpha=.37$ and $L=36 \mathrm{~cm}$. Again note [Fies. 2.40 (c) and 2.11 (c)] that the bunch converges asymmetrically. As we see from fizs. 2.42(c) and 2.43(c) we did not find a good compromise between good bunching of the inner disks and outer annuli. This solution favors the outer annuli which bunch into $250^{\circ}$ peak while the inner disks are spread over some $300^{\circ}$. Clearly the charze in the tail with phases of less than $-100^{\circ}$ will nol be captured by the buncher. In Fic. 2.14 the emiltance of the beam [Fig. 2.12(c)] is uperimposed on the low current phase apace orbits of the buncher.

The beam enters the buncher with a mean momenturn equal to the gun pulse mornentum aince there is no phase shift of the centrold with respect to the RF in the prebuncher. This is a higher momentum than the "Table 2.5" injector. A amaller $a_{2}$ is sufficient to tranaport the beam through a quarter of 2 cycle in phase opace. The beam emittance [Fit. 2.42(c)] has significant "Lazy L"-like shope. Bunching in the buncher is improved if we shift the centroid of the beam to $-15^{\circ}$ so that the particles in the "Lazy $L^{*}$ fall between the phase space orbits with asymptotic phase $\theta_{m}=-50^{\circ}$ and $t_{m}=-70^{\circ}$ (nee Fig. 2.41). The buncher does a good job a $7.6: 10^{10}$ electrom initially sprend over $200^{\circ}$ are collected into $25^{\circ}$ of S-band phace [ee Fis. 3.43(d)). Another $1 \times 10^{10}$ electrona are contained in $\triangle$ tail that extenda some $30^{\circ}$.

In the velocity-of-light section we chose a high field gradient, $a_{3}=3.7$. The bunch reaches an aymptotit phase of $-70^{\circ}$, which helps to offet the broudening of the spectrum due to wake fields, although this was not a principal concern at the time of the design. In Fig. 2.45 the emittance of the bunch at the entrance to the eccelerator section is plotted on the low current phase space orbits of the capture resion. We tee that the charze contained in the $30^{\circ}$ tail of Fig. 2.43(d) Is folded into the core of the bunch during eapture; thus $8.5 \times 10^{10}$ electrons are ultimately captured into $\approx 24^{\circ}\left(0 \approx 7^{\circ}\right)$ bunch (nee Fig. $\left.2.43(\mathrm{e})\right)$. This derign meets the original epecifications as deacribed in Chapter 1 . 


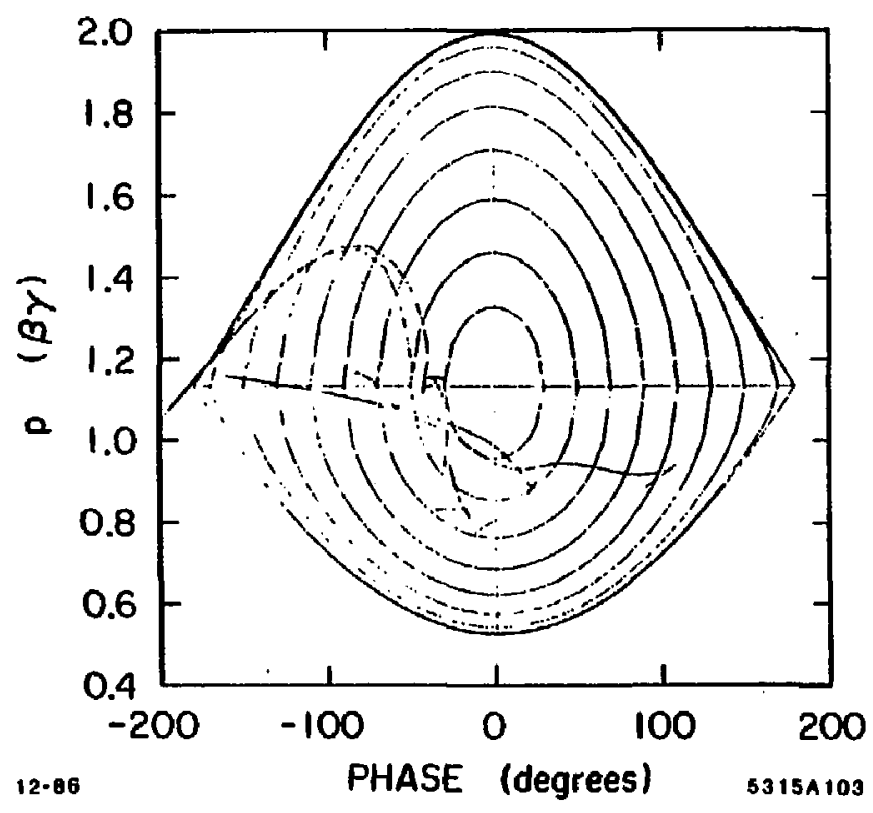

Fig. 2.44. Beam emittance al the entrance to and exit from the S-band buncher auperimposed on the low-current buncher phase epace orbith of the oricinal ClD deaicn.

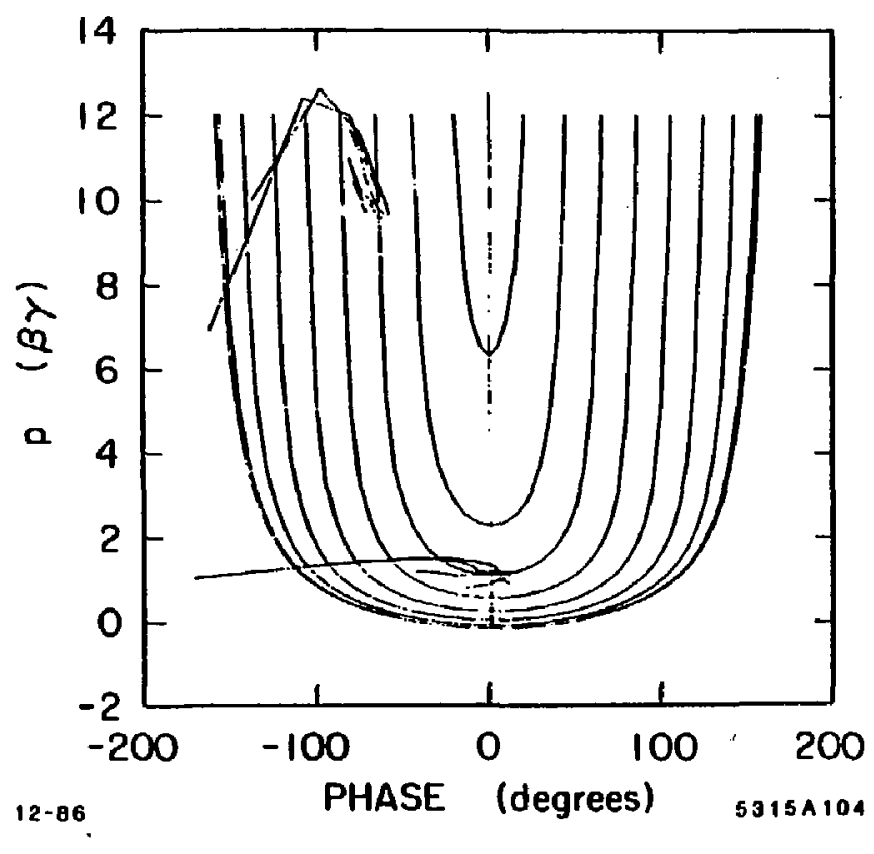

Fig. 2.45. Beam emittance at the entrance of the caplure recion and $30 \mathrm{~cm}$ downatream superimposed on the capture region low current phase apace orbite of the original GID desigit. 
2.3. Description of the Ring and Disk Model Computer Code

\subsubsection{Description}

In order to calculate apace charge effects during the bunchint procesa, we modet the beam as a finite number of infinitely thin disks and rings of charge in an infinitely long conducting cylinder (zee Fig. 2.27). ${ }^{13,14}$ The apace charge lorees between the annuli are found by solving for the average static force between annuli in the presence of the zrounded conductint cylinder.

The potential of an infiniteaimal susface charge locsted at $r=6, \theta=\phi$, and $z=0$ in an infinite conducting cylinder of radiun $c^{13}$

$v_{m}(r, \theta, z)=\frac{\rho d_{0}}{\pi e_{0} a} \sum_{m=0}^{\infty} \sum_{n=1}^{\infty}$

$$
\left\{\frac{1}{1+\delta_{m 0}}\left[\frac{\left.f_{m}\left[\left(j_{m n} / a\right) b\right] J_{n} \mid\left(j_{m n} / a\right) r\right]}{\left[j_{m n} J_{m+1}\left(j_{m n}\right)\right]^{3}}\right] \times \exp \left(-j_{m \infty} \frac{|z|}{a}\right) \cos (\theta-\phi)\right\}
$$

where

$J_{m}=$ the $m^{\text {ih }}$ Bensel function

$j_{m}=n^{\text {th }}$ zero of $m^{\text {in }}$ Besel function

ab = charce denuity on infinitesimal autface element $d v=b d b d \phi$

r = magnitude of the radial component in cylindrieal coordinates

$\theta$ "E magnitude of the aximuthal component in eylindrical coordinates

- = longitudinal position

$\omega_{0}$ = dielectric constant in MKS units

$\delta_{m}=1$ for $m=0,=0$ for $m \neq 0$

The potential of an annulus of charce with inner radius $b_{1}$ and outer radius in in

$$
\psi(r, \theta, r)=\int_{h}^{h} \int_{0}^{2 \pi} \psi_{\mu}(r, \theta, z ; b, \phi) b d b d \phi
$$

The longiludinal electric field is found by differentiatine the potential

$$
E_{s}(r, \theta, z)=-\frac{\partial \psi(r, \theta, z)}{\partial z}=-\frac{\partial}{\partial z} \int_{b_{1}}^{h} \int_{0}^{2 \pi} \psi_{p l}(r, \theta, z ; b, \phi) b d b d \phi
$$

Given a second annulus of charge localed at $z_{1}$ with inner radius $r_{1}$ and outer radius $r_{2}$, the average longitudinal field on the second annulus due to the first

$$
\begin{aligned}
& \bar{E}_{21}=\frac{\int_{p_{1}}^{r_{1}} \int_{0}^{2 \pi} E_{4}(r, \theta, z) r d r d \theta}{\int_{p_{1}}^{n_{2}} \int_{0}^{2 \pi} r d r d \theta} \\
& =\frac{\int_{n_{1}}^{n_{2}} \int_{0}^{2 n} \int_{b_{1}}^{b_{1}} \int_{0}^{2 r}\left\{-\frac{\phi_{1}}{d \psi_{p 1}}\left(r_{1} \theta_{1} x_{i} b_{1} \phi\right)\right\} b d b d \phi r d r d \theta}{\pi\left[\left(r_{2}\right)^{2}-\left(r_{1}\right)^{2}\right]} .
\end{aligned}
$$

The change in the energy of the second disk or annulue due to this overage field

$$
\frac{d y_{z}}{d x}=\frac{e}{m_{0} c^{2}} E_{n} \text {. }
$$

The variable $a$ in the exponent of Eq. (2.50) repreaents the distunce between the two annuli. If we measure the position of each disk by its phase relative to the RF actelerating wave with $\lambda f=c$, the approximate distance between the annuli in the lab frame it

$$
\therefore=v_{1} \frac{\lambda}{c} \frac{\theta_{2}-\theta_{1}}{2 \pi}=\beta_{1} \lambda \frac{\theta_{2}-\theta_{1}}{2 \pi}
$$

where

1 = phase of annulus 1 with respect to the RF wave

$a_{2}=$ phare of annulus 2 with reapect to the RF wave

$p_{1}=$ normalized velocity of annulus 1 in the laboratory frame. 
Since we are calculating the force on the exond annulun, we must write this distance in its reference Irame

$$
v=m \beta_{1} \frac{\theta_{1}-\theta_{1}}{2 \pi} \lambda .
$$

Performing the integration in Eq. (2.02) and summing over all other annuli, we Find that the change in eneray of the $m^{\text {ih }}$ ennulus due to all other annuli is

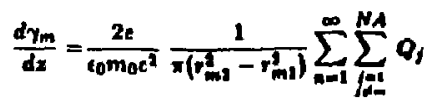

$$
\begin{aligned}
& \int \frac{r_{m 2} J_{1}\left[j_{m}\left(r_{m 2} / \alpha\right)\right]-r_{m !} J_{1}\left(j_{m}\left(r_{m 1} / a\right)\right]}{\left(r_{j 2}^{2}-r_{j 1}^{2}\right)}
\end{aligned}
$$

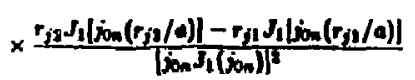

$$
\begin{aligned}
& \left.\times \exp \left(-1 \frac{\dot{j}_{m}}{\pi} \gamma_{m} \theta_{j}\left(\frac{\Delta_{m}-\theta_{i}}{2 \pi}\right) \times 1\right)\right\}
\end{aligned}
$$

where

$$
\begin{aligned}
n & =\text { Index for aum over zeros of } J_{0} \\
j & =\text { index for sum over all ather annuls } \\
\boldsymbol{Q}_{j} & =\text { total charge on the } j^{\text {th }} \text { annull } \\
N_{A} & =\text { tolal number of diake and annull } \\
r_{j,} & =\text { inner radius of } j^{\text {th }} \text { ennulus } \\
r_{j,} & =\text { outer radius of } j^{\text {th }} \text { ennulus. }
\end{aligned}
$$

For an initially Gaussian churee diatributlon, the chatge on each annulua is given by

$$
Q_{f}=Q_{0} \exp -\left(\frac{t_{j}}{20^{2}}\right)
$$

where

$Q_{0}=$ tolal charge on the annulus which leaves the gun at the center of the Gaussian pulse

$t_{j}=$ the time at whlch the $j^{\text {th }}$ annulj leaves the aun with respect to the center particle

- = tigme of the Gausian distribution.

The longitudinal equations of motion for the $m^{\text {th }}$ annulus (Eqs. 2.4 and 2.5) in the prenence of apace charge are

$$
\begin{aligned}
& \frac{d \gamma_{m}}{d \xi}=-\alpha \sin \theta+\frac{2 \lambda \varepsilon}{c_{0} m_{0} \varepsilon} \frac{Q_{0}}{\pi\left(r_{m 1}^{2}-r_{m L}^{2}\right)} \sum_{j=1}^{N A} \exp -\left(\frac{t_{t}^{2}}{2 a^{2}}\right) \sum_{n=1}^{\infty} \\
& \times\left\{\frac{r_{m 2} J_{1}\left[i_{m}\left(r_{m 2} / 2\right)\right]-r_{m 1} J_{1}\left[i_{n}\left(r_{m 1} / a\right)\right]}{r_{j 2}^{2}-r_{j 1}^{2}}\right. \\
& \times \frac{\left.r_{j 2} J_{1}\left[i_{m}\left(r_{i 2} / a\right)\right]-r_{j 1} J_{1} \mid j_{i n}\left(r_{j 1} / a\right)\right]}{\left[j_{n} J_{1}\left(i_{i=1}\right)\right]^{2}} \\
& \left.\times \exp \left[-\left|\frac{\dot{j}_{m}}{2} \gamma_{m} \rho_{j}\left(\frac{\theta_{m}-\rho_{j}}{2 \pi}\right) \lambda\right|\right]\right\}
\end{aligned}
$$

and

$$
\frac{U_{m}}{d t}=2 \pi\left(\frac{1}{\beta_{\infty}}-\frac{1}{\beta_{m}}\right)
$$

2.3.2 Une of the RINGMODEL Computer Program

The proeram RINGMODEL integrates Eq. (2.67) and (2.68) th the bunch moves from the cun through the subharmonic bunchers, the S-band buncher, and the three-meter accelerator section. While this approseh to modeling opace charge effects in bunching aystems is very uselul, it has a number of limitationa 
which users must keep in mind. The program ealculates the atotle forces between infinitely thin diske of charge in a emooth conducting cylinder. Each of the boldfuce adjectives presents limitations:

1. The program calculatea atatic forces between particles. This is a good approximation of the forces between particles as lonk as the enercy spread within the bunch is a amall fraction of the total eneray. In this case it is rexsonable to apeak of the "rest frame" of the electron bunch. II $\triangle E / E$ to latge (w it is in the aubharmonic and S-band buncher buncher regions), there $b$ no reasonable reat frame of the bunch. Note that in Fig. 3.10 (Sec. 3.2) at the output of the S-band buncher, the momentum of particles in the bunch rangen from .7 to $1.9 \mathrm{mo}$. In wueh a case an electrostatic calculation connot provide a good model of the intrabunch forces, and a fully electromenetic catculation in requited. An axample of an effect that depends on the magnetic fielda is the back EMF produced as the beam current is "(urned on" at the front of the bunch and "lurned on" at the rear of the bunch (nee Fit. 2.46). The back EMF opposes the upreadine due to opace thare. This entect is clearly important in Herrmannsfeldi's lesertton timuletion. ${ }^{20}$

2. The program calculate the average Coularnb forcen balween \& relatively amall number of Infinitely thin dirke and annuli. Very near the surface of the disk [i.e., es 2 appronches zero in Eq. (2.59)], the fields due to the disk approuch those of an infinite sheel of charge.

$$
E_{x} \underset{s \rightarrow 0}{\infty} \frac{\rho}{2 c_{0}} \text {. }
$$

If the charge were represented by thousands of particles (as in the MASK program), we would expect that the field due to a thin "rlice" of charge would 10 to zero al the center of the slice. Thus the infinitely thin disk epproximation may overentimate apace charge forces a diaks pas each other. In Fige. 2.29(e) and 2.33(b) we see that large momenture changes
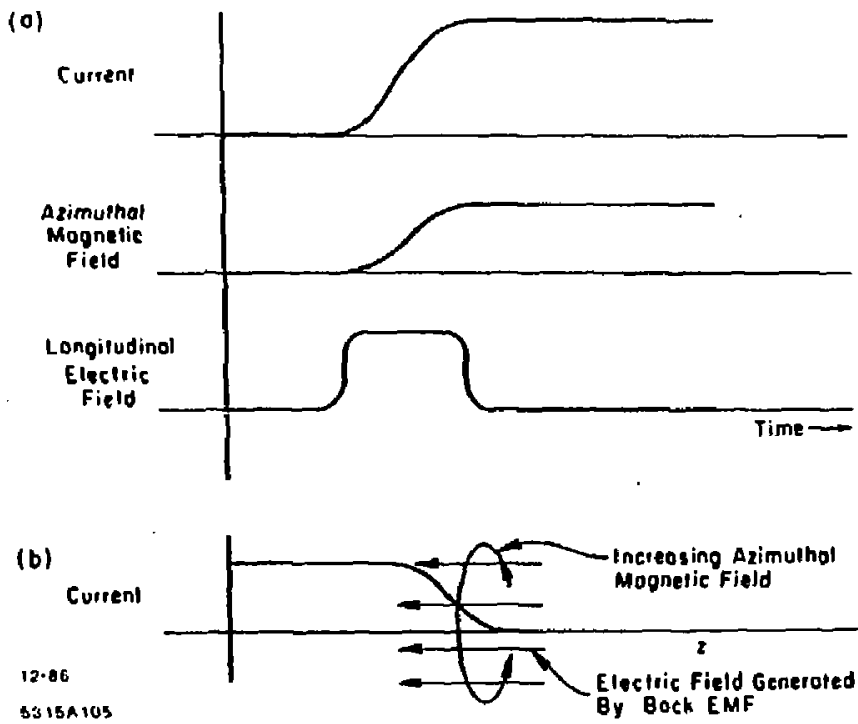

Fiz. 2.46. Fields as a "trapezoid" of charge passes a given point $z$. (b) As the current increuse a growing arimuthal magnetic field produces increasing flux lines in the 1 direction. These crowing hux liner are opposed by a back EMF which resulte in ar electric field in the $-f$ direction. (b) Fields induced at the front of the bunch oppose apace charge opreadins (note that the absysal wis is t). 
occur a the disks interact at close diatances. These "hernias" in phase epace may be an artifact of this model, due in part wo out calculation of $E_{\text {, }}$ near a diak.

3. The model calculates apace churge force in a amooth conducting cylin. der. This b an adequate madal in the nubharmonic buncher recion where

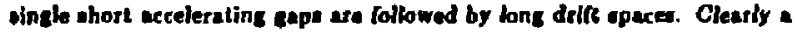
omooth conducting cylinder is a grest overaimplification of the bounderies In the diak-touded waveguide which intles up tho buncher and eccelerator wections. We choose to model the ayatem w though a smolh conductIne cylinder were located at the inner rodiun of the wavegulde, and the opace chare force are calculated accordingly. Wakefield efrect at the oubhurmonic buncher zapa and in the buncher have been neglected. Since momentum apread ensly in the ayatem $b$ important In determining the $\mathrm{t}$ nel bunch length, these ofiecte mur be important. Furthes modeling with MASK in needed to clarlfy thim inve. In the refocily-of-light nection the wakefields are calculated as thouph all particles were moving at upeed $c$. $\Lambda$. shown in Fies. 2.39(a) and (b), the wals felde ceuse a 10 to $16 \%$ change in bunch length.

4. The most important limitation of this model $b$ that it it a one-dimentional model; no attempt is made to model rudial motion, which in elearly coupled co longlludinal molion. In AINGMODEL wo coume that the radil of the diste and annuli remain constent throughout a given bunching element. The radil of the annuli are cakculaled by asuming that radial Coulomb repulsion is offect by focusins due to the reff-magnetic field of the beum and external aolenoidal focuuing. This calculation in deacribed in detall in the next aection.

The edvanteges of RWGMODEL are threefold: It in ewy to ute, 11 is hast to run, and mont importantly it was written and uable when CID was designed. A designer can make many runs in a lay, varying field strengths, phase shifts, drilt lengethe, and ocher parameters. A program of this kind is certainly uneful for getting an injector design underway, l.e., getting a "feel" for the problem at hand. In the future a prostam lite RINGMODEL is best used in conjunction with - mare powerful (but more cumbernomo) prozram like MASK. RINGMODEL, could be used to get a handle on the problem, while MAsK b used for finel confrmation of a rewonable dealgn. 


\subsection{Radial DyNamics}

As mentioned in Section 2.3, the lontitudinal dynamica of the beam have been modeled assumine that the beam radius in constant throughout a civen bunching region. Clearly, longitudinal apace charge forces are minimized if we choose a large a bearn radius as can be trangported through the beam pipe. In the subharmonic buncher drift spaces we choose large diameter beam pipe $[3.5 \mathrm{~cm}$ 1.D.) and allow the beam to fll the pipe to minimize apace charte effects. In the hicher power traveling wave structures a large beam radius leads to large radial emiltance growth a discused in detail below. Therefore, beam radius in the buncher and capture region must be chosen to allow longitudinal bunching while . keeping the radial emittance within apecifications.

\subsubsection{Radial Emittance Growth}

Figure 2.47(a) in a echemalic diagram of the electric and magnetic fields of the TM fundsmental mode in a smooth conductine cylinder. Arrows within the structure indicate the direction of lines of force on an electron. Electrons nenr point $A$ experience forces due to three components of the field:

1. The longitudinal electric field, $E_{z}$, focuse the electron loward point $A$. Thit point b stable loneitudinally.

2. The radial electric field, $E_{\mathrm{p}}$ exerts a defocusing force on the electrons.

3. The aximuthal magnetic field, $B_{\phi}$, exerts a radially focusing force on the electrons.

As we shall show directly, this force is weaker than the radial defocunine when $\rho$ of $\beta_{p}$ is lest than unity. Hence point $A$ is radially unstable. In the case of $\rho=\beta_{p}=1$ the two radial forcea cancel. In analogous fushion we find that point $B$ is unatable fongitudinally and atuble radially.

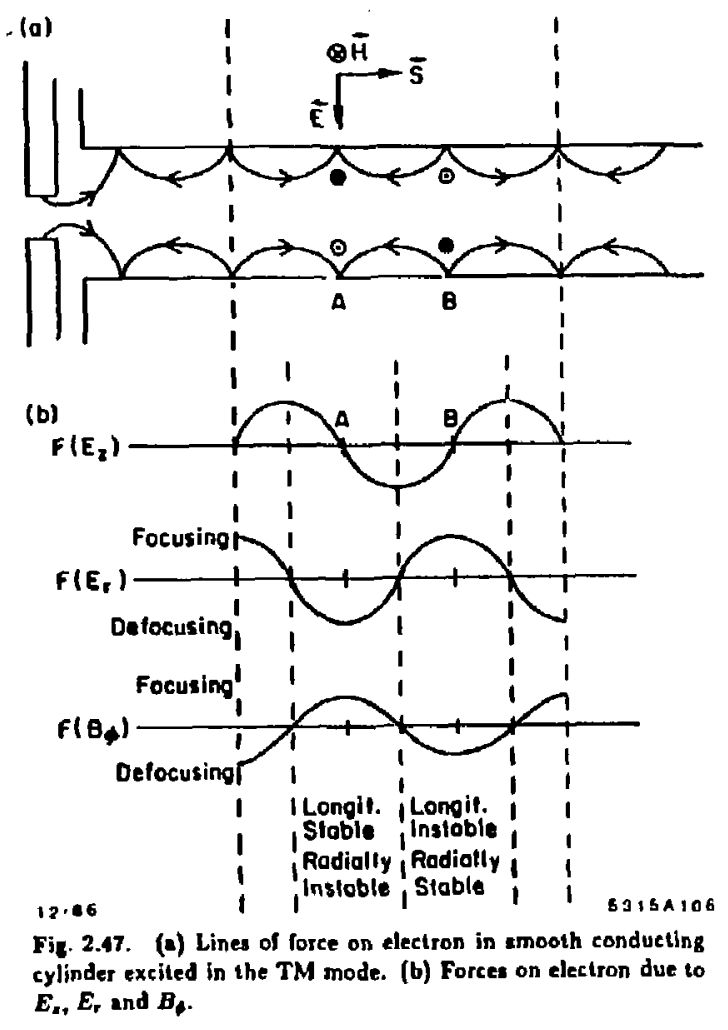


Figure $2.47(b)$ is a shemntic repreaentation of the efiect of the three force components on the electrons. Note that in Region $\mathbf{A}$, the rexion of greateat londitudinal bunching, the radial defocusing helds are at their maximum values. The gradient of the emplitude of the radial field b a alowly resying function in this region and thus all electrons in the linear resion of the longitudinal feld see essentially equal radial forces.

Rndial emitlance growth is not cauned primarily by the difierence in the amplitude of radial fields seen by particlea, but by the feet that particles initially at poolive longitudinal phases foel the radial force for a longer time. Conalder particles 1 and 2 in Fiz. 2.48. Both particles have the aume phue st the end of the atructure (i.e., both particles mava to point 3). But particle 2 apende more time in the structure and thus receive a larger radial momentum kick.

We now diacuse quantitutive eslimate of radial emittance growth in the CID injector.

Ao discussed in Rer. 17, the longitudinal electrk fiald in the TM mode in a cylindrical conductor in given by the real part of

$$
E_{1}=i E_{0}(s) J_{0}\left(t_{r} r\right) \exp \left|i\left(\omega t-k_{2} s\right)\right|
$$

where

$$
k_{r}^{2}+k^{2}=k^{2}=\left(\frac{2 \pi}{\lambda}\right)^{2}
$$

and $\lambda$ is the free apace wavelength of the wave. From Gause' theorem we find

$$
E_{r}=-\frac{1}{k_{r}}\left(k_{2} E_{0}+i \frac{\partial E_{0}}{\partial z}\right) J_{1}\left(k_{r} r\right) \exp \left[i\left(\omega t-k_{2} z\right)\right] .
$$

From $\vec{\nabla} \times \vec{B}=1 / c \partial \vec{E} / \partial t$ (c.e.s. unite)we find

$$
B_{4}=-\frac{1}{k_{r}} \frac{\omega}{c} E_{0} J_{1}\left(k_{r} r\right) \exp \left\{i\left(\omega t-k_{2} z\right)\right\}
$$

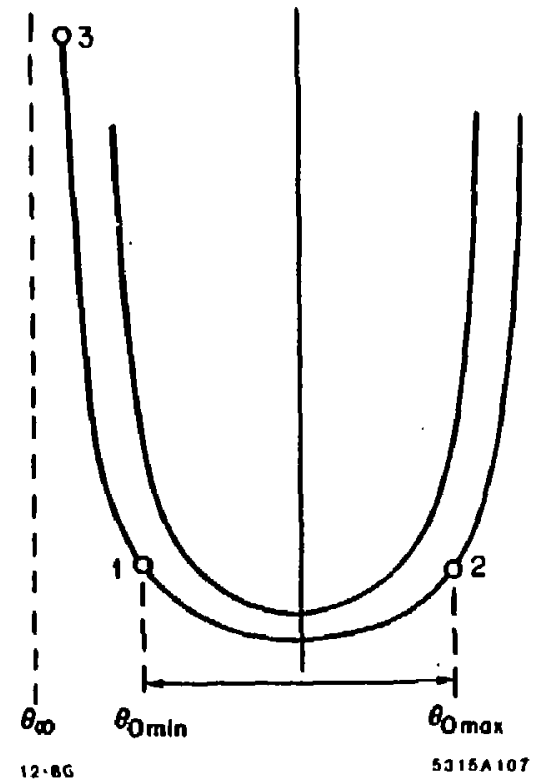

Tig. 2.48. Particlea with the same $\iota_{\infty}$ but with different $\Delta p_{r} \Delta$ the end of copture rezion. 
For imall values of $r$, we can approximate

$$
J_{0}(k, r) \approx 1 \quad \text { and } \quad J_{1}(k, r) \approx \frac{1}{2} k, r
$$

Thus

$$
\begin{gathered}
E_{1} \cong i E_{0}(s) \exp \left[i\left(\omega t-k_{z} z\right)\right] \\
E_{\mathrm{r}} \approx-\left(t_{\mathrm{H}} E_{0}+i \frac{\partial E_{0}}{\partial z}\right) \frac{\mathrm{r}}{2} \exp \left[i\left(\omega t-k_{2} z\right)\right]
\end{gathered}
$$

and

$$
B_{\varphi} \simeq-\frac{\omega}{c} E_{0} \frac{\tau}{2} \exp \left|i\left(\omega t-k_{2} z\right)\right|
$$

In regions where of $¥ 0$ (i.e., away from the fringins flelds at the beginning and end of the structure)

$$
\frac{\partial E_{z}}{\partial z}=k_{z} E_{0} \exp \left[i\left(\omega t-k_{z} z\right)\right]
$$

and

$$
E_{r} \cong-k_{x} E_{0} \frac{r}{2} \exp \left(i\left(\omega t-k_{z} z\right)\right]
$$

Thus

$$
E_{1} \simeq-\frac{r}{2} \frac{\partial E_{2}}{\partial z}
$$

We see that the radial fields are larzest (and defocueing) when the longltudinal field have the most gradient, l.e., at the phase atable longitudinal field null.

To calculate the emittance growth due to the sadial fields, we muat find the change in radial momentum due to the radial force on a particle in the electric and meenetic field. The Lorentz force law gives

$$
F=\frac{d \vec{p}}{d t}=c\left(\vec{E}+\frac{1}{c} \vec{v} \times \vec{B}\right)
$$

The radial component of the normalized torce is

$$
\frac{d p_{r}}{d t}=\frac{c}{m_{0} c}\left(E_{q}+\beta_{+} B_{q}-\beta_{d} B_{\phi}\right)
$$

where $p_{r}$ is the normalized radial momentum $=\gamma \beta_{r}$. In the $\mathrm{TM}_{01}$ mode under consideration, $B_{z}=0$ and the change in the radial momentum a a function of $z$ is given by

$$
\frac{d p_{1}}{d z}=\frac{\epsilon}{\beta m_{0} c^{2}}\left(E_{t}+\beta B_{t}\right) \quad \text { where } \quad \beta=\beta_{x}
$$

Setting $=w t-k_{y} 2$ and taking the real parts of Eqs. (2.73) and (2.74) we obtuin

$$
\frac{d p_{c}}{d z}=\frac{e E_{0} J_{1}\left(t_{\mathrm{r}} r\right)}{k_{\mathrm{r}} m_{0} c^{2}}\left(k\left(\frac{1}{\partial B_{0}}-1\right) \cos \theta+\frac{1}{\rho} \frac{1}{E_{0}} \frac{\partial E_{0}}{\partial z} \sin \theta\right\},
$$

where $\hat{\beta}_{w}=\left(k / k_{2}\right)$. For amall r

$$
\frac{d p_{0}}{d x} \cong \frac{e E_{0 r}}{2 m_{0} c^{2}}\left\{k\left(\frac{1}{\partial B_{-}}-1\right) \cos \theta+\frac{1}{\beta} \frac{1}{E_{0}} \frac{\partial E_{0}}{\partial x} \sin \varphi\right\} .
$$

The firt term of Eq. (2.82) is due to radial electric felds inside the structure, the second term is due to azimuthal magnetic fields and the bial term in due to fringe fields at the ends of the utructure. From Eq. (2.82) we vee that radial momentum arowth is a function both of radius and phase. It is the functional dependence on phase that zives rise to radial emiltance growth. If $\mathrm{Eq}_{\mathbf{q}}$ (2.82) were independent of 4 , we could offset the linesy sadial force with solenoidal focusing.

In the general case, Eq. (2.82) is not integrable by simple analytic techniques. $A$ detailed analysis of radial emittance srowth requires computer modeling. We thus set ourceives the more modest soal of atudying Eq. (2.82) in a special case 
which leade to an integrable form. This opecial case at least allows us to know the order of magnitude of radial emittance growth and eubsequent limitations on longitudinal bunching. In the esue where the phese veloclly of the atructure, $\boldsymbol{\beta}_{\text {, }}$ is equal to unity, the cont term of Eq. (2.02) becomet

$$
k\left(\frac{1}{\beta}-1\right) \cos \theta=-\frac{d \theta}{d z} \cos \theta
$$

a given in Eq. (2.5), and Eq. (2.82) becomes

$$
\frac{d p_{r}}{d z}=\frac{e E_{0} r}{2 m_{0} e^{2}}\left[-\frac{d \theta}{d x} \cos \theta+\frac{1}{\beta E_{0}} \frac{\partial E_{0}}{\partial x} \sin \theta\right] \text {. }
$$

The Arat term of Eq. (2.84) becomes negligible w $\rightarrow-00^{\circ}$; that is, the firat term contribute to traneverue emalttunce growth only in the capture region. The second term contributes only in reglons of eppreclable fringing fields.

Asuming $r$ ro and incegrating to abtitury $\approx$ beyond the caplure reglon

$$
\int_{0}^{t} \frac{d p_{r}}{d x} d z=\frac{e r_{0}}{2 m_{0} t^{2}}\left\{-\int_{0}^{\infty} E_{0} \frac{d \ln \varphi}{d x} d x+\int_{0}^{\infty} \frac{1}{\beta} \frac{\theta E_{0}}{d x} \sin \theta d x\right\} .
$$

Awuming that Eo(e) is alowly varying over most of the capture region and that

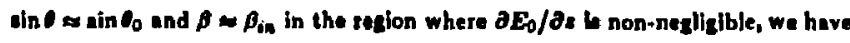

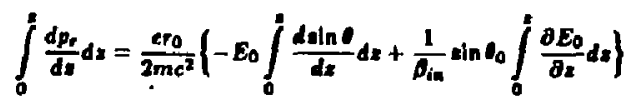

integrating we have

$$
\Delta p_{r} \cong \frac{\operatorname{ero}}{2 m_{0} c^{2}}\left\{E_{0}\left(\sin \theta_{0}-\sin \varphi_{\infty}\right)+\frac{1}{\partial_{i n}} \sin \theta_{0} E_{0}\right\}
$$

or rearranging terme

$$
\Delta p_{r} \cong \frac{e r_{0} E_{0}}{2 m_{0} c^{2}}\left[\left(1+\frac{1}{\rho_{\text {is }}}\right) \sin \omega_{0}-\operatorname{in} \theta_{\infty}\right]
$$

where $\beta_{i n}=$ nomalized velocity of the particlea at they enter the eapture region.
Radial emittance arowth results from a difference in the total radial momentum kick for particles which enter at different phanes. We are concerned with the variation of $\Delta \mathrm{pr}$ as initial lanzitudinal phase, $\boldsymbol{O}_{0}$, chanzes:

$$
\frac{d \Delta_{P r}}{d D_{0}}=\frac{c E_{0} r_{0}}{2 m_{0} c^{2}}\left\{\left(1+\frac{1}{\theta_{i n}}\right) \cos \theta_{0}-\frac{\sin \theta_{0}}{\sin \theta_{\infty}} \cos \theta_{\infty}\right\} .
$$

From Eq. (2.87) we the that radial amittance growth in the cepture region is minimized if

1. We choose to make the beam rediun, ro, we nmall as possible.

2. We choose a low teld atrength, $E_{0}$, in the eapture region.

3. If we capture the bunch on the RF erest, $\cos \ell_{\infty} \cong 0$ and the second term - in Eq. (2.87) is neglibible. To minimize the Brat term, we should choose $t_{0}$ away from the longitudinal feld null, which results in a amaller value of $\cos 6$.

Conditione 1, 2, and 3 all kead to poorer longltudinal bunching.

Thus our bunching technique allows for greater Jonzitudinal bunching only ot the expenee of radial emittance growth. We can extimnte the amount of radial emiltanes growth in the CID aceokerator capture region. From Fis. 3.D(d) (In Sec. 3.2), we eatimate that the CID bunch eubtenda nome $60^{\circ}$ at the entrance to the accelerator structure. If one asumea capture In the vlelnity of the creat, the second term in Eq. (2.a7) iv quite amall. Aasuming $\beta_{0}=\beta_{\text {in }}=.75$, $e E=$ $170 \mathrm{KV} / \mathrm{cm}$, and $r_{0}=.25 \mathrm{~cm}$ (eee Sections 2.4 .2 and 3.2 ), the epread in radial momentum is

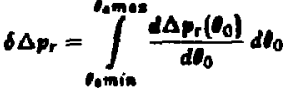

$$
\begin{aligned}
& =\frac{e E_{0+0}}{2 m_{0} c^{2}}\left(1+\frac{1}{\beta_{i n}}\right)\left[\sin 30^{\circ}-\sin \left(-30^{\circ}\right)\right\}=.40 \text {. }
\end{aligned}
$$

The radial emittance $t$, is given by $r \delta \Delta p_{r}$ 


\subsubsection{Radial Focusine}

$$
c_{r} \text { (estimate) }=2.5 \times 10^{-4} \text { radian meter } .
$$

As discussed later in Section 3.3 , the CID emittance has been measured. For $5 \times 10^{10}$ ejectrons captured, the measured emittence is

$$
\text { C,(messured) }=1.5 \times 10^{-4} \text { radian meter (invariant) }
$$

We see that our estimated emittance is pessimistic, but in of the correct order of meznilude.

The astumptions necessary to get an analytle nolution to Eq. (2.82) are not unrewonable in the caplure region, but do nat really apply to the buncher region (where $B_{u}=.75$ ). However, the phuse apace orbits of the particles in the buncher are quanlitatively quite aimilar to their orbits in the capture region, and wo can look to Eq. (2.87) to euggest trends in the buncher. The fields in the buncher are lower by $a$ factor of $\$ 10 \$$, but the initial bunch length is larser by $\&$ faclor of three, which means that foin $\nu_{0}-$ win $\left(-\phi_{0}\right)$ ) is lerger by a factor of two, and we would expect the buncher contribution to radial eniltance growth to be smallor than that of the capture resion by a factor of two or more; at lower field atrength it may even be negligible a compared to the capture region.

Oae more point is worth noting. We eatimate that the radial emittonce at the CID zun is approximately

$$
\epsilon_{\text {oun }}=3 \times 10^{-6} \text { radian meters. }
$$

One cometimes reads that the radial emittance crows "by a factor of $x^{n}$ due to RF Gelds in bunching and capture regions. This is misleading in the aense that the RF Gelds would cause the ane amount of radial emittance growth even if the redial emittance at the gun were negligible. Soying that the emittance "orowa by a factor of $x^{n}$ might lead one to think that emittence growth due to RF can be lesened by a lower gun emittance, which is not the case.
Radial acceleration in the presence of a solenoidal magnetic field is given by

$$
\gamma m_{0} \bar{r}=\gamma m_{0} r \dot{\phi}^{2}+\frac{e}{c} r \dot{\phi} B_{\alpha}+\frac{2 e \rho_{l}}{r}-\epsilon \frac{2 I}{r c} \rho
$$

where

$$
\begin{aligned}
p_{t} & =\text { charge/unit length }=J / B C \\
I & =\text { beam current. }
\end{aligned}
$$

The first term in Eq. (2.91) is due to the accelerating coordinate nystem. The second term is the focusing force due to the external longitudinal magnetic field, the third in the defocusing force due to spece charge and the last in the focusing force of the self-magnetic field of the beam. The azimuthal velocity of the beam i can be abtained by considering the tate of chenge of angular momentum as electrons pars from the cathode to the interior of the solenoidal maenetic field. ${ }^{19}$ The rate of chenge of ancular momentum is civen by

$$
\begin{aligned}
\frac{d}{d}\left(r m_{0} r^{2} \phi\right) & =r F_{\phi}=r\left(\frac{e}{c} \bar{v} \times \bar{B}\right) \\
& =r \frac{e}{c}\left[-r B_{s}+\dot{d} B_{r}\right] .
\end{aligned}
$$

Multiplying by 2ade we heve

$$
2 \pi d\left(7 m_{0} r^{2} \phi\right)=-\frac{c}{c}\{2 \pi r(B, d r-B, d x)\}
$$

Upon examining Fig. 2.49 we see that the magnetic flux through the beam boundary is given by

$$
d \psi=\vec{B} \cdot d \vec{a}=\vec{B} \cdot\left(\frac{d \varepsilon}{d \theta} f+\frac{d r}{d \theta} \xi\right) d s r d \phi
$$

where $d s$ is an infinitesimal perpendicular to $d \phi$ along the beam envelope. 
$d \phi$

The flux through a small bend of the boundary is found by integrating over

$$
d \psi=2 \pi r\left(B_{2} d r-B_{1} d z\right) .
$$

Equatine (2.93) and (2.95) and integrating we have

$$
\int d\left(\tau m_{0} r^{2} \phi\right)=-\frac{e}{2 \pi c} \int d \psi
$$

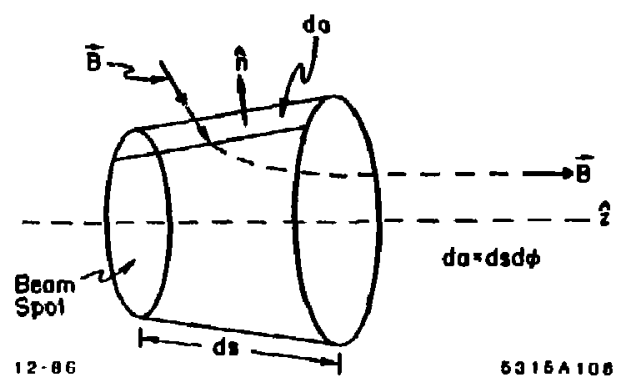

Fig. 2.49. Magnetic aux.through the beam boundary.

We define $\psi_{c}$ an the maznetic aux through the beam apot at the cathode and assume that the electrons have no arimuthal velocity leaving the cathode.

Equation (2.96) yield.

$$
\phi=-\frac{c}{2 \pi \tau^{\prime} m_{0} e r^{2}}\left(\psi-\psi_{c}\right)
$$

Thus the eximuthal velocity of the beam is proportional to the total change in flux across the beam surface. Inide the salenoid where the field is uniform in the $l$ direction, $\psi=\pi r^{2} B_{*}$. With a little manipulation Eq. (2.91) becomes

$$
F=-r\left(\frac{c B_{b}}{2 \tau m_{0} c}\right)^{2}\left[1-\left(\frac{\psi_{c}}{\phi}\right)^{2}\right]+\frac{2 c t}{\gamma m_{0} e r}\left[\frac{1}{\beta}-\beta\right] .
$$

From Eq. (2.96) we see that the aux at the cathode muat be less than the flux inside the eolenoid for any nat focuning to occur. For the common case of the cathode shlelded from the wolenoldal mognetic Beld, Eq. (2.98) reduces to

$$
\tau=-r\left(\frac{\epsilon B_{2}}{2 \gamma m_{0} c}\right)^{2}+\frac{2 e I}{\gamma m_{0} e r}\left[\frac{1}{\beta}-\beta\right] .
$$

If the beam is focused to a waist $(\dot{r}=0)$ at a given radius $r_{0}$, the condition for a beam of constant radius (Brillouin flow) thereafter is

$$
r\left(r_{0}\right)=0
$$


To meet this condition the field inside the solenoid must be

$$
B_{2}=\sqrt{\frac{.8}{300} \frac{1}{\rho_{\gamma}}\left(\frac{m_{0} c^{2}}{c}\right) \frac{1}{r_{0}^{2}}},
$$

whete $m_{0}=2 / e$ is measured in volt, $I$ in amps, ro in centimetern, and $B$ in Gauss. The original CID cesign called for a beam radius of $\sigma=.8 \mathrm{~cm}$ in the subhermonic bunchers and the drift spaces following them. The design called for a beam radius of $\theta=.8 \mathrm{~cm}$ in the $\mathrm{S}$-band buncher and capture regions. For an initial current of 15 amps and initial enercy of $200 \mathrm{kV}$, the field needed to maintain a beam radius of. $\mathrm{c} \mathrm{cm}$ is

$$
B_{*}=182 \text { Gaun . }
$$

The field must become atronger $\Delta$ bunching proceds and the current increases.

During much of the CID development effort we operated with the parameter outlined in Table 3.5 (see Sec. 3.2). The focuning solenoids were run at currents which produced the field profile shown in Fis. 2.50. Entimating the peak eurrents from Fig. 2.50 as the benm in bunched, we can calculate the beam radius. Our calculations yield sverage beam radis of about half of the deaign radiun, or $r=$ $2.5 \mathrm{~mm}$. As diseused in the last section, smaller beam radii in the buncher and capture resions cacrifice optimal longitudinal bunching for a decrease in radial emithnce growth. Thia operating mode came about in the days when transverse beam breakup eeverely limited transminsion through Sector 1 to the damping ring. Thus trading longitudinal bunching for less emittance growth may have increased overall tranamission to the damping ring. Since a atronger focusing tattice has been inalalled in Sector 1 , radial enitince growih is not likely to be the limiting factor in total charge transmitted to the damping sing.

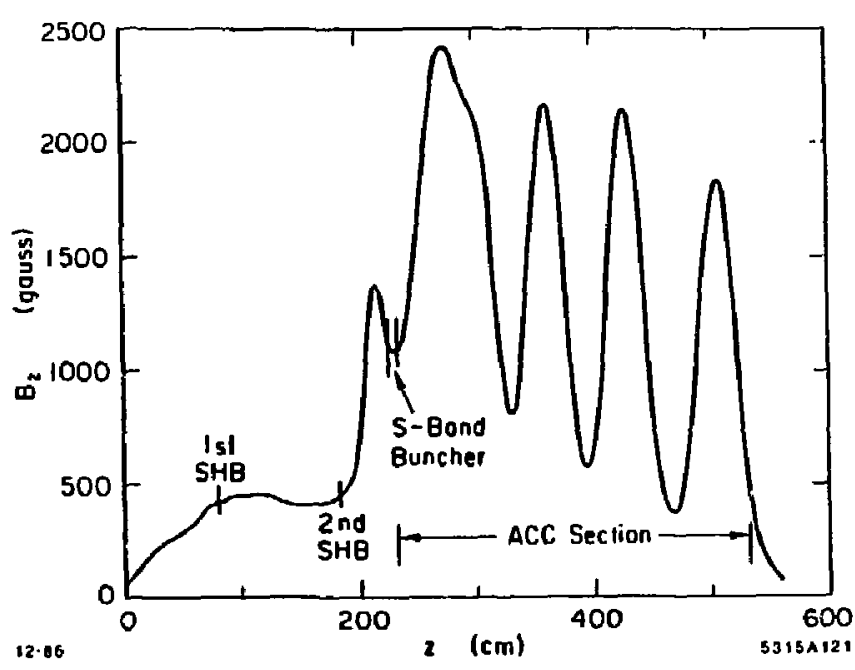

Fic. 4.50. Inongitudinal magnetic field profile in the CID subharmonic prebunchers, S-band buncher and eapture region. 


\subsection{HaRdWAFE DEscription OF THE CID INJECTOR}

CHAPTER 3.

PERPORMANCE OF GID

The collider injector dlacunaed in Seetion 2.2.3 was asembled and comminaloned in the apring of 1981.12 From 1981 to 1984 the injector was used extensively to study the dynamies of high current aingle bunch beams in accelerator atructures and to provide single bunch beame for damping ring atudies." ClD was also avallable intermittently for atudias to underatand and Improve injector performance. 10,20 Since the fall of 1004, CID has been uned continuoualy to provide high cursent electron bunchen to the 8LC. From the spring of 1081 untll apring of 1984, by far the moal cerious and time-consumins probletm of the injector/Sextor 1 development project wa our inablity to tranamit high current ingle bunch beame from CID through Seclor 1 to the dempine rine. We were unable to transmil more than $2 \times 10^{10}$ electrona in a aingle bunch through fector 1 becauae of misaliznment between CID and the old main injector and tranuverse emittance srowth due to wake fielda." Due to this impase most of the meanurements discusued in this cheptet were made on bunches containing approximately $5 \times 10^{10}$ electrons at the end of the CID accelerator vection, the lower limit of the SLC opecification.

In the next wection we describe the hardware that makes up the CID injector; we then deacribe a "kypical" operaling mode which produce sinute bunchea enntaining $5 \times 10^{10}$ electrons. We compare this "typical" mode of operation to our initial design and to an updated RINGMODEL calculation. Finally, we ditcuas trantverse emittance measurements.
As discussed in Section 2.2 .3 the collider injector consiata of a thermionic electron gun, two gap-and-drift prebunchersat the 16 th oubharmonic of the BLAC S-band accelerator frequency, $=10.5 \mathrm{~cm}$ lone traveling-wave buncher and a threemeter lons S-band travelling-wave accelerator aectlon, of which roughly the firat $20 \mathrm{~cm}$ act as the capture recion (see Fit. 3.1). Euch component of the ayatem lo discusared in detail below.

\subsubsection{Electron Gun}

Electron pulet for CID are provided by a high current, thermionic gun (see Fig. 3.2). The cun conaist of a diepenser eathode, a biased grid, focus electrode, anode and an avalunche-type pulser dealgned by R. F. Koontz." 1,13 Untll the aummer of 1024 the pulser, cathode and grid were mounted inaide a high voltuge tank filted with one atmoephere of SF. This tank dependably atood of $-150 \mathrm{kV}$, but way lew rellable at higher voltages; thun the gun was regularly run at $-180 \mathrm{kV}$. In the aummer of 1984 the $S F_{0}$ tank wat replaced by a moothourfaced high voltage deck that reliably ntands off $-200 \mathrm{kV}$ in alr. Becaure moet of the measurements reported here took place before nummer 1981 , all computer oimulations and mearurements in this report were made at cathode voltuges of -150 \&V.

The grid bies vollage can eaily be varied between $60 \mathrm{~V}$ and $200 \mathrm{~V}$. At the bles voltuge is reduced, the peak current of the gun pulse increases from 0 to a maximum of 10 amps. Unfortunutely, the width of the tun pulse is a strons function of peat current (see Fis. 3.3). The pulser produces a roughly Gaussianshaped pulse of fixed FWHM. An the bien in applied, the pulse in "clipped" from the bottom, leaving a "amaller" Gavasian.

At a bias of $60 \mathrm{~V}$ the thermionic iun can easily produce up to $2.5 \times 10^{11}$ electrons (10 amps, $1 \mathrm{~ns}$ FWHM) in one pulse. This pulse is much too wide to 


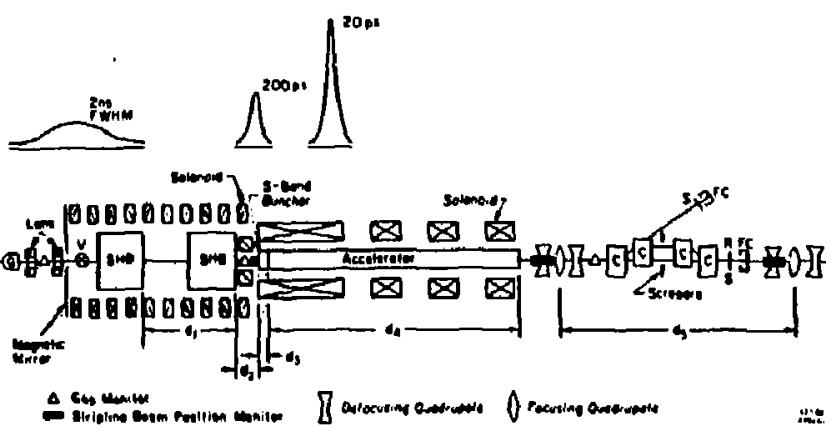

Fis. 3.1 Schematic of collider injector in spring 1984.

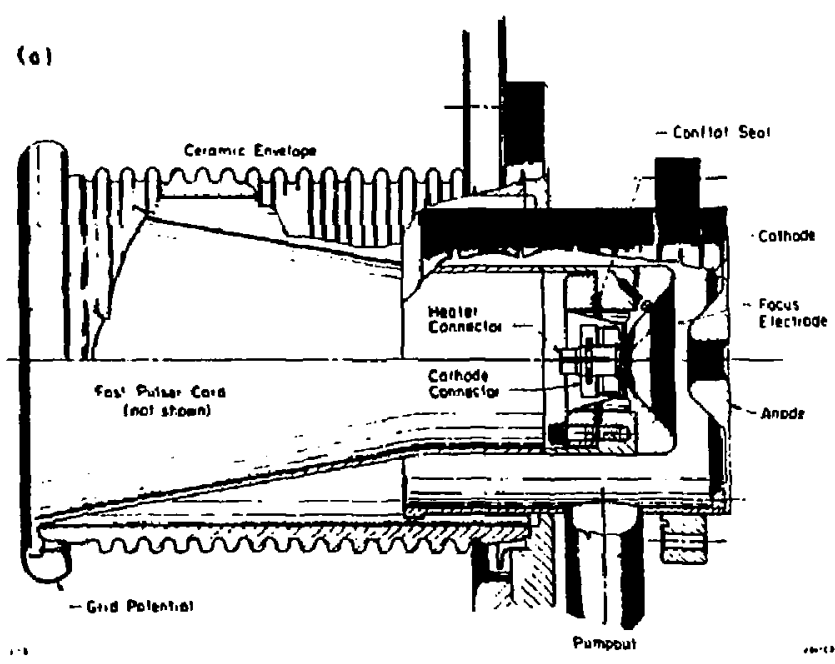

Fig. 3.2.(a). Cut-away view of the CID thermionic gun essembly. 


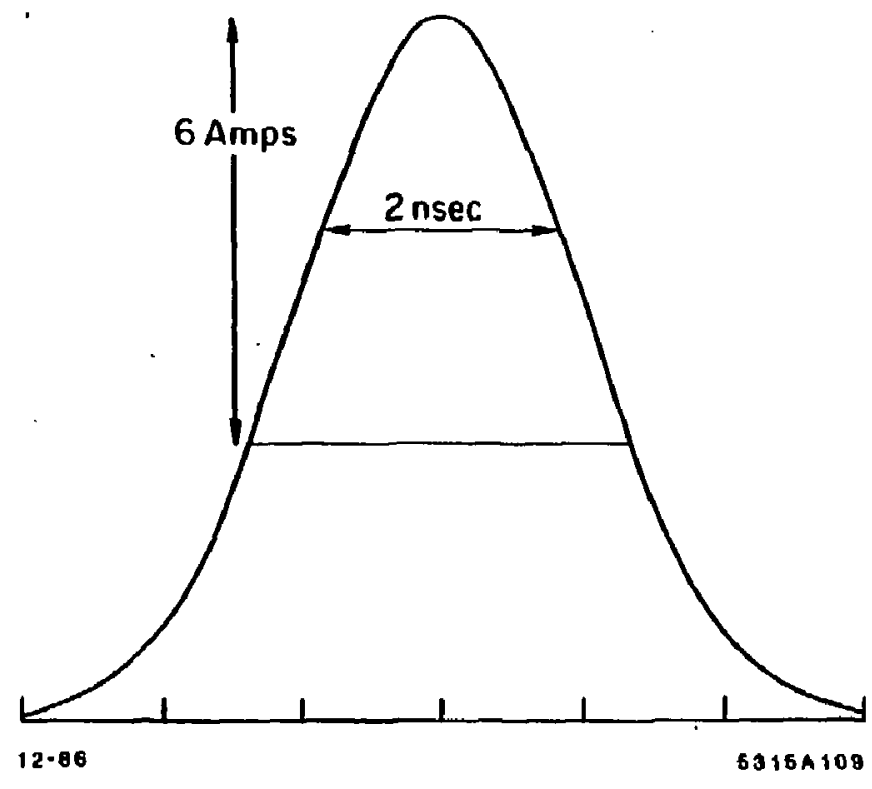

Fig. 3.3. Sketch of e spece cherge Jimited Gauseian zun pulae which produces a 6 A, 2 nu FWHM pulae at a bias of $150 \mathrm{~V}$.

126

127 
be captured into a single S.band bunch. Even at $7.5 \times 10^{10}$ electrons per pulse, the CID can produces a pulse twice as wide as anticipaled in the original desitn. Rather than a 12 amp and $1 \mathrm{n}$. FWHM pulse, the CID Eun produces a 6 amp, 2 ns FWHM pulse. This affect the bunching process.

Table 3.1. Peak current and F WHM

veruus bies voltuge on the CID gun.

\begin{tabular}{|c|c|c|c|}
\hline $\begin{array}{c}\text { Bist } \\
\text { Voltage }\end{array}$ & $\begin{array}{c}\text { Peak } \\
\text { Gurrent }\end{array}$ & FWHM & $\begin{array}{c}\text { Total } \\
\text { Charge }\end{array}$ \\
\hline $65 \mathrm{~V}$ & 8.5 & 1.2 & $22 \times 10^{10}$ \\
\hline $150 \mathrm{~V}$ & 6.0 & 2.0 & $7.5 \times 10^{10}$ \\
\hline $290 \mathrm{~V}$ & 5.0 & 1.1 & $3.4 \times 10^{10}$ \\
\hline
\end{tabular}

3.1.2. Subharmonic Bunchert

The eap-and-drift prebunchers each consiat of a atendine wave bunchar ot the 16th subbarmonic of 5-band followed by an appropriate drift epace. The ubhormonic binchers (SHB) are one-quarter wavelength, conxial cavitiea, with a $4 \mathrm{~cm}$ tap in the innez conductor at one end of each eavlty (see Fig. 3.4). The cavities are driven at $170.5 \mathrm{MH}$ in the TEM mode. As thown in Fir. 3.4, the sap in the inner conductor distorts the transverse electric field, producing a langitudinal electric field ecross the gap.

The cavities have unlonded $Q$ 'o of approximately 12,000 . The gap voltuse, $V$ as a function of time is given by

$$
v(t) \propto\left(1-e^{-\left(\omega / 2 Q_{2}\right) k}\right)
$$

where $Q_{L}$ is the londed $Q$ of the cavities.

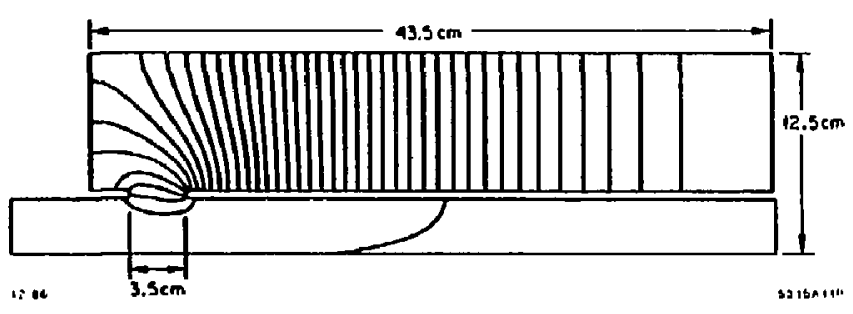

Fic. 3.4. Crose tection of a quarter-wave length coaxial wubhurmonic buncher cavity showing elertric field lines. 
At the time of CID's construction, the earliest svailable trituter came $25 \mu$ before beam time. For $\approx Q_{L}$ of 12,000 , the cavities reach $95 \%$ of their atendy. atate fields after $25 \mu \mathrm{s}$. By overcoupling the cavitien we reduced the loaded $\boldsymbol{Q}$ to epproximately $\mathbf{4 0 0 0}$, which decreased the filling time by a facter of three, so that the cavities were less than .1\% below their ateady atalo value after $25 \mu$. As SLC callo for two electron pulses apaced 89 na apart, we need to know the difference in sap voliage for the two pules. Let $\Delta \boldsymbol{V}$ be the difference in the gap voltage between the pulses and $\Delta t$ the time between pulves:

$$
\frac{\Delta V}{V}=\frac{(d V / d t) \Delta t}{V}=\frac{\omega}{2 Q_{L}} \cdot \frac{e^{-\left(\omega / 1 Q_{L}\right)}}{1-e^{-\left(\omega / 2 Q^{2}\right)}} \Delta t
$$

For our eavities we find

$$
\begin{array}{ll}
Q_{L}=12000 & \frac{\Delta V}{V}=3.6 \times 10^{-1} \\
Q_{L}=4000 & \frac{\Delta V}{V}=2.7 \times 10^{-1}
\end{array} .
$$

In either case, the change in gap voltage between bunchea is negligible. Given the resonant frequency and $Q_{0}$, the shunt impedance of the cavities has been calculated by SUPERFISH, a compuler code which solves Maxwell's equation. in the prenence of eylindrically aymmetrical boundary conditions. ${ }^{24}$ The cavity thunt impedance are approximately $2.2 \times 10^{\circ} \mathrm{n}$.

The steady state gap voltage in each cavity b proportional to

$$
V_{\text {rap }} \text { or } \sqrt{R_{1} P}
$$

Typical operating voltages for the cavities are $V_{\text {op }}=42 \mathrm{kV}$ for the first gap and $65 \mathrm{kV}$ for the second gap.

As diacussed extensively in Chapter 2, optimum bunching by the subharmonic bunchero is accomplished when we exploit the curvature of the ainusoidal RF by shifting the phese of the null of the eine wave with reapect to the center of the electron pulse.

The phases of the SHB cavilies relative to the phases of the S-band buncher and accelerator have not been meaured directly. We were able to measure the difference in time of fight of the electrons from the gun to just downstream of the accelerstor aection with the SHB gap volteges on and off. Figure 3.5(a) shows a gap monitor aignal from junt downatream of the aecelerator section with the SHB power off. The 2 ne FWHM Gaussian ahaped gun pulse is captured onto approximately ten adjacent S-band creats. The aignal on the left of Fig. 3.5(b) in the anme 2 ne gun pule with the SHB power on with no phase adjustment. The signal on the right is the 2 ns gun pulse with the $8 H B$ phases adjuated to achieve the most electrons on a aingle S-band creat. Note that the electrona now arrive at the gap monitor $\sim 700$ na later; this $i s$ due to the phase shirt in the subharmonic bunchers. At diecuned in Section 2.2.1, the wubharmonic bunchers are more effective if the phase of the RF is ahifted by $30^{\circ}$ or 10 , decelerating the center of the electron gun pulne. The center of the bunch arrives at some downatream point (i.e., the gap monitor) at a later time than it would have had the SHB'. been ofi. The difference in arrival time at the gap monitor between the phase shifted and non-phawe shifted bunches is

$$
\Delta l=t s H-t_{N S H}=\frac{d_{1}}{\beta_{1} c}+\frac{d_{2}}{\beta_{2} c}-\frac{\left(d_{1}+d_{3}\right)}{\beta_{0} c}
$$

where

$$
\begin{aligned}
t_{S H}\left(t_{N S H}\right)= & \text { time of tight of the center of the bunch with the } \\
& \text { phese of the SHB's ehifted (not ohilted) } \\
\beta_{1}\left(\beta_{3}\right)= & \text { velocity of the center of the bunch after the first } \\
& \text { (second) SHB } \\
\beta_{0}= & \text { velocity of the center of the bunch with the SHB'b of } \\
d_{1}\left(d_{2}\right)= & \text { drift distence following the first (necond) SHB's } \\
& \text { (nee Fig. } \left.3.1, d_{1}=108 \mathrm{~cm}, d_{2}=36 \mathrm{~cm}\right) .
\end{aligned}
$$


$\beta_{1}$ and $\beta_{2}$ are given by

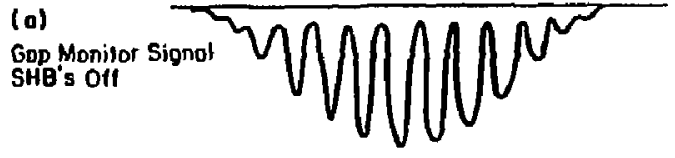

(b)

Gop Monitor Signal

SH8's on
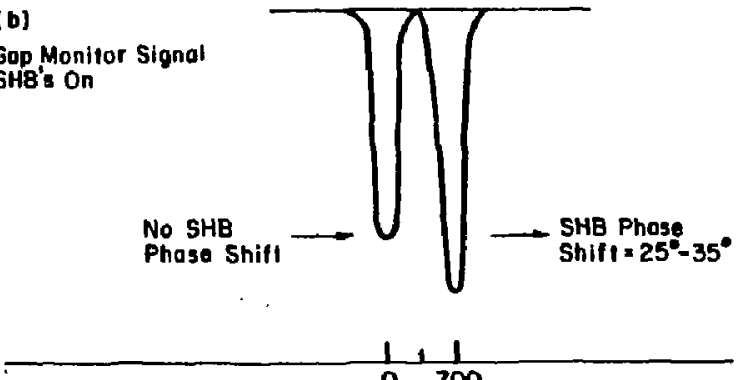

$12 \cdot 16$

1 (ps)

$5313 A 111$

Fig. 3.5. Beam current versus time as messured by a gap monitor located jurt downstren of CID's threesmeter accelerstor section. (a) Gap monitor vignal with subharmonic bunchers ofi. (b) Gep monitos sizmal with subharmonic bunchers on. No phese shift resulis in the signal on the left /the compressed bunch arrives at the cap monitos at the same time $\Delta$ the peal of the uncompresied bunch of Fig. 3.5(a)). A phare shift of $25^{\circ}-35^{\circ}$ results in the signal on the right. The thift has resulted in lower veloeilies, thus the later arrival time al the cap moniter. More electrono have been captured into s ingle S-band bunch produc. Ine a bigher peak tignal.

$$
\beta_{1}=\sqrt{1-\frac{1}{\gamma_{3}^{2}}}=\sqrt{1-\frac{1}{\left(\frac{E_{0}-E_{1} \ln t}{m_{n_{2}} t}\right)^{2}}}
$$

and

$$
\theta_{2}=\sqrt{1-\frac{1}{\gamma_{2}^{2}}}=\sqrt{1-\frac{1}{\left(\frac{E_{1}-\left(E_{1}+E_{2}\right) \sin d}{\left.\operatorname{mog}^{2}\right)^{2}}\right)^{2}}} .
$$

Actual CID operating parameters are given in Table 3.5.

Table 3.2 shows the time of Aight as a function of phase shift in the SHB' where we have aseumed that both bunchers are shifted by the same amount of phase.

Table 3.2. Time-of-tight as a function of sHB ph
\begin{tabular}{|c|c|}
\hline $\begin{array}{c}\text { Phese Shift } \\
\text { (degrees at 178.5 MHz) }\end{array}$ & $\begin{array}{c}\text { Time-of-flight } \\
\text { (pate) }\end{array}$ \\
\hline 35 & 840 \\
\hline 30 & 690 \\
\hline 25 & 560 \\
\hline 20 & 130 \\
\hline 15 & 310 \\
\hline
\end{tabular}

From Table 3.2 we aee that 15 to $20^{\circ}$ phase shift should result in the center of the bunch being captured one S-band bucket later than it would be captured with no phese thilt; 25 to $35^{\circ}$ phase thilt resulta in the bunch being coptured two S-band buckets later. In tuning CID one usually finds that the most charge is taptured two buckels hter, implying as shift of $\sim 30^{\circ}$ an expected.

The SHB's can compreas $\sim 2.5 \mathrm{~ns}$ of the gun pulse into one cycle of S.band. Electrons at greater distances from the center of the bunch are lost or ch, tured in to earlier or later S-bund buckets. 


\subsubsection{The Traveling-Wave Buncher}

The buncher is a traveling wave diak-londed atsucture with phase velocity $\boldsymbol{\beta}_{r}=$.75. The buncher consiate of four caviliea. AF power from the CID klyatron is coupled into the firat eavity, fown through the middle cavilies and is extracted from the fourth cavity. The buncher operate in the $2 \pi / 3$ mode (l.e., three cavities per guide wavelength, $\lambda_{f}=\rho_{-} c / f$, where $f$ in the S-band frequency). Thus the four cavities are one free space wavelength long. The main features of the buncher are eummarized in Table 3.3 .

Table 3.3 Bunchet puramelers.

\begin{tabular}{|c|c|}
\hline Frequency & $F=2050 \mathrm{MHz}$ \\
\hline Disk aperture dismeler & $2 \varsigma=2.26 \mathrm{~cm}$ \\
\hline Shunt impedance & $r / Q=30.9 \mathrm{ohm} / \mathrm{cm}$ \\
\hline Cavity inuide diameter & $26=8.33 \mathrm{~cm}$ \\
\hline Group velocily & $v_{0} / c=0.0118$ \\
\hline Dink thickneas & $l=.884 \mathrm{~cm}$ \\
\hline Peak power & $\delta .4 \mathrm{MW}^{\star}$ \\
\hline Periodic length & $d=2.626 \mathrm{~cm}$ \\
\hline Peak field & $110 \mathrm{kV} / \mathrm{cm}^{*}$ \\
\hline
\end{tabular}

•Maximum evailable.

The buncher is coupled to the CID accelerator eetion by means of a $1.0 \mathrm{~cm}$ thick copper specer with $\mathrm{a} .95 \mathrm{~cm}$ inner radius. Power for the buncher 1 proulded by the CID klystron by way of $=7.25 \mathrm{~dB}$ coupler located in the CID vault. Approximately 5.6 MW of klyatron power b coupled to the buncher. A phase ahifter and attenuatar downstream of the $\mathrm{T} \mathrm{dB}$ coupler allow for independent control of buncher phase and power.

\subsubsection{Accelerator Section}

The CID accelerator rection is a standard SLAC three-meter accelerator section which is described in great detail in Rel. 25 . Briefly, the section is made up of 86 cavities whose disk aperture diametera and inside cavity diameters vary wuch that the field gradient acrose each cavity is conatant along the section. The accelerator aection has a phare veloeity $\beta_{0}=1$ and operates in the $2 \pi / 3$ mode. Features of the accelerator sectlon are aummarized in Table 3.4 .

Table 3.4 Acceleralor Parameters

\begin{tabular}{|c|c|}
\hline Frequency & $f=2856 \mathrm{MHz}$ \\
\hline Strueture type & Conatent gradient \\
\hline Shunt impedence & $t=67 \mathrm{Mn} / \mathrm{meter}$ \\
\hline Diak aperture diemeler & $2 a=2.62-1.92 \mathrm{~cm}$ \\
\hline Group velocily & $v_{\mathrm{a}} / \mathrm{c}=0.0204-0.0065$ \\
\hline Gevily inaide diameter & $2 \mathrm{~b}=8.35-8.8 \mathrm{~cm}$ \\
\hline Peal power & $25 \mathrm{MW}$ \\
\hline Diak thickneas & $t=.584 \mathrm{~cm}$ \\
\hline Peak lield & $178 \mathrm{KV} / \mathrm{cm}$ \\
\hline Perlodic length & $d=3.5 \mathrm{~cm}$ \\
\hline
\end{tabular}

Power to the CID section 1 provided by the CID klyatron, which has e peak power of $37.1 \mathrm{MW}$. After wavetuide attenuation and coupling to the S-band buncher, $25.3 \mathrm{MW}$ of power seaches the three-meter accelerntor section. Given the Ref. $17 \mathrm{r} / Q$ of $42 \mathrm{n} / \mathrm{cm}$, this yields a peak field gradient of $178 \mathrm{kV} / \mathrm{cm}$. 
3.2. Comparison of a Typical Performance to Calcllated PerTORMANCE OF CID

As discussed in the introduction to this chapter, moat of the development work on CID concerned captured bunche containing approximately $5 \times 10^{10}$ electrons. In this section we present the performance data for a typical operating setup and compare it to results predicted by the computer simulation prosram, RINGMODEL. The operating parameters are summatized in Thble 3.5 and deucribed in detsil below.

The parameters of Table 3.5 were used a input to the RINGMODEL computep prosran. Fizures 3.6-3.11 lllustrate the predictions of the model for bunchine and capture of $\& 6$ amp, $2 \mathrm{na}$ FWHM, Gausian gun pulse. The results of the simulation are deacribed below. Finally the bunch produced by the CID injector is compared to the jesults of the aimulation.

As stated earlier, CID was originally derigned to bunch a 12 amp. 1 na FWHM gun pulse. The actual gun pulec containing the same charge $\left(\sim 7.5 \times 10^{10}\right.$ electrons) is cloner to 6 ampa, 2 ne FWHM and b illustrated in Fis. 3.9(a). The \pm 20 extent of the pule it some $3.4 \mathrm{me}$. Figure $3.8(\mathrm{a})$ thown the longitudinal emittance of the bunch immedintely downotream of the frat subhermonic buncher gap. It is clear that the $3.4 \mathrm{n}$ pulse extends far beyond the linear resion of the $178.5 \mathrm{MHz}$ tine wave, over some $215^{\circ}$ of eubharmonic phwe. As discussed in Section 2.2.1, better bunching in the subharmonic buncher region is obtained if the bunch in shifted $30^{\circ}$ forward on the RF, as shown. The bunth drifls for $108 \mathrm{~cm}$ producine the bunch shown in Fin. 3.O(b). The bunch ha leen compressed by about a factor of two. Note that it is reasonably symmetrical.

Upon entering the second SHB, the phase of the bunch with rexpect to the RF is again shifted by $30^{\circ}$. Figure $3.8(\mathrm{c})$ represents the emittance at the end of the $36 \mathrm{~cm}$ drift followine the second SHB. As thown in Fic. $3.9(\mathrm{c})$, eame $80 \%$ of the original cun pulse has been bunched into $200^{\circ}$ of S-band phase. The bunch has been compreased by a factor of five.
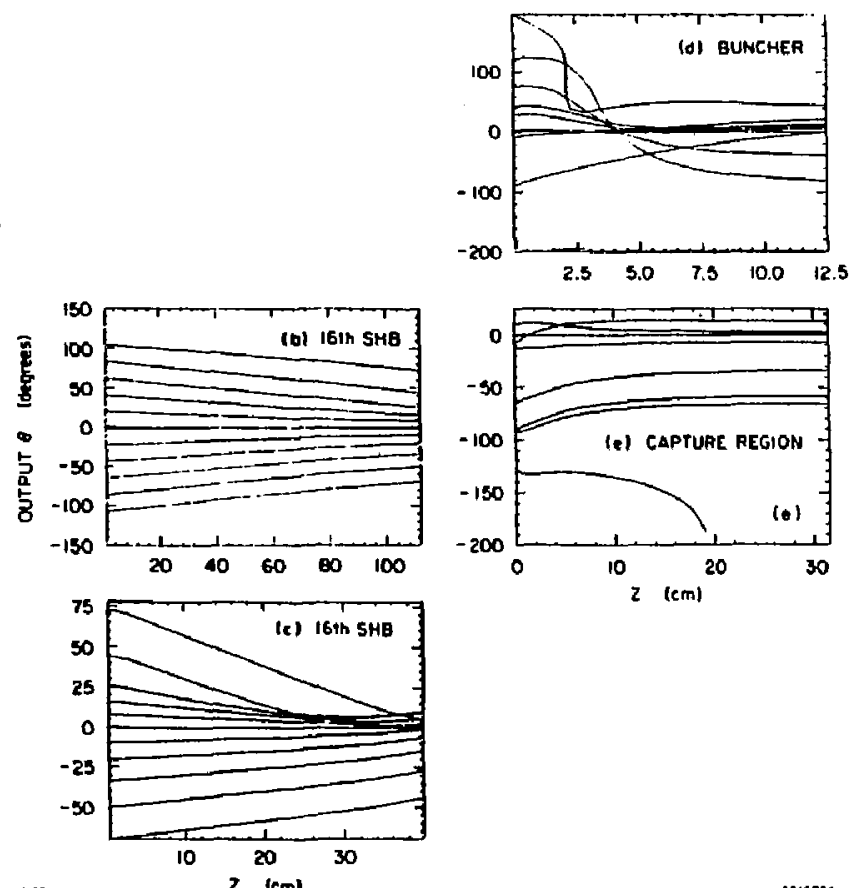
$2 \mathrm{~cm}$

Fic. 3.6. - versus 2 for every third of the 31 innet diaks of charge traversing the injector as apecified in Table 3.5. (b) Firat 16 th eubhermonic buncher gap and $108 \mathrm{~cm}$ drift. in messured in degrees at $178.5 \mathrm{MHz}$. (c) Second 10 th subharmonic buncher cap and $36 \mathrm{~cm}$ drift. 0 is measured in degrees at $178.5 \mathrm{MHz}$. (d) S-band buncher and $2 \mathrm{~cm}$ drift. is measured in degreez at S-band. (c) First $30 \mathrm{~cm}$ of the three-meter nccelerator section. 1 is measured in deprees at $\mathrm{S}$-band. 

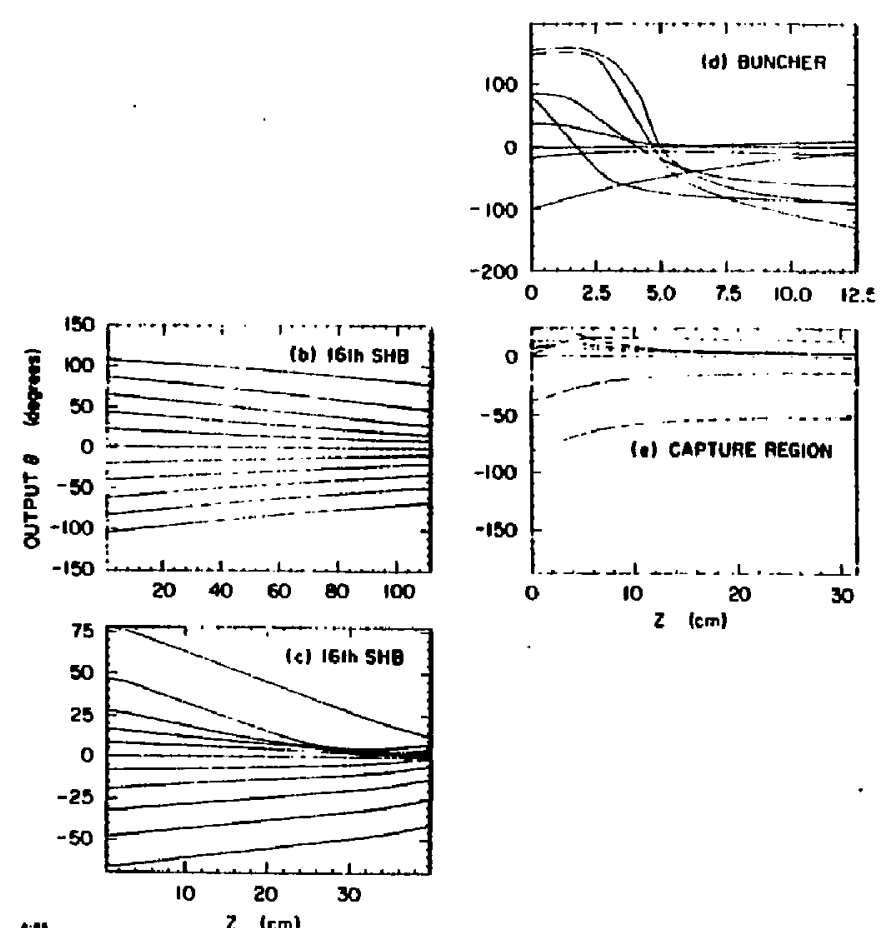

uncest

Fic. 3.7. veraus $\mathrm{z}$ for every third of the 31 outer annuli of charge traverain. the injector as specified in Table 3.5. (b) First 16th oubharmonic buncher gap and $108 \mathrm{~cm}$ drift. is measured in desrees at $178.6 \mathrm{MHs}$. (c) Second $16 \mathrm{th}$ aubharmonic buncher eap and $36 \mathrm{~cm}$ drift. 0 in measured in derees al $178.5 \mathrm{MHE}$. (d) 8-band buncher and $2 \mathrm{~cm}$ drift. 0 is measured in decrees at S-band. (e) Firat $30 \mathrm{~cm}$ of the three-meter acceleralor section. 1 is meaured in degrees at S-band.
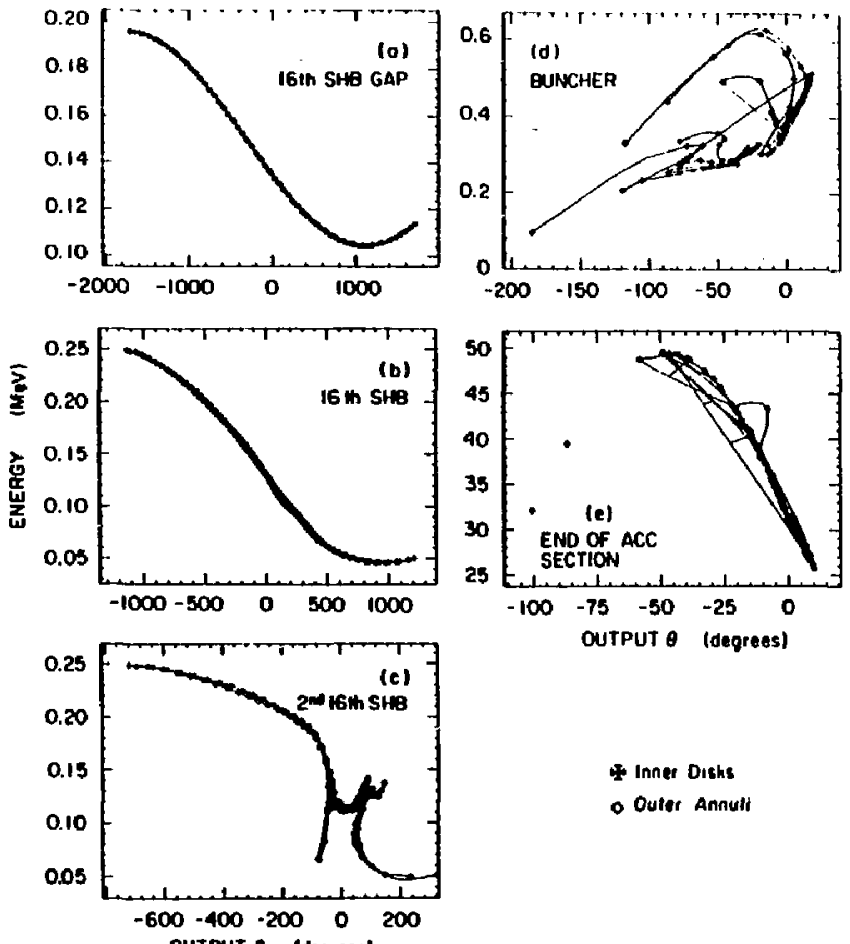

OUTPUT $\theta$ (degrees)

\$ Inner Disks

- Outer Annuli

12.14

OUTPUT $\theta$ (degees)

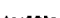

Fis. 3.8. Longitudinal emittance at five locations in the injector as apecified in Table 3.5. In all segree in measured in degrees at S-band. (a) At output of the firat 16th subharmonic buncher gap. (b) End of $108 \mathrm{~cm}$ drilt. (c) End of $36 \mathrm{~cm}$ drift followin weeond 16th subharmonic buncher rap. (d) End of $2 \mathrm{~cm}$ drift followinc S-band buncher. (e) End of three-meter accelerntor aection. 

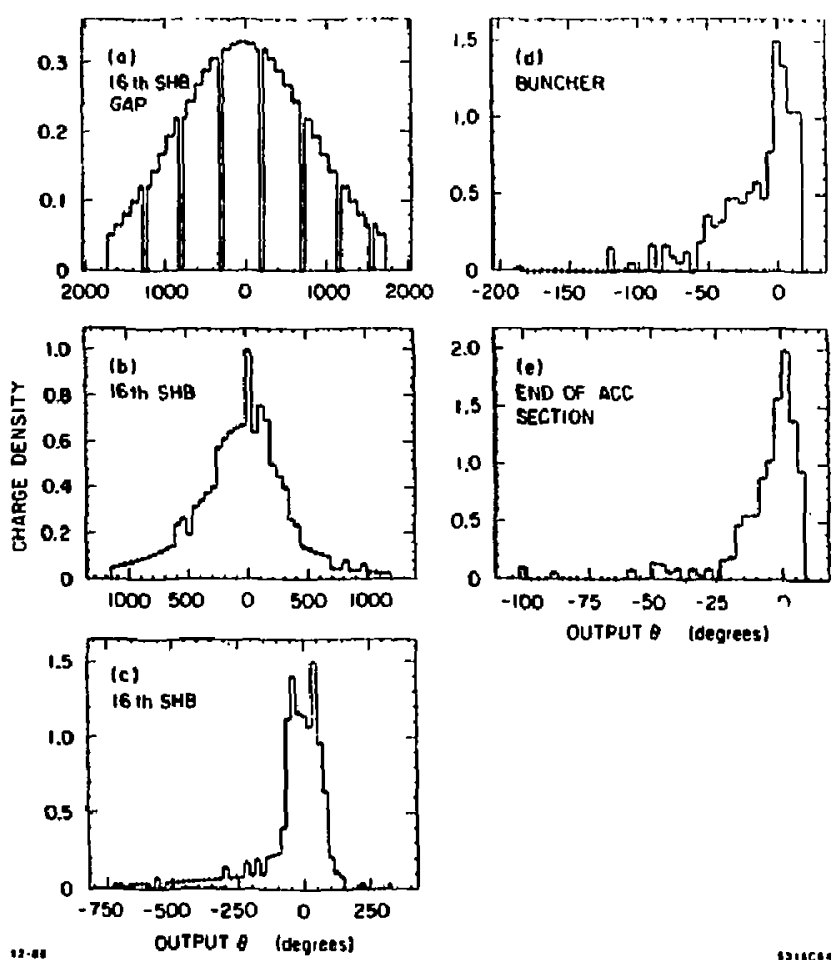

OUTPUT $\theta$ (degrees)

Fig. 3.9. Bunch length at five locations in the injector as apecified in Table 3.5. - in all figures it measured in degrees at S-band. (b) At output of the firat 16th anblarmonic bunches eap. (b) End of $108 \mathrm{~cm}$ drift. (c) End of $36 \mathrm{~cm}$ drift following second 16th subharmonic buneher sap. (d) End of $2 \mathrm{~cm}$ drift following S-band buncher. (e) End of three-meter accelerator section.

Table 3.5. Bunch length and current at five locations in the CID injector for a typical operating configuration.

\begin{tabular}{|c|c|c|c|c|c|}
\hline Element & $\begin{array}{c}\text { Pesk } \\
\text { Current }\end{array}$ & $\begin{array}{l}\text { FWHM } \\
\text { S.band } \\
\text { Desrees }\end{array}$ & $\begin{array}{c}\text { Buse } \\
(\sim \pm 2 \sigma) \\
\text { S-bund } \\
\text { Degret: }\end{array}$ & $\begin{array}{l}\text { Total } \\
\text { Charge }\end{array}$ & $\begin{array}{c}\text { Field } \\
\text { Strength }\end{array}$ \\
\hline Gun (experimental) & 6 amps & $2000^{\circ}$ & $3400^{\circ}$ & $7.5 \times 10^{10} e^{-}$ & $150 \mathrm{kV}$ \\
\hline $\begin{array}{c}\text { End of finat } \\
178.5 \mathrm{MHz} \text { SHB }\end{array}$ & 14 ampl & $850^{\circ}$ & $2400^{\circ}$ & $7.5 \times 10^{10} e^{-2}$ & $\begin{array}{l}12 \mathrm{kV} / \mathrm{cm} \\
(\times 3.8 \mathrm{~cm})\end{array}$ \\
\hline $\begin{array}{l}\text { End of second } \\
178.5 \mathrm{MHz} \text { SHB }\end{array}$ & 83 amps & $80^{\circ}$ & $400^{\circ}$ & $6.8 \times 10^{10} e^{-}$ & $\begin{array}{l}18 \mathrm{kV} / \mathrm{cm} \\
(\times 3.8 \mathrm{~cm})\end{array}$ \\
\hline S-band buncher & 240 amps & $35^{\circ}$ & $100^{\circ}$ & $6.3 \times 10^{10}$ & $14 \mathrm{kV} / \mathrm{cm}$ \\
\hline $\begin{array}{c}\text { Accelerator } \\
\text { section (calc.) }\end{array}$ & B75 amps & $10^{\circ}$ & $48^{\circ}$ & $6.2 \times 10^{10}$ & $175 \mathrm{kV} / \mathrm{cm}$ \\
\hline (Experimenta\}) & 430 amps & $18^{\circ}$ & $14^{\circ}$ & $6.5 \times 10^{20}$ & \\
\hline
\end{tabular}

The beam emittance entering the buncher is shown in Fig. 3.8(c). In Fig. 3.10 this emittance is thown superimposed on the low current phase opace orbits of the S-band wave buncher. As the bunch travels through the S-band buncher, it "folds over" in phase opace producing the emittence shown in Fis. 3.8(d). Nole that the field is a faclor of three higher than the design field. Higher felds are necesuary becaune the beam enters the buncher at a lower momentum due to the phose shilts in the subharmonic bunchers and exits the buncher at a higher momentum than pw. As bhown in Fig. 3.O(d). wll of the charge within $\pm 100^{\circ}$ al the entrance to the buncher is now within $75^{\circ}$, with snother $.5 \times 10^{10} e^{-}$in a tuil extending out some $100^{\circ}$.

Phase space orbits in the capture region are plotted in Fig. 3.11. At the end of the secelerator section $80 \%$ ar the eun pulse or $6.2 \times 10^{10} e^{-7}$ has been captured into $40^{\circ}$ with $=10^{\circ}$ FWHM. The longitudinal bunch shap $z_{1}$ spectsum, transverse emittance and lotal charge have been measured with diagnostic devices located downstream of the CID three-meter accelerator ecction. 


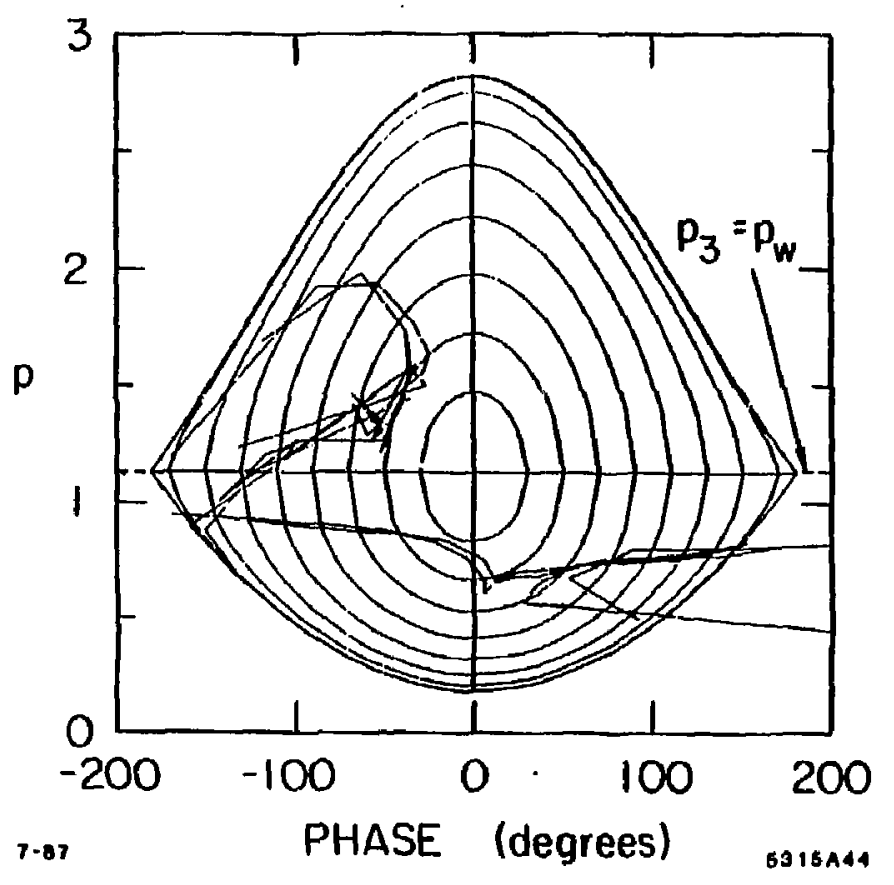

Fin. 3.10. Beam emittance at the entrance to and exit from the S-bend buncher superimpowed on the low-eutrens buncher phase apace orblts for the parametere upecified in Table 3.5.

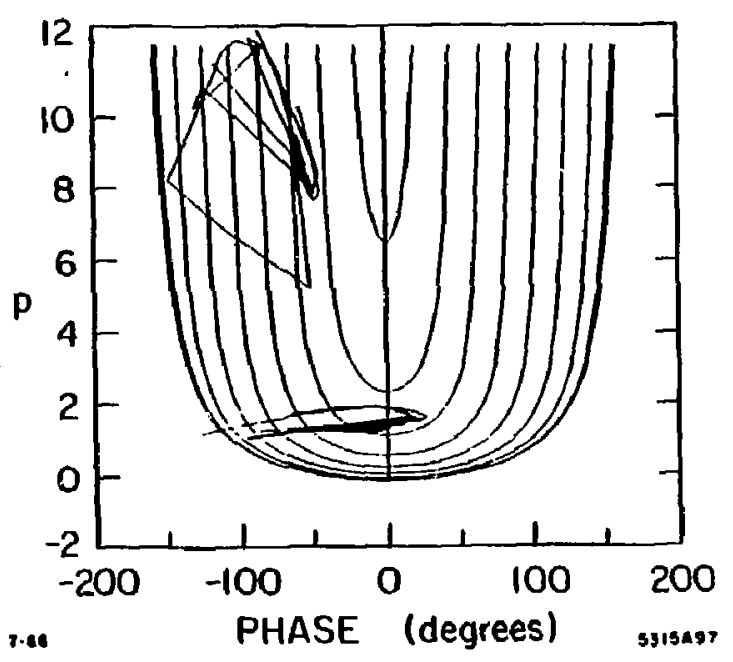

Fik. 3.11. Beam emiltance at the entrance to the capture refion and $30 \mathrm{~cm}$ downatream euperimponed on the capture region low-current phase space orblo for the parameters apecified in Ta ble 3.5 . 
The longitudinal bunch shape is meaured uvins a atreak camera vis the optical ayrtem deacribed in Appendix A. Degradation in resolution from a number of sources causes broudening of the streak camers image. The effect of this dezradation on the streat camera imate is estimated in Appendix $A$ and shown eraphically in Fit. 3.12(b). A delta function charge density would produce : siznal with a FWHM of 4 pe duration with a baeline of 32 pt duration. Before comparing the calculated bunth shape [Fig. 3.9(e)] to the experimental bunch shape, we must convolve the calculated bunch shape with the (eatimated) resolution degraded delta function. Figure 3.12(a) is the calculaled bunch of Fiz. 3.O(e). Fizure $3.12(c)$ is the calculated bunch ahape as teen by the streak camera fi.e., after Fig. 3.12(a) is convolved with Fig. 3.12(b)). In Fig. 3.13, we compare the resolution-broadened caleulated bunch shepe with the bunch thape meaured by the streak camera. The calculated base width and total charge are in good acree ment with experiment. On the other hand the mesured FWHM is somewhit wider and the tise time is about twice as lone as expected. These discrepancies are not explained by the calculated image degradation due to the imoging aystem and streak camera.

As discusced in Appendix $A$, we sutpect that other factors contribute to the image degradation, which prevent us from seting the fater rise time we expect and that the actual buem shape is in cloner atreement with calculation than is demonstraled here.

To meet collider epecifications, the expertinental bunch ehape of Fig. 3.13 muat have $\Delta E / E< \pm 1 \%$ at the entrance to the damping rinn. By a propet choice of phase shift, we can use the wake fields to partially offuet Lil. riation in enerey due to the ainusoidal $\mathrm{R} \overrightarrow{\mathrm{F}}$. Loew and Wans ${ }^{28}$ have pointed out that by judicious choice of bunch shape and phase shift, one can use the wake fields to offet the variation in eneray due to the RF to achieve excellent apectra.
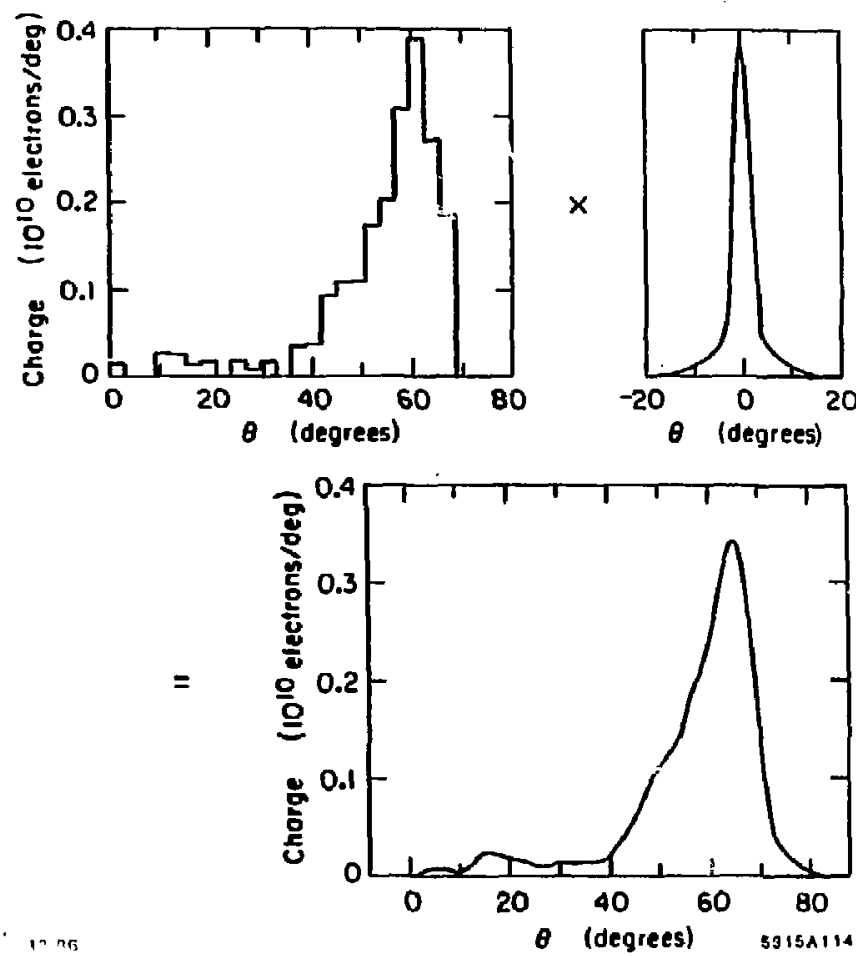

Fig. $0 .$. (a) The calculated bunch shape at the end of CID for the parameters given in Table 3.5. (b) The otreak camera signal from a 6-Function pulse given the resolution limitations described in Appendix A. (c) The calculated bunch shape convolved with the eatimated resolution error. 


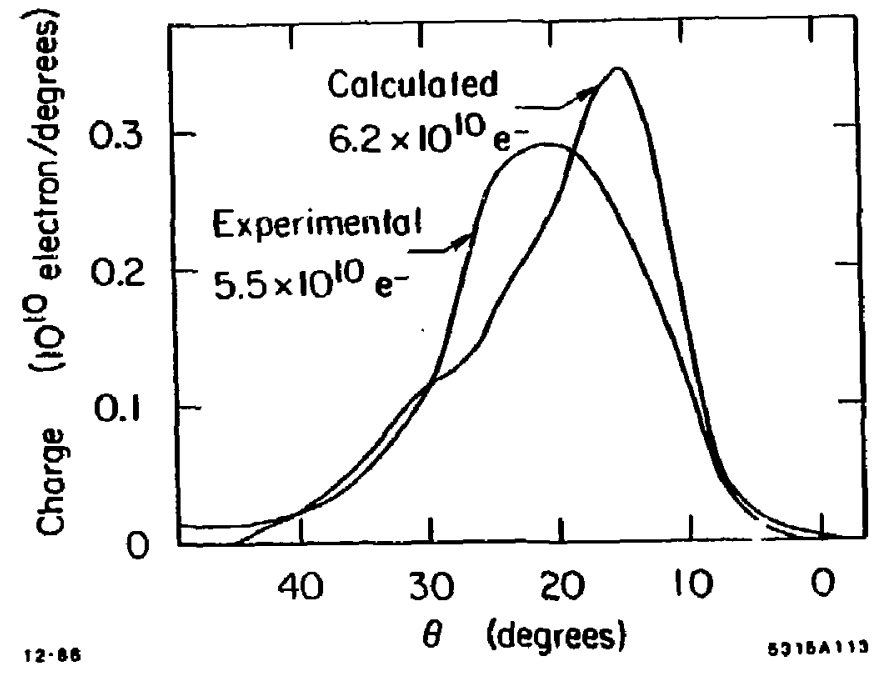

Fit. 3.13. Calculated and meanured bunch shape at the end of CID for the operating conditions outlined in Table 3.5 .
Figure 3.14(a) is the experimental bunch ahope of Fis. 3.13. The hend of the bunch is on the far tight at $0^{\circ}$; the tail of the bunch is at $44^{\circ}$. For a low current beam, the energy of each paticle at the entrance to the damping ring is a function oniy of its phase with respect to the accelerator RF fields. In Fig. 3.14(b), the dashed eurve showa particle energy as a function of AF phase for a low current bearn. The head of the bunch $\left(0^{\circ}\right)$ has been ahifted $12^{\circ}$ forward of the RF erest. The solid line showe particle energy as a funetion of phase for our actual beam current. Again, the head of the bunch has been thilked $12^{\circ}$ forward of the RF creat, and the energy of the parteles near the creat b reduced by the wate fields. Figure 3.15 is the calculated apectrum at the entrance to the damping ring given

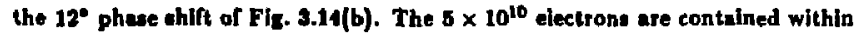
$\pm 1 \%$ with another $0.6 \times 10^{10}$ electrone falling to fall within the demping ring acceptance. As predicted, $5 \times 10^{10}$ electrons have been succesafully injected into the dampine ring. 

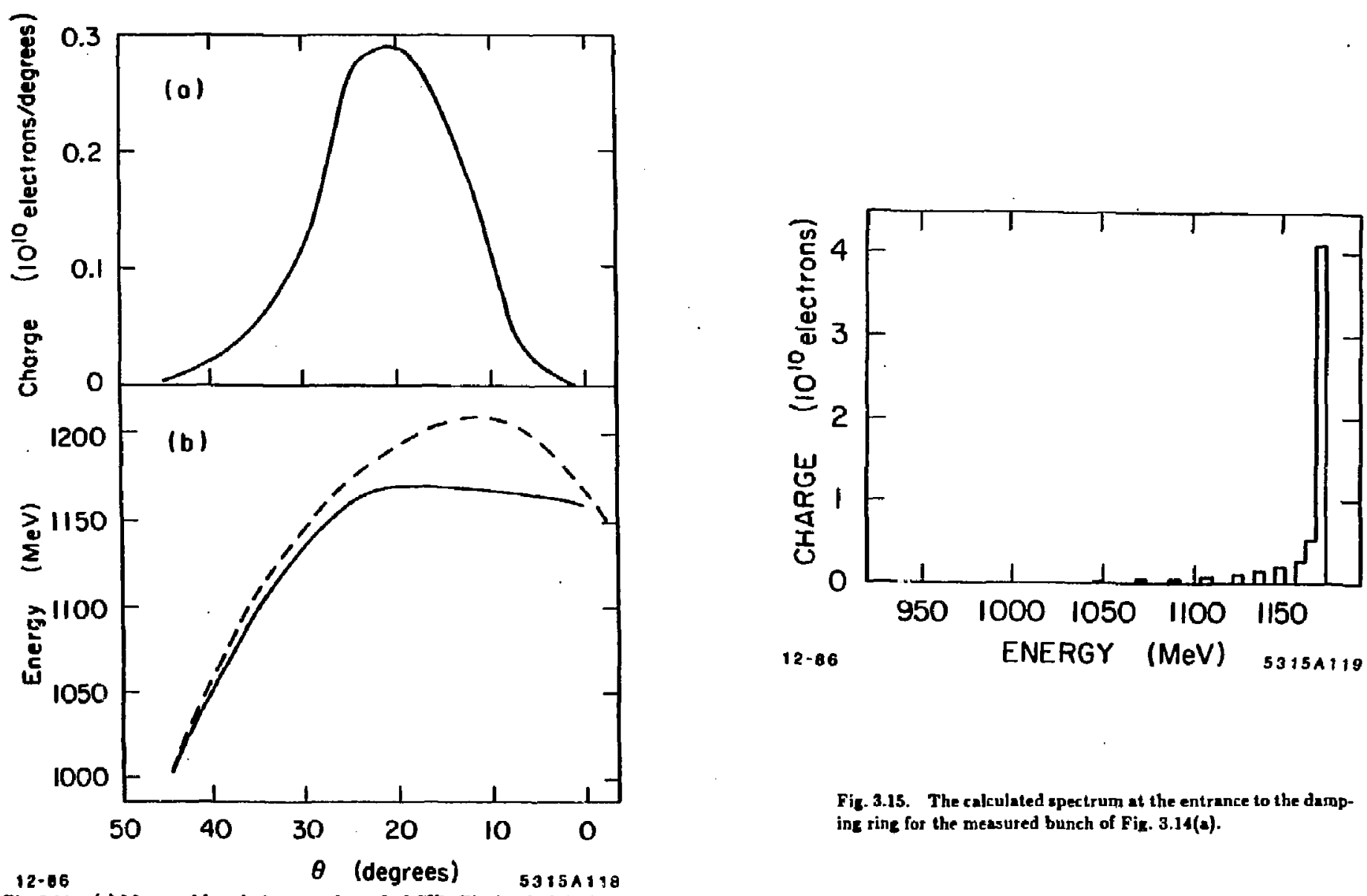

Fit. 3.14. (a) Measured but sh thape at the end of CID. The head of the bunch is at the far ritht at $0^{\circ}$. The tail of the bunch is at $4^{\circ}$. (b) The dached curve whow the energy of the particles at the entrance to the damping rinz as a function of phase in the low current limit. The head of the bunch, $0^{\circ}$, in shifted $12^{\circ}$ ahead of the RF ereat. The tail of the bunch in $32^{\circ}$ behind the RF crest. The wolid curve showe enercy as a function of phase fo: the actual CID current.

Fig. 3.15. The calculated spectrum at the entrance to the dampine ring for the measured bunch of Fie. 3.14(a). 
gVerse EmitTAhCE MEAgUREMENT

In this axclion we dincuan the moasurement of the tranaverse emittance of the CID boem a a function of current. Wo beiln with a qualitative discuesion of the mewusement technlque which is deacribed in detall in Rel. 27.

The tyanovorse emittence of the CID basm is meanved by varying the atrength of a quadrupole triplet located Junt downul raam of the CID accelerator section. The beam then drifu to a mereen located 1.2 metera downaiteam of the triplet where the traneverse epol alzo is read by a "reticon" array. If we plot one dimenslon of the beam apot dize a a function of the inveres focal length of the triplet, It can be shown that the reaultias furction is a hyperbola (cen Fis. 3.10). The minimum of the hyperbole and the alope of the pasitive acymplote tell wo the omiltanes of the beam at the triplat. To oblals a qualltalive understanding of this technique, it it helpful to reatrict the followint diecusion to an emittance meaurement in the $x, x^{\prime}$ plane, where $x^{\prime}$ is $p_{a}$, tho nosmalized tranoverse parti. cle veloclly in the $x$ direction. The emittance in the $y, y^{\prime}$ plane is measured in identical fashon.

Lat ue asurne that the arbitrary ellipes I of Fis. 3.10(a) represents the $x_{1} x^{\prime}$ phase apace jost upatream of the quadrupote triphe. It in Inatructive to cirsum-

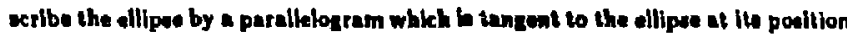
extreme and at its interection with the oxdinale axis.

Concoptually, If is simpleat is thint of the quad tripht as performing two Independent take and that these take are performad by two independent lenw.

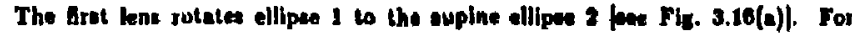
ellipese 2 the moximum value of $x_{1}$ and $x$ eive us the emittence. The recond lene in varied to yield the functional depandence of opot aise on focal lenth, from which we can caleulate the maximum values of $x_{1}$ and $x_{i}$ of Fis. 3.16(a).

To find $x_{j}$ we chowe the focal atrength of the excond kene to sehieve a minimum spot size on the acreen a diatance 2 downtrenum of the lone. The lens wheers Allpes 2 of Fis. 3.16(b) to ellipes 3. Note that this oheerlng due to locusing doen
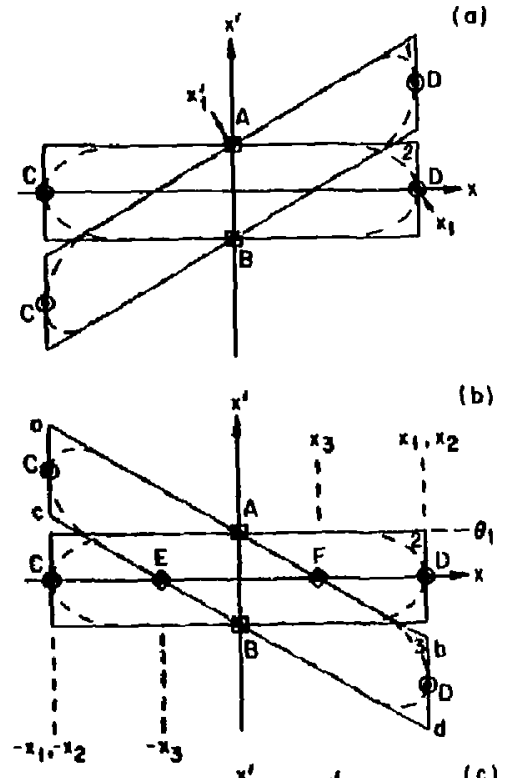

$12 \times 6$

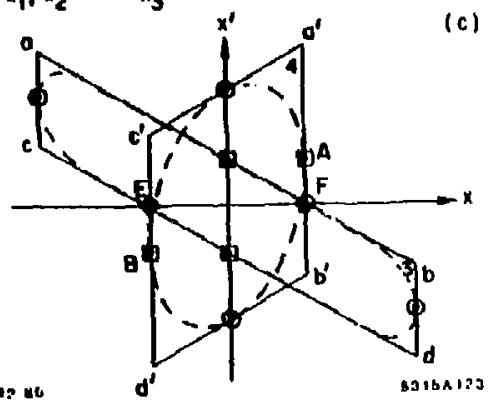

Fis, 3.16. (a) The erbilrary ellipe I represents the horixontal beam emiltance Fig. 3.16. (a) The erbitrary ellipas 1 represents the horisontal beam emiltance at the upetrear: edge of the lenw. The "firat lens" in uted to rotate the ellipte to the supine poeitiun. (b) The eupine ellipte 2 is sheered by the "aecond lens" to to achieve the amallest apot, ellipse 4. 
not affect points $\mathbf{A}$ and $B$. We have chosen the ieno atrength ouch thai after a drift of kength $L$, ellipus 3 is theeted to ellipie 4 of Fis. 3.15(c). Since theering due to deiftine doet not affect points $E$ and $F$, the minimum apot blue $k$ obtained when line asment at aheers to tha vertkal line egment 75 . Note that the focusing and drifting represented in Fir. $3.10(b)$ and (c) has iranstormed point $A$ from the angular extremum to the position extremum. Fizure $3.17(a)$ repreaents the ray correspondins to point A of Fizs. 3.16(a), (b) and(c). At a, (before the lens) the ray $k$ on the $z-a x i s$ and $k$ diverging from the axis at an angle $x$. $A$; this ray is not focused by the lens, its position at 2 , is given by

$$
x_{\min }=x_{i}^{\prime} L
$$

Where $x_{3}$ min is the minimus pot gize at the acreen. Rearranging, we have

$$
x_{i}=\frac{x_{\min }}{L}
$$

Thus we know the momentum extent of the aupine ellipse of Fis. 3.10(a) in terms of the measurable quantlties $x_{3} \min$ and $L$.

To find the position extent, $x_{1}$, of the euplne ellipae of Fh. 3.16(e) we choose to make the focal kngth of the kns very ahort (we Fh. 3.te, ellipee B). The beam

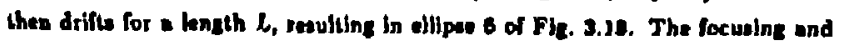
drlfing of Fic. 3.18 ha transformed point $D$ from the ponitive poeltion extremum to very close to the nerative position extremum. Figure 3.17(b) rapresents the

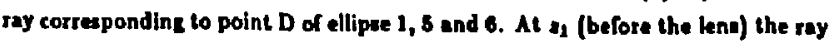
is displaced a diatance $x_{1}$ from the e-exis and is parallal to the axia $(x f=0)$. At

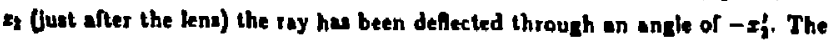
displecement of the ray at the screen in given by

$$
-x_{3}=x_{1}-x_{j}^{\prime} L
$$

(o)

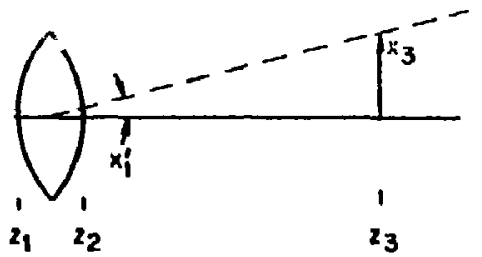

(b)

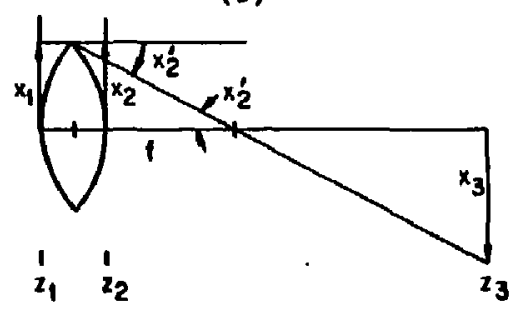

$12-86$

S315A124

Fig. 3.17. Ray optica of (a) point A of Fis. 3.16, (b) poini D of Fis. 3.18. 


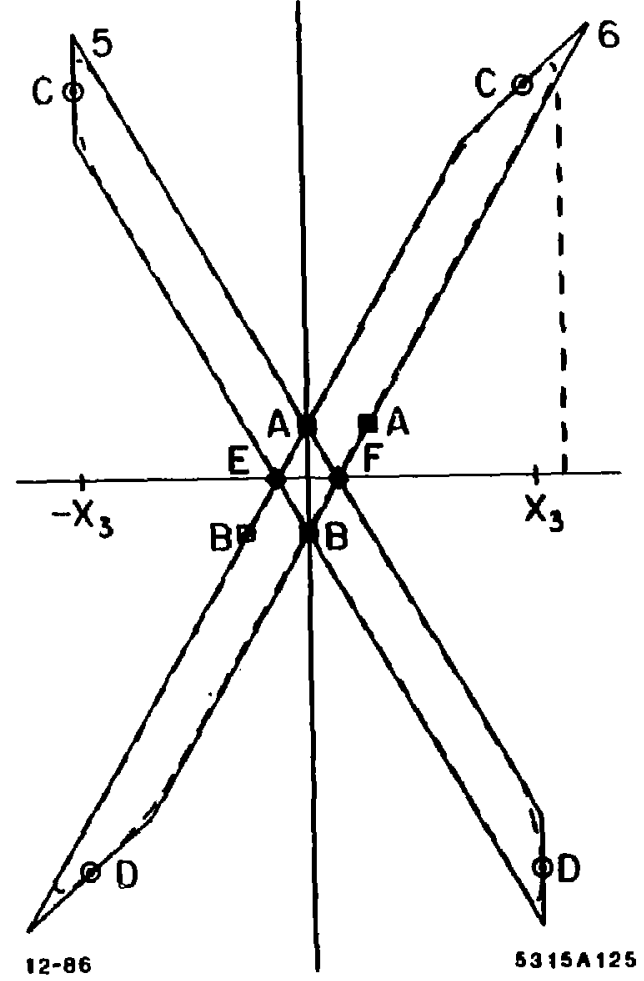

F4. 3.18. Ellipse 2 of Fin. $3.18(b)$ to theered by atrond focuning to produce ellipse 8 . The beam drifts to produce ellipae 6 at the sereen.

$$
x_{3}=-x_{1}+\frac{x_{1}}{f} L
$$

Taking the derivative of $\mathrm{ta}_{\mathrm{a}} \mathrm{a}$ a function of $1 / \mathrm{f}$ we have

$$
\frac{d x_{3}}{d(1 / f)}=x_{1} L
$$

$$
x_{1}=\frac{1}{i} \frac{d x_{3}}{d(1 / f)} .
$$

Thu we know the ponition extent of the aupine ellipue 1 of Fig. 3.16(a) in terms of the measurable quantitia $d x g / d(1 / f)$ and $L$ provided $d x g / d(1 / f)$ in not varyine appreciably (i.e., near the aymptoto).

Fhere 3.19 be stelch of the bean spol vire a a function of inverae focal length. An indkated by Eq. (3.8), the minimum of the hyperbole eiver the inzular extent at the focusing ken; from Eq. 3.10 we see that the alope of the aymptote cive the tranaverse displacenent. Tracing out the entire curve gives a complete emiatence meanurement. The preceding discuasion to intended to canvey the principle of the emiltence meanurement. For a detaited diecuerion of the actual mathematkal cool and experimental procedure wee Ref. 27.

In Fls. 3.20 we plot emittence in both the vertical and horlsontel planea w a function of benm current for neveral currents between 0.6 and $6.5 \times 10^{10}$ electrons per bunch. Error baso are at \pm 0 . Where no error bats are shown there were inofificient dute to delesmine o. At $5 \times 10^{10}$ electrons per bunch, the invariant emittance along both the horizontal and vertical axea is epproximately $1.5 \times 10^{-4}$ moc metere (invariant), which ba (actor of two below the value apecified for the SLC.

The mearured emittance an a function of beam intensity is jeasonably fitted to a parabols given by $e=7 \times 10^{-6} \sqrt{I}$ meter redian (invariant), where $I$ is the current in $10^{10} e^{-}$/pulae. The form $e=k I^{1 / 2}$ is appropriate when the density in phase space remaina constant a the current b varied. 


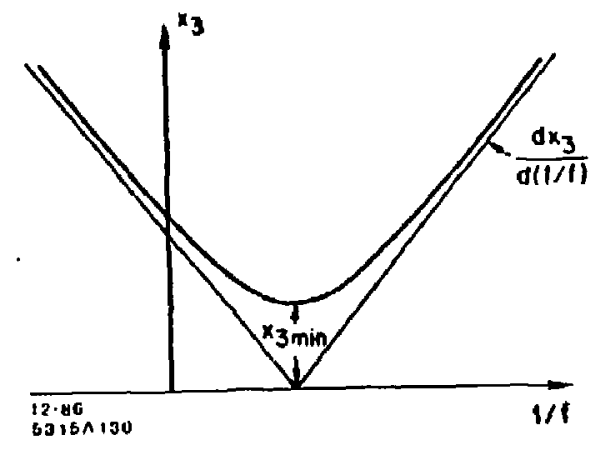

Fit. 3.19. Characteristic plot of beam opot size at a function of inverse focal length.

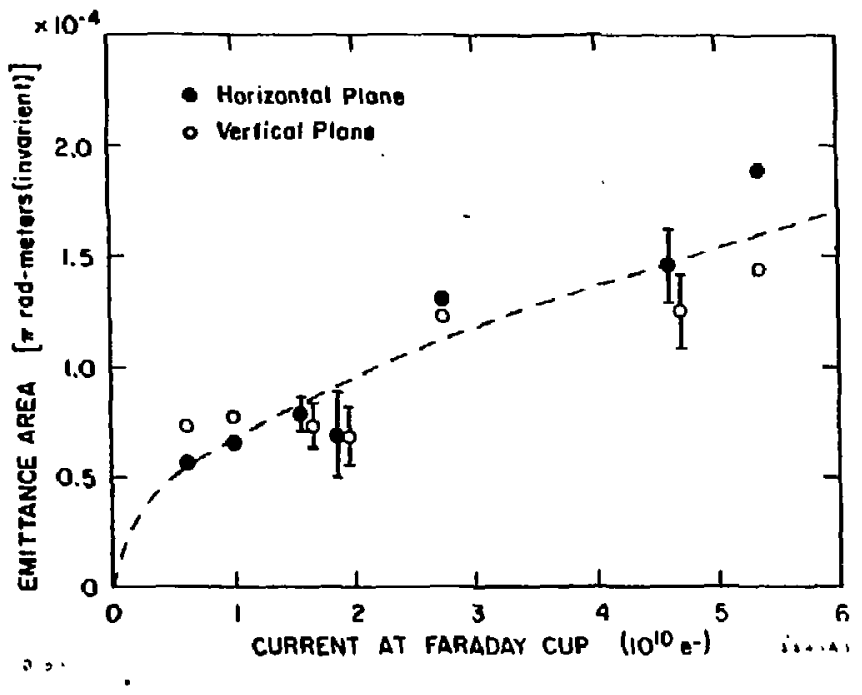

Fit. 3.20. Invariant transverse ernittance as a function of current for the CID beam measured at beam eneray of approximately $45 \mathrm{MeV}$. 


\section{Chapter 4. CONCLUSION}

This theain has deactibed the deign and parformance of the high intenaity electron injector (CIO) for the SLAC Linen Collider (BLC). This injector aurcensully cepture $5.5 \times 10^{10}$ electron into a aingle 8-band RF creat. The gun

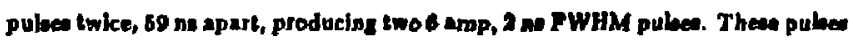
are compreased by a factor of 100 through e eerlow of bunching elemente comprbed of two cap-and-drifl prebuncherm at the 16th oubhumonic of 8-band, a travaling wave buncher with phene velocity $\rho_{-}=75$, and a velocity-of-light capture rezion. By Judicious choice of RP phesen, we can capture $90 \%$ of the charce into a \pm 1 enerey apread at the entrance to the demping ring. This buneking and capture of $3.5 \times 10^{10}$ electronu into the dempine ring longitudina) admittunce

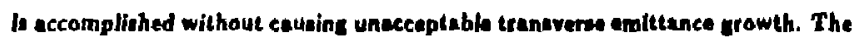
invariant tranavetue emittance at the end of CID $101.6 \times 10^{-4}$ redian-moters in both the horinontal and vertical pienes, efector of two befow the decien limit. The collider injector meets all of the opecilacation outlined in the intsoduction.

The computer code RINGMODSL wae uned in simulale the bongitudinal beam dynemica in each of the four bunching elements. The aimulation predicte the calculated bunch thape of Fic. $\mathbf{3 . 1 3}$ for the operaling conditions apecified in Table 3.5. While the calculated bee width and tolal cherce are in good atreement with experiment, the calculated FWHM and ribe times are about half the meaured values. Wo suppet that the stcest camers signal has efufered sinnifleant resolution degradation, makine a fayt ( $-\mathrm{p}-6 \mathrm{pa})$ rise time seen at on earlier timo with another streak camera. ${ }^{10}$

The general epprouch to injector deaign presented in this text, a thermionic sun followed by a series of bunchine elemente at fnereaing subharmonic frequeneles of the accelerator RF, was completely adequate to meet the SLC specifica- tione end required no development of unproven technologies. It was, therefore, a cound cholce. Using one or two unore bunching elements might lead to another fuctor of ten in pesh current, but currente beyond this will sequire now approaches, wuch as laser-induced photoemlesion of high current, picosecond bunches directly from a wolid tate cathode or atacking bunches in a small storige ring, or other novel colutions. 


\section{APPENDIX A}

\section{STREAK CAMERA OPTICS AND RESOLUTION}

The length of the GID ejectron bunch in meaured by letting it pase through a querte radiator just downatream of the compressor magnets (set Fiz. 3.1), The beam gives off Cherenkov tight, which b traneported through an optical syatem to a strenk camera. The quarte radiator in 1.5 metere downutream of the lest quadrupole and it is thus impossible to form * small $(\sim 1 \mathrm{~mm})$ spot at its location. Both the intenaity and resolution of the signal at the slreak camera are affected by the relatively large apot size $(-1 \mathrm{~cm})$ at the quartz. The light transport optics syatem in described below and resolution limits are discussed. As shown in Fir. A.1 the electron bunch pases through a $1 \mathrm{~mm}$-thick quarte radistor and gives of Cherenkoy radiation. The intensity of the Cherenkov radiation is proportional to the current in the bunch. The direction of propagation of the Cherenkov light relative to the beam velocity vector is given by the Cherenhov angle

$$
\sigma_{c}=\arccos \frac{1}{\beta n}=4^{\circ}
$$

where

$\beta=$ velocity of the electron bunch

$n=1.41=$ index of refraction of visible light in quarte.

The optics of the light transport ayatem is aimplified if the quarts is oriented so that the direction of propagation of the Cherenkov light is normal to the quartz/vacuum interfoce. In this case the angle of incldence and the angle of refraction acrose the interface are both zero. Thus we chose to tilt the quartz through an angle $90-1$, with respect to the beam line (eee Fig. A.2).

After leaving the quartz, the light passes through an optical system with o $90^{\circ}$ focusing lattice. This lattice consists of four $1 \mathrm{~cm}$ diameter lenses with two meter focal lengths, spaced approximately four meters apart. The $90^{\circ}$ lattice is followed by $22 \mathrm{~cm}$ drift space, a lens with a focal length of $1.6 \mathrm{~cm}$ and a $8.8 \mathrm{ctn}$

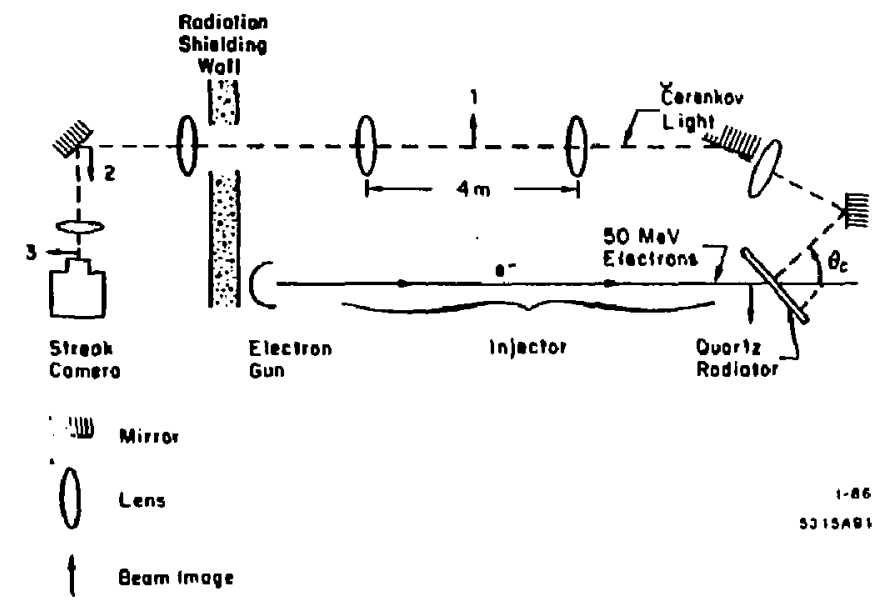

Fig. A.I Optical system used to measure GID bunch length. 
drift dealgned to produce a demagnibed ( $M=0.3$ ) image of the Cherenkov light at the slit of the atreak camern. Resolution of the bunch length as mensured by the atreak camera is limited by lour effects:

1. Broadening due to the finite width of the quartz,

2. Broadening due to the Bnite width of the camera slit,

3. Brondenine due to error in the location of the beam image at the camera alit, and

4. Resolutton limitullone internal to the atreak camera.

Becaune of the large beam apot ale at the quarts radiator and the finite thiekneas of the quarts alab, the Cherenkov light zenerated by electrono with the same lonsitudinal position in the bunch reaches the camera over a finite time $\Delta T_{1}$. We can quantify $\Delta T_{\mathbb{l}}$ by careful examination of Fig. A.3. Aasume that the width of the bunch in subatentially greater than the width of the quartz. In addition, asaume that the atreak camern is a perfect pinhole camera (the resolution degradation dute to finite alit width is discussed below). Two electrons it points (a) and (b) reach the aume axial position in the beam pipe $(\mathrm{a}=0)$ at che anme time $(t=0)$. We are interested In the time at which photons radiated by these two electrona resch point (d), wince only these electrons are detected by i pinhole camera at (e). The electron at point (a) at $t=0$ arrives at (d) at $t_{1}=\left(h / c \cos D_{c}\right)$ where $h$ to the thickness of the quarts. Mesnwhile, the electron at point (b) at $t=0$ travela to (c) in time $t_{2}=h$ ain $t_{c}$ tan $t_{c} / c$. At point (c) it radiates Cherenkov light which travele to (d) in time $t_{3}=[\mathrm{nh} / \mathrm{c})=\left(\mathrm{h} / \mathrm{c} \cos \theta_{c}\right)$. Although the two electrons are at $z=0$ at $t=0$, the Cherenkov signals reach the camera slit $\Delta T_{1}$ eeconds apart where $\Delta T_{1}$ is given by

$$
\Delta n_{1}=\left(t_{2}+t_{s}\right)-t_{1}=\frac{h}{c} \operatorname{tin} \theta_{c} \tan v_{c}
$$

For $h=1 \mathrm{~mm}$ and $\theta_{c}=45^{\circ}, \Delta T_{1}=2.4 \mathrm{ps}$. 


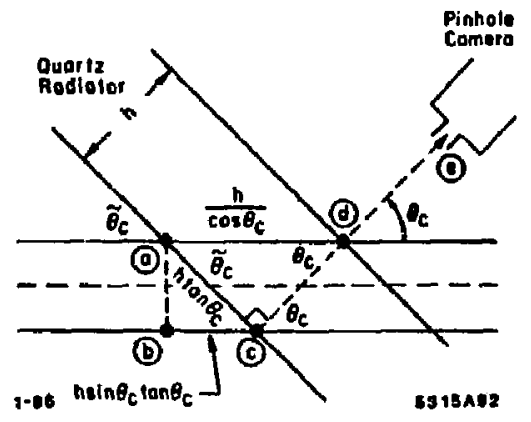

Fis, A.3. Image broadening due to finite width of quarty radiator. Photone radialed at points e and $d$ enter the pinhole camera at point $e_{1} h \sin \theta_{c} \ln \theta_{c} / c$ seconds apart.
The camera slit width causes resolution degradation which is proportional to the slit width and inversely proportional to the magnification of the light transport optics. For this calculation, seseme the quartz radjator to be infinitely thin. Al thown in Fig. A.1, electrons at (a) and (b) are at $z=0$ at time $t=0$. The electron at (a) crowses the quartz radiator at $t=0$ and emits Chetenkov lizht. The electron from (b) arrives at $(c)$ at a time $\Delta t_{z}$ later and crosses the quarte, radiating Cherenkov iight. From Fig. A.4 we vee

$$
\Delta t_{2}=\frac{w_{0} \sin \theta_{c}}{M c}
$$

where

$$
\text { w, = camera slit width, and }
$$

$M=$ imaze maznification in the optice aystem.

For $w_{\triangleleft}=.01 \mathrm{~cm}$ and $M=0.3, \Delta t_{7}=1.1 \mathrm{ps}$.

The resolution of the cystem worsens if the final inage of the Cherenkov light is alightly in front of or behind the camera alit. To calculate this effect; we ussume that all imager are umall compared to the diameler of the transport ayatem lenses. From Fig. A.S(a) we see that says which diverge from the axis at angles greater than $\theta=\nu_{0}$ do not remsin in the light transport aystem. $\theta_{0}$ is given by

$$
G_{0}=\frac{d}{L}
$$

where

$d=$ diameter of lenses $1-4$ in Fig. A.5(a) $=3.8 \mathrm{~cm}$

$L=$ distance between fenses 1, 2,3, and 4 in Fig. A.5( $(a)=4$ meters

From Fir. A.5(b) we see that rays which diverge from image 2 at an angle of to diverge from image 3 at an angle $A_{1}$ given by

$$
a_{1}=\frac{O_{0}}{M}=\frac{d}{L M}
$$




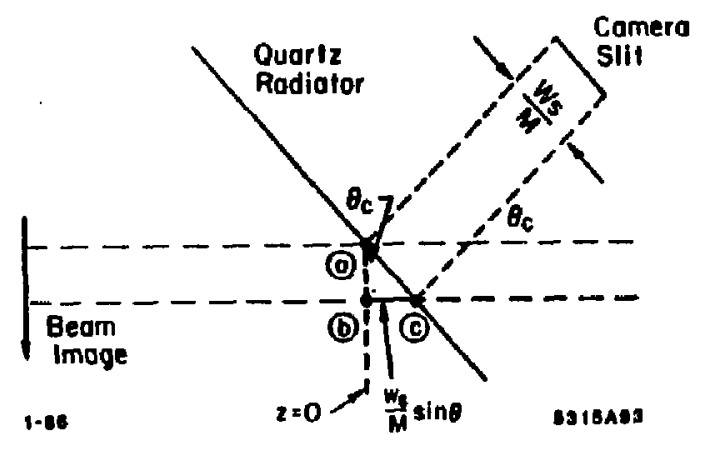

Fig. A.4. Image broadening due to anite width of camere alit. (a)
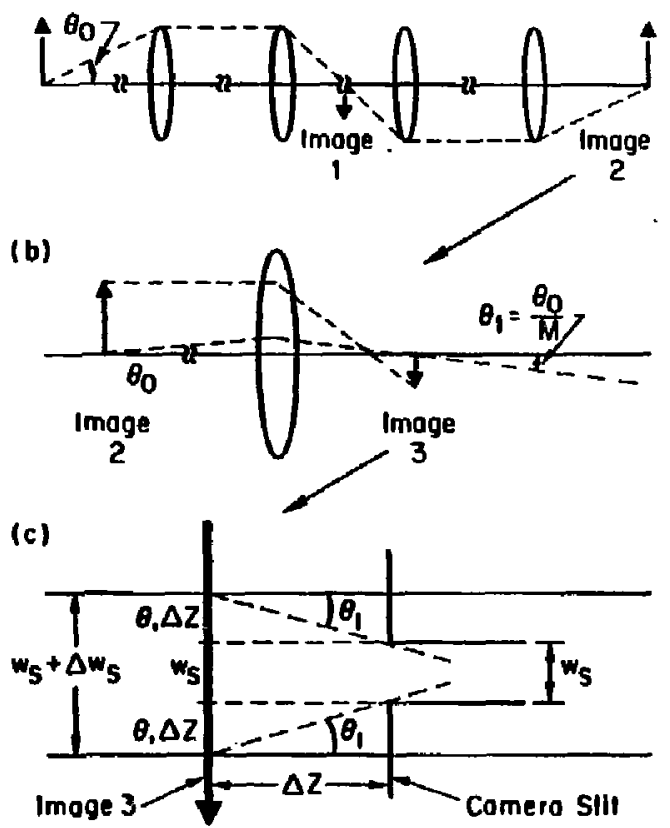

$12-86$

S315A90

Fiz. A.b. (a) Optice trom source to second image; (b) Oplica from wecond to third image; (c) Image broadenins due to thift of final imace to $\Delta x \mathrm{~cm}$ in front of alit. 
From Fic. A.5(c) we see that if image 3 is a distance $\Delta Z$ in front of (or behind) the camera slit, the image tormed inside the camers is broadened by $20, \Delta Z$. Thus the alit width of Eq. (A.3) is effectively increased by

$$
\Delta w_{0}=2 \sigma_{1} \Delta Z=\frac{2 d}{L M} \Delta Z
$$

The additional resolution degradation due to $\Delta w_{0}$ is given by Eqs. (A.3) and (A.6)

$$
\Delta f_{\mathbf{J}}=\frac{2 d \sin \theta_{c}}{L f^{2} c} \Delta Z
$$

The error in the position of the final image, $\Delta Z$, results from two sources, uncertainty in the porition of image 2 (Fic. A.1) and uncertainty in the position of the final lens. The slit position (relative to imege 2) and focal length of the final lens were chosen to achieve a magnification of 0.3 for the find image. While this magnification increases resolution degradation, it is necessary to obtain a reasonable signal-to-noise ratio from the atrenk camers aystem. A maznification of 0.3 is achieved by choouint

$$
\begin{aligned}
& f=\text { focal length of final lens }=4.6 \mathrm{~cm} \\
& p=\text { distance from image } 2 \text { to } 6 \mathrm{nal} \mathrm{km}=19.9 \mathrm{~cm} \\
& q=\text { distance from final lens to imuge } 3=6.0 \mathrm{~cm}
\end{aligned}
$$

The exact position of image 2 is difficult to measure, but ws are confident in its parition within $\pm 2 \mathrm{~cm}$. If $p$ is in error, the efror in $q$ is given by

$$
q=\frac{1}{1 / f-1 / p} \Rightarrow \frac{\Delta_{q}}{\Delta p}=-\frac{f^{2}}{(p-I)^{2}}
$$

For $\Delta p=2 \mathrm{~cm}, \Delta q=.09 \mathrm{~cm}$, or $1 \mathrm{~mm}$ of error.

Uncertainty in the position of the fnal lens with respect to the alit is no more than $\pm 2 \mathrm{~mm}$. Thus the error in position of the final image is given by

$$
\Delta Z \leq .1 \mathrm{~cm}+.2 \mathrm{~cm}=.3 \mathrm{~cm}
$$

This gives a resolution degradation of [Eq. (A.P)]

$$
\Delta t_{3}=8.0 \times .3=1.6 \mathrm{ps}
$$

In addition to the external optics aystem, the camers itself has optical and electronic recolution limitations. In a non-sweeping mode (focus) the camera

\begin{tabular}{|c|c|c|c|}
\hline $\begin{array}{c}\text { Camere } \\
\text { Focus } \\
\text { (channels) }\end{array}$ & $\begin{array}{c}\text { Sweep } \\
\text { Speed } \\
\text { (po/channel) }\end{array}$ & $\begin{array}{c}\text { Beam } \\
\text { Signa) } \\
\text { (pa) }\end{array}$ & Resolution Degraded Signal \\
\hline \multirow[t]{4}{*}{12} & $\begin{array}{c}27 \\
(20 \mathrm{ps} / \mathrm{mm})\end{array}$ & 6 & $\begin{aligned} \sqrt{(5)^{2}+(2.4)^{2}} & +(1.1)^{2}+(1.6)^{2}+(3.2)^{2} \\
& =6.7 \mathrm{p}\end{aligned}$ \\
\hline & & 15 & $\begin{array}{l}\sqrt{15^{2}+19.8} \\
=15.6 \mathrm{p}\end{array}$ \\
\hline & $\begin{array}{c}.70 \\
(50 \mathrm{p} / \mathrm{mm}) \\
\end{array}$ & 5 & $\begin{aligned} \sqrt{(5)^{2}+(2.4)^{2}} & +(1.1)^{2}+(1.6)^{2}+(8.4)^{2} \\
& =10.3 \mathrm{pg}\end{aligned}$ \\
\hline & & 15 & $\begin{array}{l}\sqrt{15^{2}+80.1} \\
=17.5 \mathrm{ps}\end{array}$ \\
\hline
\end{tabular}
illuminates a narrow portion of its reticon array with a roughly Gausian signal. The sienal is 10-12 chennels FWHM, which corresponds to $1.7-9.2 \mathrm{ps}$ on the (20 ps/mm) sweep speed and to $7.0-8.4 \mathrm{ps}$ on the $(50 \mathrm{py} / \mathrm{mm})$ sweep speed.

Combining these four resolution errors in the most straightforward way, we estimale the resolution degradation of the beam induced nignal. Table A.1 thows resolution degradution for $S$ and 15 po signals at two different camera speeds.

Table A.1. Streak camera resolution. 


\section{REFERENCES}

1. BLAC Linear Collider Conceptual Dedien Report, BLAC Report No. 229, June 1 seo.

2. 8LC Deilan Handbook, SLAC Internal Document, December 1984

3. G. E. Fiacher, SLAC-PUB-3302, July 1984.

4. R. H. Miller et d., IEEt Tran. Mucl. Sci. NE-12, 1085, p 804.

5. R. H. Miller el d., The Stanford Two-Mile Aceelerator, R. B. Nenl, editor, W. A. Benjamin Inc., New Yotk, 1968, pp 241-200.

6. G. Deme, Electron Bunching by Ualform Boctom of Disk-Losded Wavesvide, Part A: General Siudy. Technikat Report M-242.A, Hanten Laboratories, Stenford, Calffornls, December 1000.

7. J. C. staler, Review of Modem Phyoles 30, p 473, 1948.

8. E. L. Chy, ML Report No. 140, W. W. Hanen Laboratoriea of Physico, Stanford Univereity, Stenford, Californie.

9. A. J. Lichtenbers as referented In Miller of d., The stanford Two-Mile Accelerator, ibid.

10. P. B. Wikon and K.L.F. Bane, BLAG Report PEP-220A (unpublinhed), March 1977.

11. A. T. Drobol el d.. IESE Trara. Nuel. Bel Ne-32, p 2733, Oclober 1985.

12. M. B. James and R. H. Miller, IEEe Trans. Nuel. Sel. NS-28, p 3461, June 1081.

13. C. B. Willieme and M. H. MacGrezor, IDES Trans. Nucl. Sci. N9-14, p 681, 1987.

14. G. Mevrozenea et al., IEEh Trans. Nuel. Bel. NB-20, p 019, June 1973.

15. W. R. Bmythe, Static and Dynamic Electriclty, MeGraw-Hill Book Company, New York, 1050.
16. W. B. Herrmannareldt, SLAC-Note-AP-41, April 1985.

17. R. H. Helm and R. H. Miller, Linear Accelerntors, P. M. Lapostolle and A. L. Septier, editora, pp 115-145, North Holland Publishing Company, Amsterdam, 1970.

18. J. E. Clendenin ef al., Proceedings of the 1981 Linear Accelerator Conference, p 130, Los Alamod National Laboratory, 1981.

10. M. B. James el d., IEEE Trana. Nucl. Sci. NS-30, p 2992, Auguat 1083.

20. J. E. Clendenin el al., Proceadings of the 1984 Linear Acceleralor Conference, Secheim/Darmatedt, Federal Republic of Germany, 1984.

21. M. C. Row et al., IEce Trane. Nucl. Scl. NS-32, p 3160, October 1085.

22. R. F. Koonte ef al., IEEs Tranu. Nucl. Sci. N8-38, p 2213, 1981.

23. R. F. Koontx, Proceedinge of the 1981 Linear Accelerator Conference, p 64, Low Alamos National Laboratory, 1981.

24. SUPERFISH Cakulation by Richard Early, SLAC.

25. O. A. Loew ef d., The Stanford Two-Mile Accelerator, ibid.

26. G. A. Loew and J. W. Want, EEEE Trans. Nucl. Sci. NS-37, p 3228, October 1085.

27. J. C. Sheppard et al, JEEE Trans. Nucl. Sci. NS-30, p 2161, August 1093.

28. J. C. Sheppard et a., IEEE Trans. Nucl. Sci. NS-32, p 2006, October 1085. 